OAK RIDGE NATIONAL LABORATORY

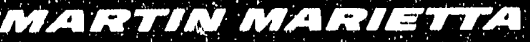

Characterization of Core Debris/ Concrete Interactions for the Advanced Neutron Source

C. R. Hyman

R. P. Taleyarkhan 
This report has been reproduced directly from the best available copy.

Available to DOE and DOE contractors from the Office of Sclentific and Technical Information, P.O. Box 62, Oak Ridgo, TN 37831; prices avallable from (615) 576-8401, FTS 626-8401.

Avallable to the public from the National Technical Information Service, U.S. Department of Commerce, 5285 Port Royal Rd., Springfield, VA 22161.

This report was prepared as an account of work sponsored by an agency of the United States Government. Neither the United States Government nor any agency thereof, nor any of their employees, makes any warranty, express or implied, or assumes any legal llability or responsibility for the accuracy, com. pleteriess, or usefulness of any information, apparatus, product, or process disclosed, or represents that its use would not infringe privately owned rights. Feference herein to any specific commercial product, process, or service by trade llame, trademark, manufacturer, or otherwise, does not necessarily constitute or imply lts endorsement, recommendation, or favoring by the United States Government or any agency thereof. The views and opinions of authors expressed herein do not necessarily state or reflect those of the United States Government or any agency thereof. 
ORNL/TM- -11761

DE92 010364

ANS Severe Accident Analysis Program

Engineering Technology Division

\section{CHARACTERIZATION OF CORE DEBRIS/CONCRE'TE INTERACTIONS FOR THE ADVANCED NEUTRON SOURCE}

C. R. Hyman

R. P. Taleyarkhan

DATE PUBLISHED: FEBRUARY 1992

Prepared for the

DOE Office of Energy Research

DOE Budget Activity No. KC0204010

Prepared by the

OAK RIDGE NATIONAL LABORATORY

Oak Ridge, Tennessee 37831-6285

managed by

MARTTN MARIETTA ENERGY SYSTEMS, INC.

for the

U.S. DEPARTMENT OF ENERGY

under contract DOE-AC05-84OR21400 
CONTENTS

LIST OF FIGURES

Page

LIST OF TABLES

$\mathrm{v}$

ACKNOWLEDGMENTS

vii

ABSTRACT

ix

1. INTRODUCTION

1.1 IMPORTANCE OF MCCI

2. ANALYTICAL AND EXPERIMENTAL MCCI RESEARCH

2.1 DESCRIPTION OF THE CORCON CODE

2.2 EXPERIMENTAL EFFORTS AT SNL

$\mathrm{xi}$

2.3 SAVANNAH RIVER LABORATORY MCCI RESEARCH

3. ANS MCCI ANALYSES

3.1 BASE CASE CORCON ANALYSIS

3.1.1 Base Case CORCON Results

3.2 EFFECT OF CONCRETE REBAR FRACTION

3.3 EFFECT OF DEBRIS SPREADING RADIUS

3.4 EFFECT OF CONCRETE TYPE

3.5 EFFECT OF CONCRETE ABLATION TEMPERATURE

3.6 EFFECT OF DEBRIS INTERNAL HEATING

3.7 EFFECT OF ADDITIONAL INITIAL DEBRIS INVENTORY

3.8 EFFECT OF OVERLYING WATER POOL 25

3.8.1 Further ANS MCCI Analyses in the Presence of Water Pools

3.9 ANS MCCI MITIGATION ANALYSIS

3.9.1 Further Alumina Concrete MCCI Analyses Without Water Pools

3.9.2 Alumina Concrete MCCI Analyses in the Presence of Water Pools

3.10 RELATIVE IMPACT OF LIMESTONE COMMON SAND AND ALUMINA CONCRETE TYPES CN ANS MCCI

3.11 RELATIVE IMPACT OF DEBRIS SURFACE-TO-SURROUNDINGS RADIATION HEAT TRANSFER AND ALUMINA ABLATION TEMPERATURE ON ANS MCCI

3.12 IMPACT OF MCCI ON CONTAINMENT RESPONSE 


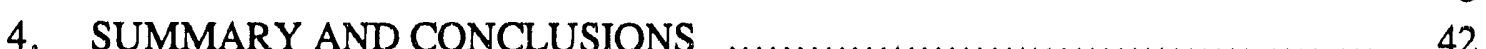

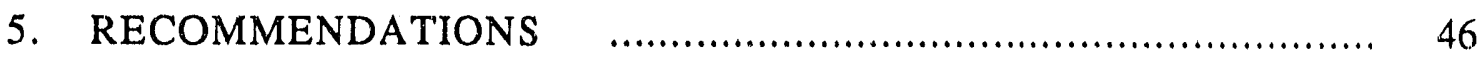

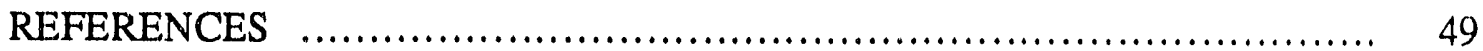

APPENDIX A. DEFICIENCIES IN CORCON MODELING …................ 53

APPENDIX B. EVALUATION OF ANS DEBRIS SPREADING

CHARACTERISTICS

57 


\section{LIST OF FIGURES}

Figure

Page

2.1 Schematic representation of layer-flip process modeling

in CORCON

2.2 Comparison of CORCON-MOD2 code predictions of ablation depth with experimental measurements

2.3 Comparison of CORCON code predictions (from different versions) of ablation depth with experimental measurements

2.4 Variation of concrete ablation with time for SWISS tests

2.5 Comparison of CORCON-MOD2 predictions for ablation depths and debris temperatures with experimental measurements

3.1 Decay power variation with time for various reactor cores

3.2 Variation of ablation depth with time (base case)

3.3 Variation of debris temperature with time (base case) $\ldots \ldots \ldots \ldots \ldots \ldots \ldots . . . . . . . .16$

3.4 Variation of MCCI gas releases with time (base case) $\ldots \ldots \ldots \ldots \ldots \ldots . . \ldots 17$

3.5 Variation of ablation and combustible gas release with rebar fraction

3.6 Variation of ablation depth and combustible gas release with debris spreading radius

3.7 Variation of ablation depth with concrete type, debris power, and water pool

3.8 Variation of combustible gas release with concrete type, debris power, and water pool

3.9 Variation of ablation depth with debris power and surface opacity ........

3.10 Variation of combustible gas release with debris power and surface opacity

3.11 Variation of ablation depth with debris power and $\mathrm{Al}_{2} \mathrm{O}_{3}$ ablation temperature

3.12 Variation of combustible gas release with debris power and $\mathrm{Al}_{2} \mathrm{O}_{3}$ ablation temperature 


\section{LIST OF TABLES}

Table

Page

1.1 Comparison of ANS preconceptual design with commercial MARK I BWRs

3.1 CORCON results as a function of concrete rebar fraction .................... 18

3.2 CORCON results as a function of debris-spreading radius ................... 20

3.3. Compositions (weight percent) and ablation temperatures of commonly used concrete

3.4 CORCON results as a function of concrete type

3.5 CORCON results as a function of concrete ablation temperature

3.6 CORCON results as a function of debris power

3.7 CORCON results as a function of initial debris inventory

3.8 CORCON results as a function of a the presence of a large overlying pool of water

3.9 CORCON results for ANS MCCI in the presence of a large overlying pool of water

3.10 CORCON results for high-melting-temperature alumina concrete compared to limestone common sand concrete

3.11 CORCON results as a function of debris power for high-meltingtemperature alumina concrete

3.12 CORCON results for alumina concrete as a furction of the presence of an overlying water pool

A.1 Anomalous CORCON results near the 3.6-h time for the case of overlying water pool reported in Chap. 3

B.1 Molten lead melt-spreading experimental test matrix f........................ 58

B.2 Molten aluminum melt-spreading experimental test matrix ................. 58

B.3 Mathematical modeling and representation of melt-spreading experimental observations based upon aluminum data 


\section{ACKNOWLEDGMENTS}

The authors wish to thank Henry Randolph, Lee Hyder, and Kevin O'Kula of the Savannah River Laboratory (SRL) for sharing the fruits of their research concerning the molten core/concrete interaction $(\mathrm{MCCl})$ issue relating to uraniumaluminum fueled reactors. Particularly helpful were the discussions with Randolph concerning his $\mathrm{MCCl}$ experiments and $\mathrm{O}^{\prime} \mathrm{Kula}$ 's willingness to provide Oak Ridge National Laboratory with the SRL version of the CORCON code developed by Dave Bradley of Sandia National Laboratories. Appreciation is also extended to Dave Bradley and George Greene for useful discussions concerning the $\mathrm{MCCI}$ issue relating to the Advanced Nevitron Source. In particular, George Greene provided the major elements of Appendix B.

Finally, the sponsorship, active support, and critique for this work provided by Colin West and Mike Harrington of the Advanced Neutron Source Project are gratefully acknowledged. 


\begin{abstract}
This report provides the results of a recent study conducted to explore the molten core/concrete interaction (MCCI) issue for the Advanced Neutron Source (ANS). The need for such a study arises from the potential threats to reactor system integrity posed by MCCI. These threats include direct attack of the concrete basemat of the containment; generation and release of large quantities of gas that can pressurize the containment; the combustion threat of these gases; and the potential generation, release, and transport of radioactive aerosols to the environment.

A background of recent $\mathrm{MCCI}$ research is provided which includes a description both of experiments and the analytical tool often used to calculate MCCI, the CORCON code. The results of a parametric study utilizing CORCON are also presented. Parameters addressed include concrete rebar fraction, initial debris-spreading radius, concrete type, concrete ablation temperature, magnitude of debris internal heating, initial debris inventory, and the effect of an overlying water pool. A limited analysis was also performed to evaluate the mitigative effect to be gained by use of an alumina concrete of very high melting temperature. Scoping estimates of potential containment response were also evaluated.

Results for common concrete types show significant (1-2 m) axial concrete ablation, depending on the concrete type and the extent of initial debris spreading on the concrete basemat.

Debris decay heating was found to be the primary factor influencing the extent of axial concrete ablation. Significant quantities of gas, about $10^{5}$ moles, were calculated to be released into the containment. An appreciable fraction of this gas was calculated to be combustible $\mathrm{H}_{2}$ and $\mathrm{CO}$. The primary factor controlling the production of the combustibles was the rebar fraction assumed for the concrete basemat.

It was found that there are at least two ways in which ANS MCCI could be significantly reduced. First, regardless of concrete type, if the internal debris heating rate is no more than $20 \%$ of the whole core decay heat (at $60 \mathrm{~s}$ after scram), there would be little or no axial concrete erosion. Second, the combination of alumina concrete and the presence of an overlying water pool was shown to significantly reduce concrete erosion, even at conservatively high debris heating rates.

It has been estimated in a base case calculation that the ANS containment would not experience gas combustion if all MCCI gases (for common concrete types) were uniformly dispersed throughout the containment (high-bay) atmosphere. In this case, the containment pressure would rise from $1.01 \times 10^{5} \mathrm{~Pa}$ to $1.05 \times 10^{5} \mathrm{~Pa}$; so the pressure difference across the containment walls would be $\sim 5 \mathrm{kPa}$, well below the proposed design pressure specification of $0.17 \mathrm{MPa}(10 \mathrm{psig})$. Combustion in local areas of the containment cannot be dismissed, however, since uniform atmospheric mixing is not assured. Assuming that all the combustible gases released stay in the subpile room and undergo combustion, an adiabatic estimate indicates that the containment high-bay pressure would reach the targeted design pressure of $0.17 \mathrm{MPa}$ (10 psig).
\end{abstract}


Among the recommendations made in this study, the most important was that further study be devoled to the design and qualification of a basemat that significantiy mitigates or even precludes debris/basemat interactions. 


\section{INTRODUCTION}

The study of the molten core/concrete interaction $(\mathrm{MCCI})$ issue represents an important component of any severe accident analysis in which core debris has left the primary coolant system and relocates onto the containment floor. It is the purpose of this report to characterize the impact of potential MCCI phenomena for the proposed ANS design. 1 Emphasis is placed on the determination of debris gas release and concrete ablation.

The issue of MCCI is $s$. ngly coupled with the general subject of core-melt progression and fission product release. Selected results from a recently completed study 2 on core-melt progression were used to define the initial conditions for the MCCI study. Because uncertainties in core-melt progression directly affect the MCCI phase of a severe accident, parametric variations in important parameters were used to address MCCI sensitivities to overall uncertainties.

The following section discusses the importance of studying the MCCI phase of a severe accident based on insights gained from extensive research sponsored by the U.S. Nuclear Regulatory Commission (NRC). ${ }^{3}$

\subsection{IMPORTANCE OF MCCI}

The study of MCCIs represents an important phase of any hypothetical severe accident that has progressed to the point of core debris relocation outside the primary system onto a concrete surface. MCCI research relating to commercial nuclear power plant severe accident analyses has been sponsored by the NRC for several years. A significant portion of the MCCI research has been conducted at Sandia National Laboratories (SNL), with formal programs addressing both experimental and analytical needs. One result of this research has been the development of the CORCON code, 4 which has been used extensively to evaluate and study several aspects of core debris/concrete interactions.

Recent analyses utilizing the CORCON code for boiling-water reactor (BWR) application $\mathrm{s}^{5,6}$ have shown that there are several consequences of $\mathrm{MCCI}$ that must be evaluated when considering the response of the concrete containment floor and the reactor vessel supports to hoi $(1000-2000 \mathrm{~K})$ core debris during severe accident conditions. Although the melting temperature of concrete is not a well-defined parameter (concrete is a solid solution of various constituents and thus melts over a range of temperatures), typical values range from 1400 to $1850 \mathrm{~K}$. Thus, the possibility exists for the concrete structure to melt, at least partially, as a result of heating by the hot core debris. In any case, there is a loss of structural strength at elevated temperatures. The concrete structures of direct interest for the ANS study are the concrete floor at the base of the reactor pool and the subpile room concrete floor.

A second aspect of the MCCI phenomenon is the large quantity of gases originating from thermal decomposition of the concrete basemat upon interaction with hot core debris. Concrete gases $\left(\mathrm{CO}_{2}\right.$ and $\left.\mathrm{H}_{2} \mathrm{O}\right)$ are generated when the $\mathrm{Ca}(\mathrm{OH})_{2}$ and the $\mathrm{CaCO}_{3}$ constituents of the concrete decompose during the melting or "ablation" process. In addition, $\mathrm{H}_{2} \mathrm{O}$ vapor can be released directly upon vaporization of the water trapped within 
the pores of the concrete. These gases enter into the debris, and they may react with steel, aluminum, or other metal therein, resulting in the production of carbon monoxide $(\mathrm{CO})$ and hydrogen $\left(\mathrm{H}_{2}\right)$, or they may pass through the debris into the containment atmosphere in unreacted form. For commercial BWR Mark I nuclear plants, the magnitude of debris gas release has been shown to be large enough to raise primary containment pressure to the point of significant leakage. 6

An additional challenge to the containment arises if concentrations of $\mathrm{CO}$ and $\mathrm{H}_{2}$ build to the threshold of combustion. Here again, analyses have shown this to be of particular concern in the secondary containment of BWR Mark I plants. ${ }^{7}$

Another major aspect of MCCI is related to the generation and release of aerosols into the containment atmosphere. Many of the fission products in the core debris may be released through this mechanism. The production of these aerosols is tied to the stirring action of gases passing through the debris and the vaporization/entrainment of MCCI materials into these gases. Aerosol transport throughout the containment and into the environment may become an important contributor to the radiological source term for the ANS. This attests to the need for understanding the physics of the MCCI phenomenon in conjunction with the proposed ANS design.

Table 1.1 presents a comparison of several parameters of interest between commercial MARK I BWRs and the proposed ANS. Several features of the ANS design suggest that the containment may not be threatened under severe accident conditions. The small masses of core materials and the limited amount of aluminum would imply that the core debris might be coolable if the debris can be configured in the proper geometry. In addition, the relatively large containment volume of the ANS may mitigate the direct pressurization effects of MCCI gases and the pressurization caused by combustion. The large

Table 1.1. Comparison of ANS preconceptual design with commercial MARK I BWRS

\begin{tabular}{lll}
\hline \multicolumn{1}{c}{ Parameter } & \multicolumn{1}{c}{ BWR } & \multicolumn{1}{c}{ ANS } \\
\hline Core power, $\mathrm{MW}(\mathrm{t})$ & 3250 & 350 \\
Fuel, $\mathrm{kg}$ & $\mathrm{UO}_{2}(173,000)$ & $\mathrm{U}_{3} \mathrm{Si}_{2}(20)$ \\
Cladding, $\mathrm{kg}$ & $\mathrm{Zr}(37,000)$ & $\mathrm{Al}(87)$ \\
Fuel melting temperature, $\mathrm{K}$ & 2922 & 1938 \\
Cladding melting temperature, $\mathrm{K}$ & 2125 & 933 \\
Volume of molten core, $\mathrm{m}^{3}$ & 40 & 0.03 \\
Decay heating, W/g & $0.5-1.0$ & 100 \\
Containment volume, $a \mathrm{~m}^{3}$ & 11,800 & 90,000 \\
\hline
\end{tabular}

aFor this BWR case, this is the sum of the drywell and wetwell volume. For the ANS, this is the total containment volume. 
ANS containment volume may also increase the retention time of aerosols inside the containment so that the decontamination factors (DFs) for the ANS containment may be larger than for the primary containment of a MARK I BWR.

The most significant parameter of concern for the ANS regarding the potential impact from $\mathrm{MCCl}$ is the highly concentrated heat source associated with the radioactive decay tNS fuel fission products. As seen from Table 1.1, the ANS decay heat per unit mass bout 100 times that of the large BWR. This parameter is considered of primary importance when assessing the $\mathrm{MCCl}$ phase of severe accident analysis for the ANS.

Chapter 2 describes the CORCON code and several of the experiments conducted to benchmark the models of the CORCON code. Chapter 2 also discusses current MCCI :vork sponsored by the Savannah River Laboratory (SRL) for uranium-aluminum fuel interacting with concrete. Chapiar 3 presents results of ANS MCCI analyses performed with a modified version of the CORCON code. Chapter 4 summarizes the study and provides conclusions concerning the $\mathrm{MCCl}$ phenomena for the ANS. Finally, Chap. 5 provides recommendations for effectively addressing this important safety and design issue for the ANS. 


\section{ANALYTICAL AND EXPERIMENTAL MCCI RESEARCH}

As mentioned previously, the NRC has active experimental and analytical programs whose purpose is to understand the physical processes occurring in the MCCI and to develop and validate analytical models describing them. Other researchers have independently developed different models to calculate the MCCI phenomena, including the WECHSL code 8 developed through the Federal Republic of Germany and the DECOMP module of the MAAP code ${ }^{9}$ developed through the U.S. Industrial Degraded Core (IDCOR) program. Because the NRC has chosen the CORCON code [which is available to the Oak Ridge National Laboratory (ORNL) team] to be an integral part of its Source Term Code Package, the following discussion is centered around it.

The remainder of this chapter describes the CORCON code and some of the experiments conducted for its benchmarking and also gives a brief description of $\mathrm{MCCI}$ research sponsored by the SRL for uranium-aluminum/concrete interactions.

\subsection{DESCRIPTION OF THE CORCON CODE}

The CORCON code, ${ }^{4}$ developed at SNL, treats mechanistically many of the important phenomena occurring during a core debris/concrete interaction. This section discusses the general features and assumptions of the code. Appendix A presents a discussion of perceived deficiencies.

CORCON treats the MCCI process as being two dimensional. It assumes that the debris is housed in an axisymmetric concrete "crucible," as shown in Fig. 2.1, with the interaction occurring only at the interface between the debris and concrete. An R,Z coordinate system is defined such that nodes are located along this interface. Node-tonode distances are specified by the user and are typically $100 \mathrm{~mm}$ apart. Interaction phenomena are calculated at each node, and as the debris/concrete interface recedes because of ablation, the coordinate system noding mesh follows it.

The MCCI heat and mass transfer events are mathematically modeled in CORCON under the following assumptions:

1. Convection and radiation are calculated through a film assumed to exist at the interface between the debris and the concrete. The film is created by gases $\left(\mathrm{H}_{2} \mathrm{O}\right.$ and $\mathrm{CO}_{2}$ ) that are liberated as concrete decomposes. The thickness of the film is controlled by the velocity of these gases. Along the bottom of the debris, it is assumed that the interface is horizontally flat and that all of the concrete gas enters the debris. Along the side-wall of the interface, the gas does not enter the debris but accumulates in the film and flows upward.

2. The surface of the concrete is assumed to be at the user-specified concrete ablation temperature. The ablation temperature is not a well-defined parameter because concrete is composed of many different materials. For conventional $\mathrm{MCCl}$ analyses, an ablation temperature is historically chosen as the concrete solidus temperature plus one-third of the difference between its liquidus and solidus temperatures. 


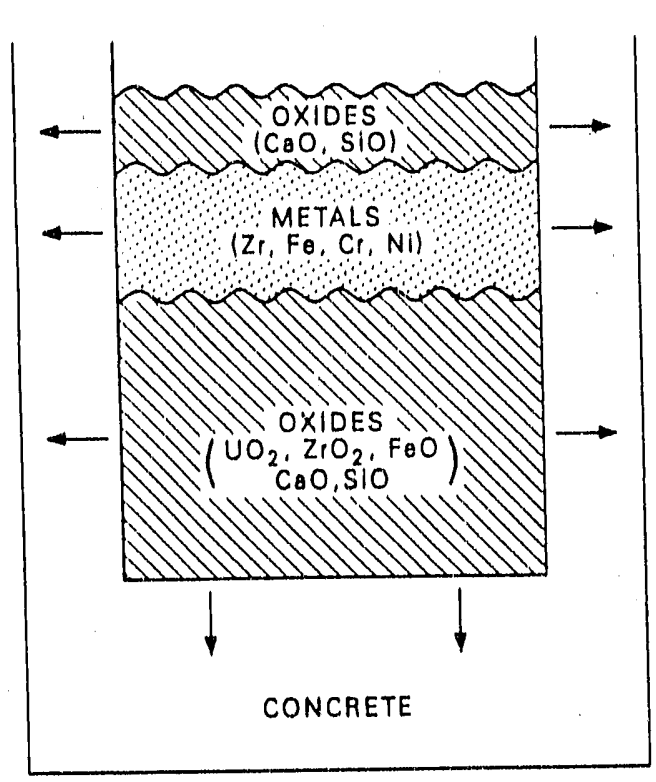

BEFORE LAYER FLIP

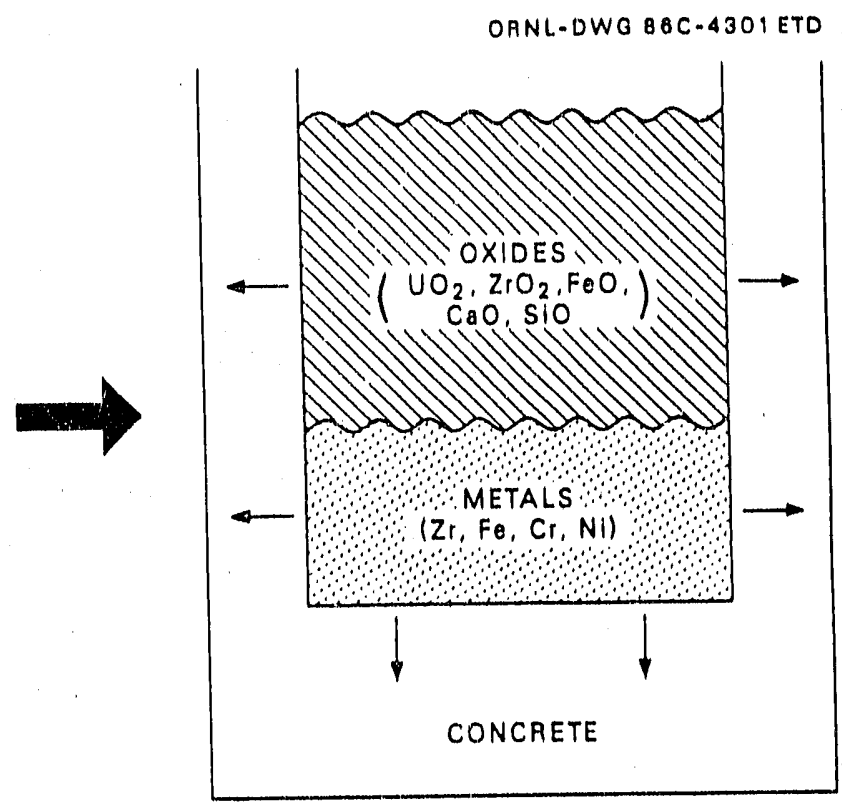

AFTER LAYER FLIP

Fig. 2.1. Schematic representation of layer-flip process mumanng in CORCON.

3. The thermal interaction with concrete is assumed to be a purely surface phenomenon. Heat transferred from the debris to the concrete is used only to ablate concrete, with the extent of ablation controlled by the concrete decomposition enthalpy. This assumption implies a steady state condition since no concrete temperature profile is calculated away from the ablation surface. It is also assumed that the debris/concrete interaction ceases if the debris temperature falls below the concrete ablation temperature, and an adiabatic boundary condition is then applied. At the free surface of the debris, convective and radiative losses are evaluated. For the radiative component, an infinite parallel plate exchange factor is evaluated. The sink temperatures for the convection and radiation are specified by the user.

4. Slag from the concrete decomposition is assumed to enter the debris. Thereafter, the debris stratifies into separate layers of metals and oxides, with the separation based on density considerations. Concrete slag is composed of low-density oxides $\left(\mathrm{SiO}_{2}\right.$ and $\mathrm{CaO})$ that either combine with a high-density oxide layer $\left(\mathrm{UO}_{2}, \mathrm{ZrO}_{2}\right.$, etc. $)$ at the bottom of the debris pool or float to the top of the debris, forming a separate layer of low-density oxide. Eventually, the concrete oxides dilute the heavy oxide layer to the point where the overlying metal layer is more dense than the underlying oxides. When this cccurs, the metal and heavy oxide layers are flipped. After this event, the metals are located at the bottom of the debris, while all the oxides are combined into a single overlying layer. CORCON does not recognize debris homogenization due to the stirring of molten material by the concrete gases passing through the pool. 
The core debris is heated by decay of fission products and chemical reactions. The decay heat is evaluated from built-in tables of decay heat (as determined by ORIGEN code predictions) appropriate for light-water reactors (LWRs). For LWR scenarios, the net chemical energy source can be positive or negative, depending on the particular reactions being calculated. During most of the calculation, decay heat is greater than the chemical source, with the exception being the time of rapid oxidation of reactive metals (zirconium, aluminum etc.). The code user also has the option to explicitly specify the energy source to the debris layers instead of using the internally programmed tables of debris decay heat vs time.

5. Chemical reactions of concrete gases $\mathrm{CO}_{2}$ and $\mathrm{H}_{2} \mathrm{O}$ with the metals such as $\mathrm{Zr}, \mathrm{Al}, \mathrm{Fe}$, $\mathrm{Cr}, \mathrm{Ni}$, etc., are modeled in CORCON. An assumption is made that the oxides in the oxide layers are inert and need not be considered in the chemistry evaluations. This may not be a valid assumption and has been relaxed slightly for a newer code version; it will be discussed in the next section. For example, Henry Randolph of SRL has pointed out that aluminum oxide can react with other concrete oxides to produce the mineral anorthite. Such reactions may release nontrivial amounts of exothermic energy and need to be properly accounted for. This aspect is described in greater detail in Appendix A.

The metals are converted to their oxide forms, while the $\mathrm{CO}_{2}$ and $\mathrm{H}_{2} \mathrm{O}$ are converted to the combustible gases $\mathrm{CO}$ and $\mathrm{H}_{2}$. If the thermodynamic conditions of the metal layer are not sufficient to reduce all of the $\mathrm{CU}_{2}$ and $\mathrm{H}_{2} \mathrm{O}$, the unreacted gases pass through the overlying light oxide layer into the containment atmosphere. The conversion of $\mathrm{CO}_{2}$ into $\mathrm{CO}$ is not direct but proceeds through an intermediate step. $\mathrm{CO}_{2}$ is first reduced to condensed carbon, which is assumed to reside in the metal layer. Once the reactive metals are exhausted, the carbon inventory is rapidly oxidized by the $\mathrm{CO}_{2}$ gas originating from the concrete. This results in large quantities of $\mathrm{CO}$ from the following reaction:

$$
\mathrm{C}+\mathrm{CO}_{2} \rightarrow 2 \mathrm{CO}
$$

Thus, 2 mol of gas are produced for every one consumed, and this is important from the standpoint of generation and release of aerosols.

The rate at which aerosols are generated depends on the internal surface area created by the gas bubbles traveling through the debris melt; so a greater gas flow through the melt increases aerosol production. Past $\mathrm{MCCI}$ analyses for power reactors have shown that this carbon burning process generally occurs at a time when the debris is near its maximum temperature. 5 Thus, the volatilization kinetics are most rapid at a time when the bubble surface area for mass transfer is also at its maximum value.

6. Internal heating of the melt decreases with time as radioactive fission product decay proceeds and as the supply of chemically reactive metals is exhausted. The debris temperature decreases, and eventually solidification of one or more of the melt layers begins. The melt may form a slurry consisting of solid and liquid components and/or may develop crusts along the outer boundaries. For slurries, the code models the 
internal layer heat transfer mechanism as forced convection driven by the gases passing through the debris, similar to the period when the debris is fully molten. Upon crust formation, heat transfer from the debris is conduction-limited through the crusts.

A simple crusting model has been incorporated into the code. Crusting is calculated on a layer-by-layer basis, with crusts forming at the layer outer boundaries. Evaluations are made independently for the top, bottom, and radial boundaries and are based on steady state energy balances.

\subsection{EXPERIMENTAL EFFORTS AT SNL}

SNL has an experimental program to study the physical processes occurring during MCCI for commercial nuclear plants. The experiments are usually one dimensional, heated either in induction furnaces or by $\mathrm{Al}-\mathrm{Fe}_{3} \mathrm{O}_{4}$ (thermite) reactions, and have been designed to consider the effects of several parameters. The parameters include concrete type, quantity and composition of debris, effect of chemical reactions, and the effect of a water pool overlying the debris. The results of the SNL experiments have been used to benchmark CORCON. Three notable examples are the TURC, ${ }^{10,11}$ SWISS, 12 and SURC ${ }^{13}$ test series.

The purpose of the TURC tests was to provide data for large-scale melt/concrete interactions using materials prototypical of commercial nuclear plants. The TURC1T test ${ }^{10}$ provided data on the interaction of a mixture of molten iron and alumina with a limestone/sand concrete basemat. The melt was prepared by the exothermic reaction of iron oxide $\left(\mathrm{Fe}_{3} \mathrm{O}_{4}\right)$ with aluminum to produce iron metal and alumina $\left(\mathrm{Al}_{2} \mathrm{O}_{3}\right)$. The quantity of $\mathrm{Fe} / \mathrm{Al}_{2} \mathrm{O}_{3}$ melt was $147 \mathrm{~kg}$, and it was prepared in a melt generator at $2700 \mathrm{~K}$ prior to the initiation of the concrete interaction. The concrete interaction was driven only by the sensible heat accumulated in the molten $\mathrm{Fe} / \mathrm{Al}_{2} \mathrm{O}_{3}$ during the thermite reaction. Because molten alumina is lighter than molten iron, the test was essentially one of metallic debris interaction with the underlying concrete. Concrete ablation occurred for about $13 \mathrm{~min}$, during which time about $75 \mathrm{~mm}$ of the concrete was ablated. A comparison of CORCON predictions with the experimental data, as seen in Fig. 2.2, showed very good agreement.

TURC1SS ${ }^{10}$ was the second of the TURC test series. The melt consisted of $106 \mathrm{~kg}$ of Type 304 stainless steel and was inductively heated to a temperature of $2350 \mathrm{~K}$ prior to the initiation of the concrete interaction. Like TURC1T, the interaction in the TURC1SS test was driven by the initial sensible heat of the molten debris as it interacted with the limestone/sand concrete basemat. It also was a short-lived experiment, with ablation occurring for only about $1.7 \mathrm{~min}$. During this time, an average of $43 \mathrm{~mm}$ of concrete was ablated. Comparison with a CORCON calculation, Fig. 2.3, shows that CORCON significantly underpredicted the observed concrete ablation. Possible explanations for this discrepancy are reported in Ref. 14 and involve the inadequacies of the debris/concrete film model and the internal debris convective heat transfer correlations used in the CORCON code.

The final two tests in the TURC test series were TURC2 and IURC3.11 The materials used in these tests consisted of mixtures of $\mathrm{UO}_{2}$ and $\mathrm{ZrO}_{2}$, with TURC3 having some metallic zirconium. It was intended that these tests provide experimental data for oxidic debris/concrete interactions. TURC2 consisted of a 104-kg mixture of $70 \% \mathrm{UO}_{2}$ 


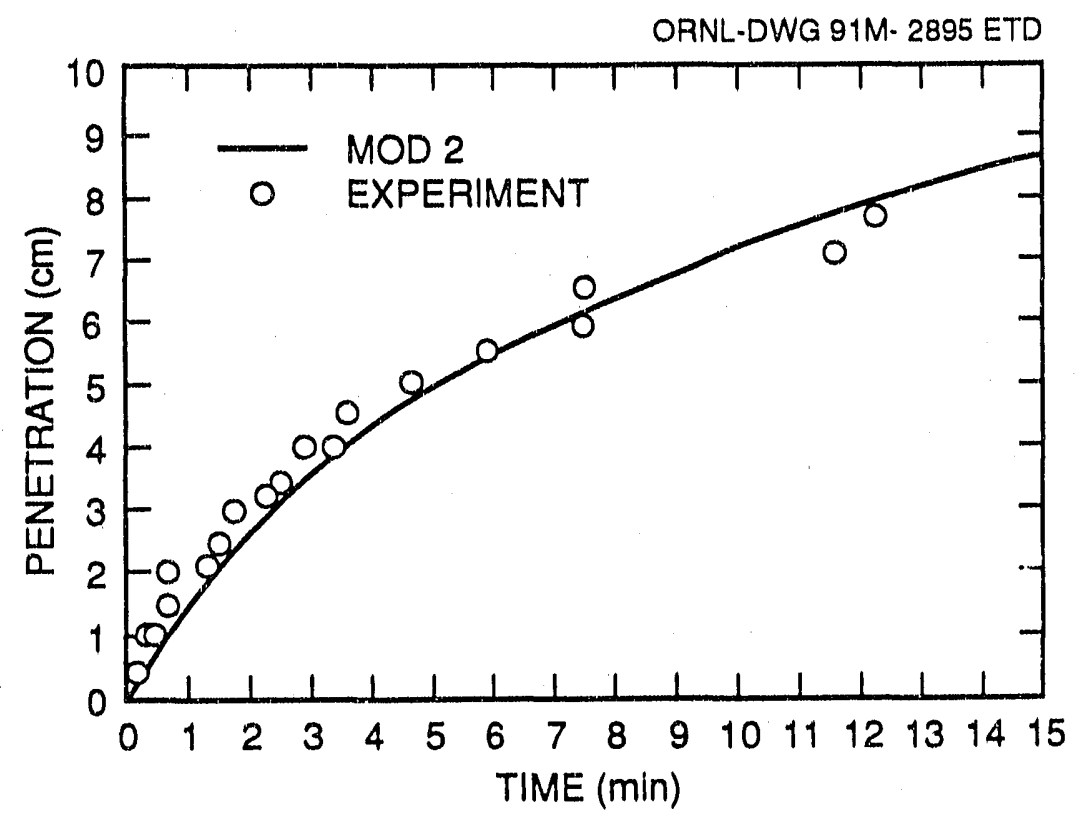

Fig. 2.2. Comparison of CORCON-MOD2 code predictions of ablation depth with experimental measurements.

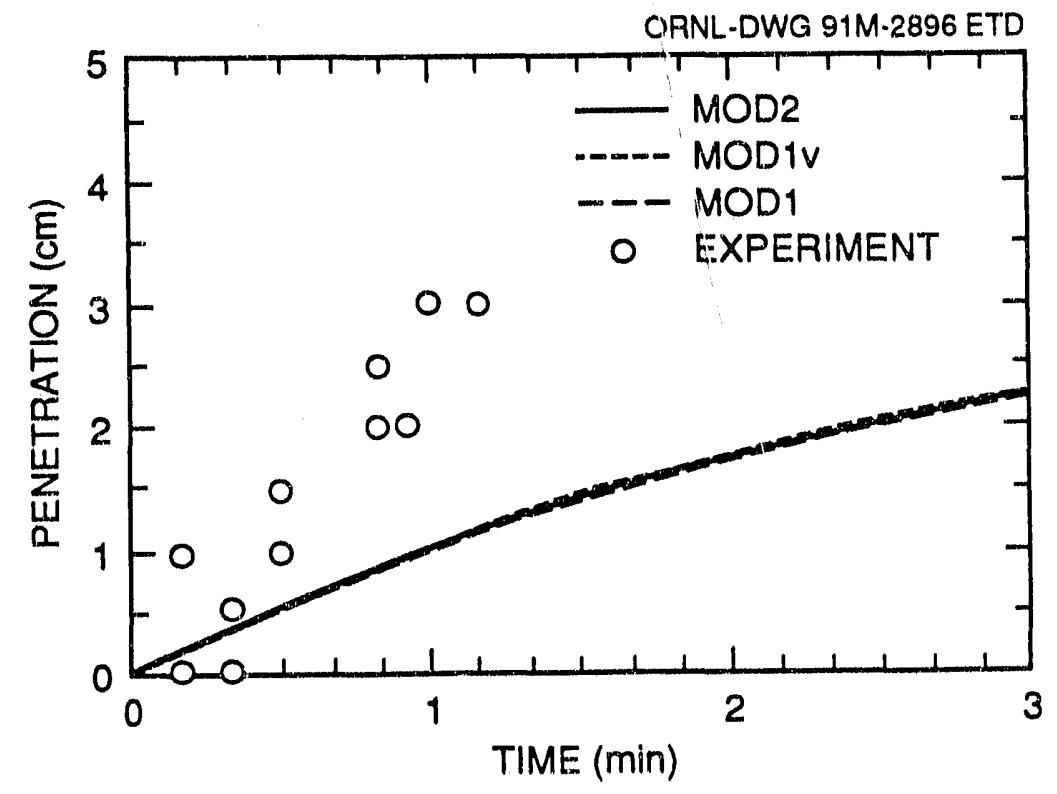

Fig. 2.3. Comparison of CORCON code predictions (from different versions) of ablation depth with experimental measurements. 
and $30 \% \mathrm{ZrO}_{2}$ heated to a temperature of $2800 \mathrm{~K}$ prior to the commencement of the interaction with concrete. TURC 3 consisted of a $47-\mathrm{kg}$ mixture of $9 \% \mathrm{Zr}, 64 \% \mathrm{UO}_{2}$, and $27 \% \mathrm{ZrO}_{2}$ heated to a temperature of $2600 \mathrm{~K}$ prior to beginning the interaction. Once again, no internal heating was supplied once the debris contacted the limestone common sand basemat. In both these tests, solid crusts formed upon initial contact with the concrete, and no appreciable concrete ablation was observed. In contrast, CORCON predicted no crusts and therefore calculated excessive concrete ablation.

The SWISS tests ${ }^{14}$ were designed to determine experimentally the effect on MCCI of a water pool overlying the debris which was simultaneously interacting with a limestone common sand basemat. SWISS1 consisted of $45 \mathrm{~kg}$ of 304 stainless steel heated to an initial temperature of $1850 \mathrm{~K}$. Water was added late in the experiment $(34.5 \mathrm{~min})$. SWISS2 was the same as SWISS1 except that water was added within 1.7 min of the beginning of the concrete interaction. In contrast to the TURC tests, an induction coil was used to provide $\sim 60 \mathrm{~kW}$ of continuous power to the melt so as to observe the steady state nature of the interaction when a water pool was present. Comparison of the results from these tests showed that there was no discernible effect caused by the presence of water (see Fig. 2.4).

In the SWISS tests, a crust formed upon initial debris contact with the concrete. Because of the heating provided by the induction coil, the crusts remelted after about 5 to $10 \mathrm{~min}$, and the concrete ablation commenced. As in the TURC2 and TURC3 tests, CORCON did not calculate the initial crust formation, and therefore the delay in the onset of concrete ablation was not predicted.

Reference 14 states, "The source of this discrepancy has been traced to the heat transfer correlation used in evaluating heat transfer between the bulk melt and the melt/gas film interface. This correlation predicts heat transfer coefficients for the TURC and SWISS

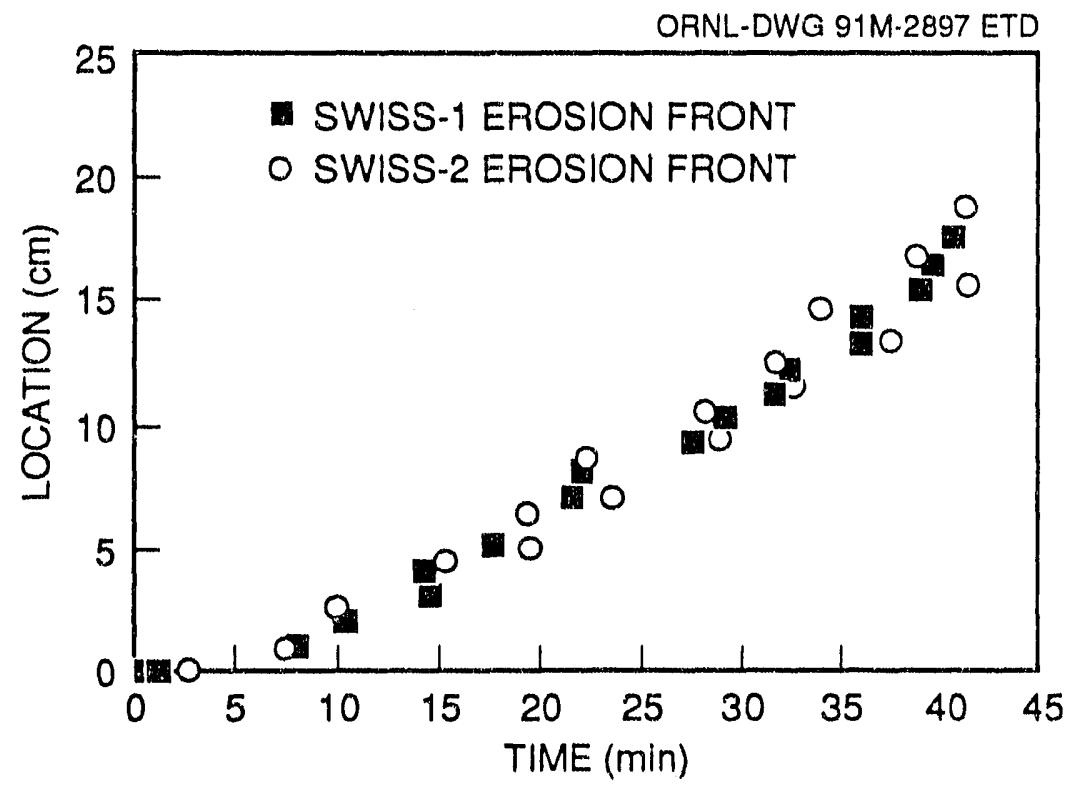

Fig. 2.4. Variation of concrete ablation with time for SWISS tests. 
melts of $>1.0 \times 10^{5} \mathrm{~W} / \mathrm{m}^{2}-\mathrm{K}$, which is much higher than heat transfer coefficients measured for similar materials under similar gas-mixing conditions. (For example, heat transfer coefficients in liquid-metal boiling are on the order of $1.0 \times 104 \mathrm{~W} / \mathrm{m}^{2}-\mathrm{K}$ or less.) For heat transfer coefficients of this magnitude, the calculated temperature difference between the bulk melt and the interface is only a few degrees, which is not nearly sufficient to force an interfacial crust to form."

The final SNL MCCI experiment that will be addressed here is the SURC4 test. ${ }^{13}$ This is one of a series of eight SURC tests that has been designed to be more comprehensive than the earlier TURC and SWISS test series. The SURC tests better represent the $\mathrm{MCCI}$ expected in commercial nuclear plants because they consider not only the MCCI of metallic vs oxidic debris, but also the effect of zirconium on the MCCI. These experiments are also more representative in the sense that there is continuous heating of the debris, supplied by electromagnetic induction, thus simulating decay heat.

The SURC4 experiment consisted of $200 \mathrm{~kg}$ of stainless steel heated by induction. After about $50 \mathrm{~mm}$ of the basaltic basemat had ablated, $20 \mathrm{~kg}$ of zirconium was added. The concrete had a high (55\%) $\mathrm{SiO}_{2}$ content and a low (7\%) gas content; so it was a good test of the chemistry model in CORCON. As noted from Ref. 13, the test exhibited a vigorous chemical reaction after the zirconium was added; in fact, the chemical power produced was sufficient to allow the induction heating to be turned off. The characteristics of the chemical reaction were a rapidly increasing debris temperature and a fast ablation rate $(0.25 \mathrm{~m} / \mathrm{h})$.

When CORCON was applied to this problem, it significantly underpredicted the debris temperature [Fig. $2.5(a)]^{15}$ although it calculated the concrete ablation reasonably accurately [Fig. 2.5(b)].15 It was deduced that modeling of the coincident chemical reactions of the metals with both the concrete oxides $\left(\mathrm{SiO}_{2}\right.$ and $\left.\mathrm{CaO}\right)$ and the concrete gases $\left(\mathrm{CO}_{2}\right.$ and $\left.\mathrm{H}_{2} \mathrm{O}\right)$ was required within CORCON. Because CORCON could not simultaneously match the concrete ablation and the debris temperature, it was also deduced that the debris/concrete stable film heat transfer model required modification. This model had also been suspect in earlier CORCON analyses performed for the TURC and SWISS tests.

Bradley and Suo-Anttila ${ }^{16}$ have developed a preliminary debris/concrete heat transfer model that, when incorporated into the CORCON code, gives better predictions for the TURC and SWISS experiments. Their model describes the debris/concrete heat transfer as being similar to the phenomenon of nucleate boiling in that molten debris is allowed to intermittently contact the concrete surface at the bottom of the melt.

In addition, Bradley ${ }^{15}$ has modified the CORCON chemistry model to include the reactions of metals with concrete oxides $\left(\mathrm{CaO}\right.$ and $\left.\mathrm{SiO}_{2}\right)$ as well as with the concrete gases. This new model, when coupled with the heat transfer model described above, results in much improved predictions of SURC4. It is expected that the improved models will be incorporated into a future released version of the code.

\subsection{SAVANNAH RIVER LABORATORY MCCI RESEARCH}

SRL is currently conducting research into the MCCI issue for material mixtures containing a large fraction of aluminum. It has experimental programs in place at Rice 

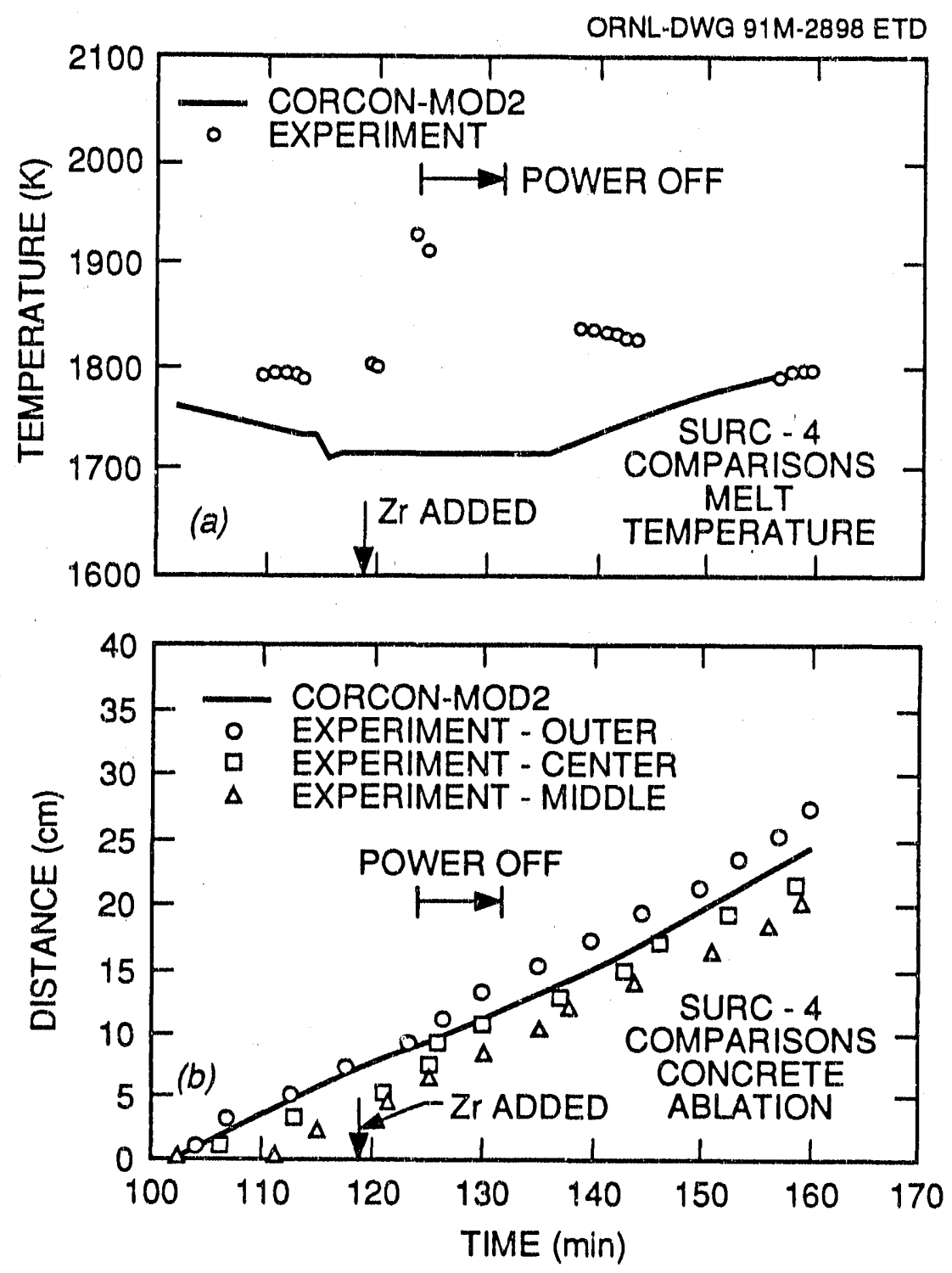

Fig. 2.5. Comparison of CORCON-MOD2 predictions for ablation depths and and debris temperatures with experimental measurements.

University (RU), SNL, and SRL. The objective of the program is to gain an understanding of the reactions that might occur between uranium/aluminum mixtures and the basaltic concrete used at the Savannah River Plant (SRP). 17

The experiments at SRL and at RU are small scale (gram quantities), whereas the experiments at SNL are on a much larger scale $(\sim 50-100 \mathrm{~kg})$. Heating in the SRL experiments is achieved with an electron beam gun, while at RU it is accomplished either with a laser or by induction heating. The SNL experiments utilize induction heating, like the SWISS and SURC4 tests described above. Because the SNL experiments use debris charges comparable to the whole core debris mass of the ANS $\left(20 \mathrm{~kg}\right.$ of $\mathrm{U}_{3} \mathrm{Si}_{2}$ and $80 \mathrm{~kg}$ of $\mathrm{Al})$, they will be discussed in somewhat greater detail. 
The initial SRP/SNL experiment consisted of a $30-\mathrm{kg}$ aluminum cylinder interacting with a basaltic concrete basemat. An induction coil provided volumetric heating of $\sim 0.5 \mathrm{~W} / \mathrm{g}$ to simulate the decay heat associated with the SPP core debris. Below $1723 \mathrm{~K}$, the concrete ablation rate was $\sim 10^{-5} \mathrm{~m} / \mathrm{s}(40 \mathrm{~mm} / \mathrm{h})$ and was sirnilar to the ablation rate observed for commercial LWR fuels $\left(\mathrm{UO}_{2}\right)$. At $1723 \mathrm{~K}$, however, the ablation rate increased to $\sim 7 \times 10^{-5} \mathrm{~m} / \mathrm{s}$ (i.e., $0.25 \mathrm{~m} / \mathrm{h}$ ) and was hypothesized to be a result of the rapid kinetics of the aluminum/silica reaction at high temperature. The $\mathrm{SiO}_{2}$ originated from the decomposition of the basaltic concrete used at the SRP and is similar to that used in the SURC4 experiment described earlier. As the experiment progressed, the debris was diluted with concrete decomposition by-products, and coupling of the magnetic field of the induction coil with the debris could not be maintained. The power level and debris temperatures then decreased, and the experiment self-terminated.

A similar decoupling from the magnetic fields was experienced in the BETA experiments ${ }^{18}$ performed at KFK in the Federal Republic of Germany. In the BETA experiments, the melts were composed of 200 to $400 \mathrm{~kg}$ of iron or steel with 50 to $150 \mathrm{~kg}$ of alumina, and the concrete basemats were mostly basaltic. It was observed that the actual power input to the melt decreased as the molten metallic phase was entrained into the lighter oxidic phase. In some of the BETA experiments, the power diminished by as much as a factor of 10 .

A second SRP/SNL experiment has been performed which duplicated the first except that air, instead of argon, was the cover gas. The initial aluminum charge was again $30 \mathrm{~kg}$ and was heated by induction, but in this second experiment the melt did not decouple from the electromagnetic induction field, and an ablation rate of $\sim 1.94 \times 10^{-4} \mathrm{~m} / \mathrm{s}(0.7 \mathrm{~m} / \mathrm{h})$ resulted.

Because the CORCON code was developed for the MCCI phenomena of a commercial nuclear plant, SRL has sponsored a series of CORCON code modifications to improve its applicability for the aluminum fuel materials of the SRP production reactors. The primary areas of CORCON code modifications include the chemical interactions of uranium and aluminum with concrete gases as well as concrete oxides; the modifications of the metallic layer melting characteristics from $\mathrm{Fe}, \mathrm{Cr}, \mathrm{Ni}$ mixtures to U-Al mixtures; and the modification of the code's internal decay heat algorithm from one based on commercial nuclear plant fuel to one based on the actual fuel in use in the SRP reactors.

An application of this modified CORCON code to the second SRL-sponsored SNL experiment described above indicates good agreement between the experiment and the code prediction. The experiment experienced an ablation rate of $0.7 \mathrm{~m} / \mathrm{h}$, whereas CORC.ON calculated an ablation rate of $0.62 \mathrm{~m} / \mathrm{h}, 19$ an error of only $11 \%$. 


\section{ANS MCCI ANALYSES}

Because the SRL version of CORCON is better suited to the aluminum fuel materials of the ANS than the standard released version, we have obtained the SRL version and used it to perform the ANS MCCI scoping analyses. MCCI sensitivities to large uncertainties in several of the important parameters input to CORCON have been addressed by parametric variation of those parameters.

Parameters addressed include the initial debris-spreading radius, the initial debris mass and composition, the extent of debris heating due to retention of fission products and gamma heat, concrete type, concrete rebar fraction, and the effect on $\mathrm{MCCl}$ of the presence of an overlying pool of water. The parameter study is not multidimensional; that is, it does not address all possible combinations of the parameters that are varied.

In addition to the parameter study, a limited analysis was performed with a noncommercial, high-ablation-temperature concrete to scudy its resistance to attack by ANS-type core debris.

Where possible, the parametric variations are bounded around best-estimate values. Good examples of this are the debris-spreading radius and the initial debris masses. In some cases, however, the variation is binary in nature; that is, the parameter is either included or it is not. An example of this is the presence of an overlying pool of water covering the debris.

The following sections discuss results of CORCON analyses addressing each of the previously mentioned parameters. Also discussed are the potential impacts of $\mathrm{MCCI}$ on the ANS containment response.

\subsection{BASE CASE CORCON ANALYSIS}

As indicated in Fig. 2.1, CORCON assumes that the debris/concrete interaction occurs in a concrete crucible. An important parameter in this configuration is the crucible inner radius, which is determined by the initial spreading radius of the debris. Factors that make the radius a difficult quantity to estimate accurately include the melt mass, its composition, its velocity as it contacts the subpile room floor, and whether the melt is deposited on the floor coherently or incoherently. Incoherent deposition may occur, for example, under pressurized melt discharge from the primary system.

For the ANS MCCI analysis, it was assumed that all of the core mass distributes coherently on the subpile room floor. As shown in Table 1.1, the collapsed volume of all the core materials is $\sim 0.03 \mathrm{~m}^{3}$. Since the subpile room floor radius is on the order of $3 \mathrm{~m}$ (Ref. 1), the question immediately arose as to the extent of debris spreading on this floor. From an experimental debris-spreading correlation (Appendix B) developed at Brookhaven National Laboratory (BNL) by G. A. Greene, 20 it was estimated that the whole core molten debris mass would spread to a depth of $\sim 8-11 \mathrm{~mm}$. This, in turn, led to the estimate of 1.9-2.2 $\mathrm{m}$ for the spreading diameter.

Figure 3.1 is a reproduction of a figure from Ref. 1 . The decay heat shown is the whole core decay heat (including gamma heating). For the base case, it was assumed that $95 \%$ of the whole core decay heat remained in the debris and was therefore available to 


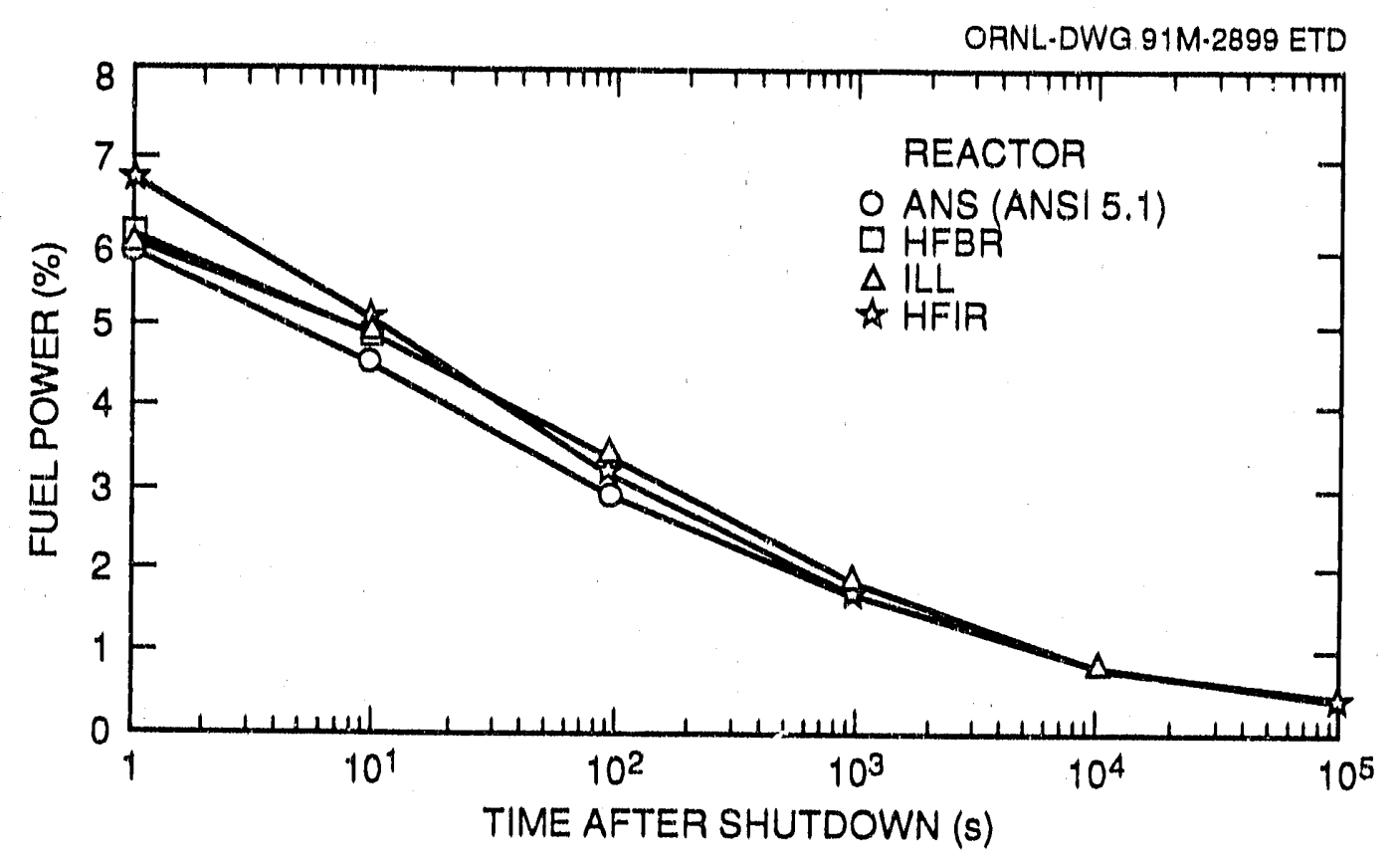

Fig. 3.1. Decay power variation with time for various reactor cores.

drive the MCCI interaction. The $95 \%$ value was chosen since it represents a reasonable upper bound on the decay heat in the debris. A five-point table of decay heat vs time was generated and input into CORCON. The times selected were 10,100,1,000,10,000, and $100,000 \mathrm{~s}$; and the powers corresponding to $95 \%$ of the total decay heating at these times were $14.96,9.64,4.99,2.00$, and $0.67 \mathrm{MW}$, respectively. The whole core decay heat was sourced into the debris oxide layer.

The base case input debris masses and composition were chosen to reflect whole core quantities. An uncertainty exists in the extent of aluminum oxidation prior to debris arrival on the subpile room floor. It was assumed for the base case that only $5 \%$ by mass of the whole core aluminum inventory had previously oxidized. This leaves $95 \%$ of the aluminum to be oxidized by concrete gases as the MCCI proceeds. This assumption tends to maximize the energy production due to chemical reactions of aluminum with $\mathrm{CO}_{2}\left(1.08 \mathrm{MJ} / \mathrm{mol}\right.$ of $\mathrm{Al}_{2} \mathrm{O}_{3}$ produced) and $\mathrm{H}_{2} \mathrm{O}$ vapor $\left(0.94 \mathrm{MJ} / \mathrm{mol}\right.$ of $\mathrm{Al}_{2} \mathrm{O}_{3}$ produced).

Since CORCON does not presently consider $\mathrm{U}_{3} \mathrm{Si}_{2}$, the whole core inventory of $\mathrm{U}_{3} \mathrm{Si}_{2}$ was split into the equivalent masses of pure uranium and silicon. The base case inventories of materials input to CORCON were $82.46 \mathrm{~kg}$ of aluminum, $8.2 \mathrm{~kg}$ of $\mathrm{Al}_{2} \mathrm{O}_{3}$, $19.06 \mathrm{~kg}$ of uranium, and $1.49 \mathrm{~kg}$ of silicon.

Since SNL experiments show sensitivity to the initial superheat of the debris (TURC tests in Chap. 2), CORCON was initialized at a debris temperature of $1000 \mathrm{~K}$. This is $\sim 100 \mathrm{~K}$ above the melting temperature of aluminum and is consistent with the hypothesis that the superheated molten debris (aluminum) would cool to near its freezing temperature before reaching its maximum spreading radius. This matter is of small consequence for the ANS because of the small specific heat of the molten debris compared with the heating 
potential represented by the decay heat. In other words, the ANS MCCI is driven by the decay heating rate and not by the initial sensible energy of the melt.

The initialization of the base case analysis was conservatively chosen as $30 \mathrm{~s}$ into the transient, and the CURCON analysis continued until the $16.9-\mathrm{h}$ point. The calculation was terminated at this time because the debris temperatures were calculated to fall below the ablation temperature of the concrete - a condition for which further application of CORCON is not justified. The concrete type assumed for the base case was limestone common sand, and the ablation temperature was specified at $1503 \mathrm{~K}$. The iron rebar fraction of the concrete was specified as 0.10 , a value typical of that found in commercial nuclear plant concretes.

The CORCON model for debris-to-surroundings radiation heat transfer included the effect of surface atmospheric opacity resulting from aerosol generation. A parametric study was conducted to note the relative impact of this modeling approach. Details of the results are given later in this chapter. However, it should be noted that the inclusion of this radiation retardant phenomenon in general tends to give only somewhat conservative results for the base case evaluations.

\subsubsection{Base Case CORCON Results}

This section presents result 3 calculated with the SRL version of CORCON cited previously with the input parameters as described in Sect. 3.1 for a melt spread thickness of $8 \mathrm{~mm}$.

Figure 3.2 reports the calculated axial concrete ablation. The average ablation rate for the entire $16.9 \mathrm{~h}$ is $68 \mathrm{~mm} / \mathrm{h}$, while the average ablation rate during the first $2 \mathrm{~min}$ is $\sim 0.8 \mathrm{~m} / \mathrm{h}$. The maximum ablation rate occurs $10 \mathrm{~s}$ after beginning the calculation and is $1.37 \mathrm{~m} / \mathrm{h}$. This early ablation rate is consistent with the observed SNL/SRL experiments of $\sim 0.70 \mathrm{~m} / \mathrm{h}$. The high ablation rate is driven by the very high decay heating, and during the first $2 \mathrm{~min}$ is supplemented by the intense chemical energy source provided by the exothermic chemical reactions of unoxidized aluminum with the $\mathrm{CO}_{2}$ and $\mathrm{H}_{2} \mathrm{O}$ gases originating from the ablating concrete. The original inventory of $82.46 \mathrm{~kg}$ of aluminum is completely oxidized by $2 \mathrm{~min}$ into the calculation.

Cumulative concrete ablation amounts to $1.14 \mathrm{~m}$ and is much higher than the axial erosion that is typically calculated $(0.3$ to $0.8 \mathrm{~m})$ for commercial BWR applications. Once again, this is caused by the $\sim 100-\mathrm{W} / \mathrm{g}$ heating rate of the ANS as compared to the $0.5-1.0 \mathrm{~W} / \mathrm{g}$ for commercial plants.

Figure 3.3 shows the calculated debris temperature as a function of time for the base case. It is seen that the temperature increases from the $1000 \mathrm{~K}$ input value to $>2550 \mathrm{~K}$ in $\sim 2$ min. It decreases rapidly, once the aluminum is exhausted, to around $1900 \mathrm{~K}$ and then slowly decreases further as the debris decay heat diminishes. Late time temperatures approach the concrete ablation temperature of $1503 \mathrm{~K}$. The calculation was terminated once the debris temperature reached this value because the CORCON algorithm is no longer valid.

Figure 3.4 presents the calculated cumulative debris gas releases as functions of time. Only $\mathrm{CO}, \mathrm{CO}_{2}, \mathrm{H}_{2}$, and $\mathrm{H}_{2} \mathrm{O}$ are presented since they collectively comprise approximately 99 mol \% of the debris gases released. As mentioned earlier, the $\mathrm{CO}$ and $\mathrm{H}_{2}$ 


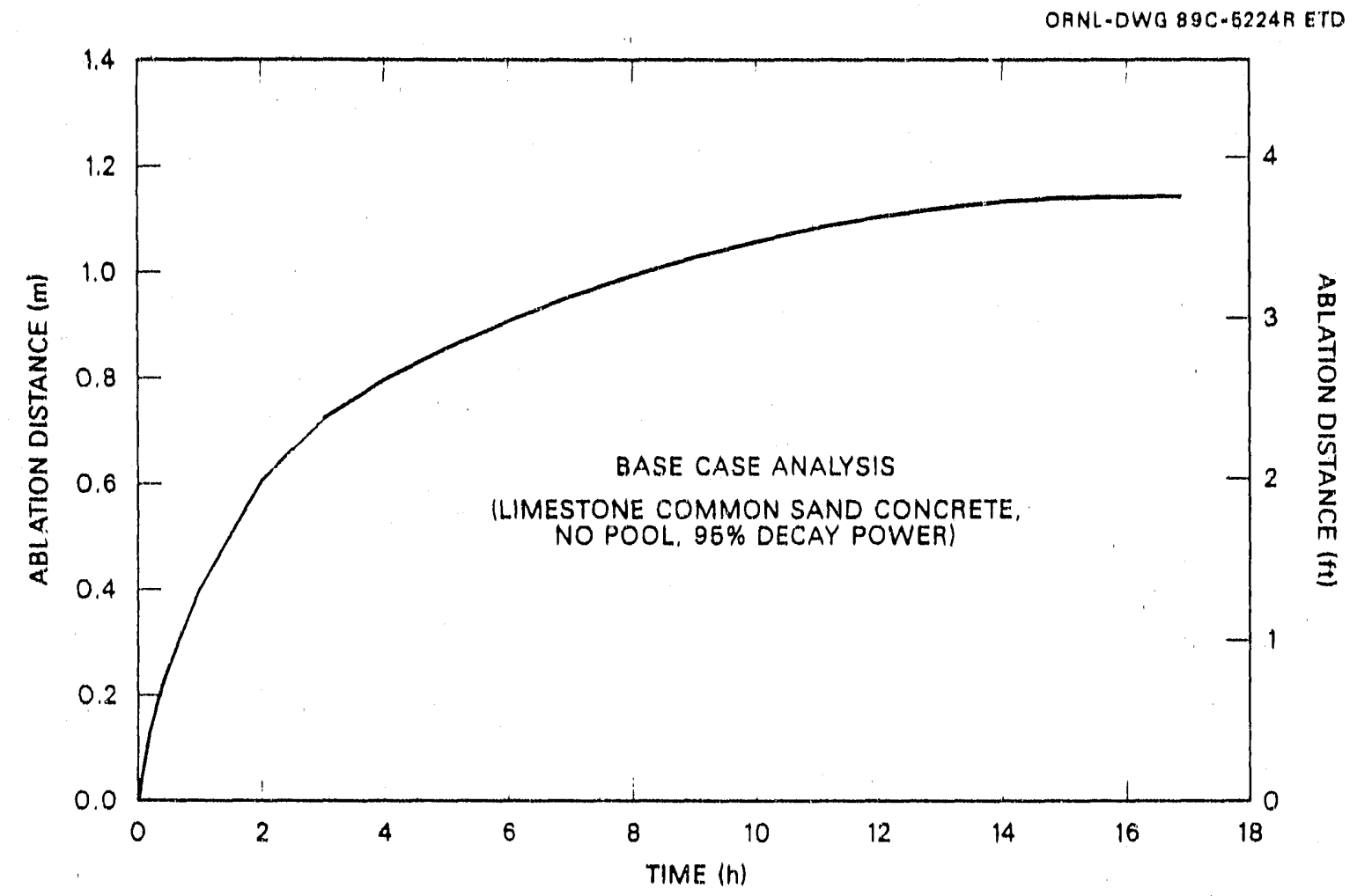

Fig. 3.2. Variation of ablation depth with time (base case).

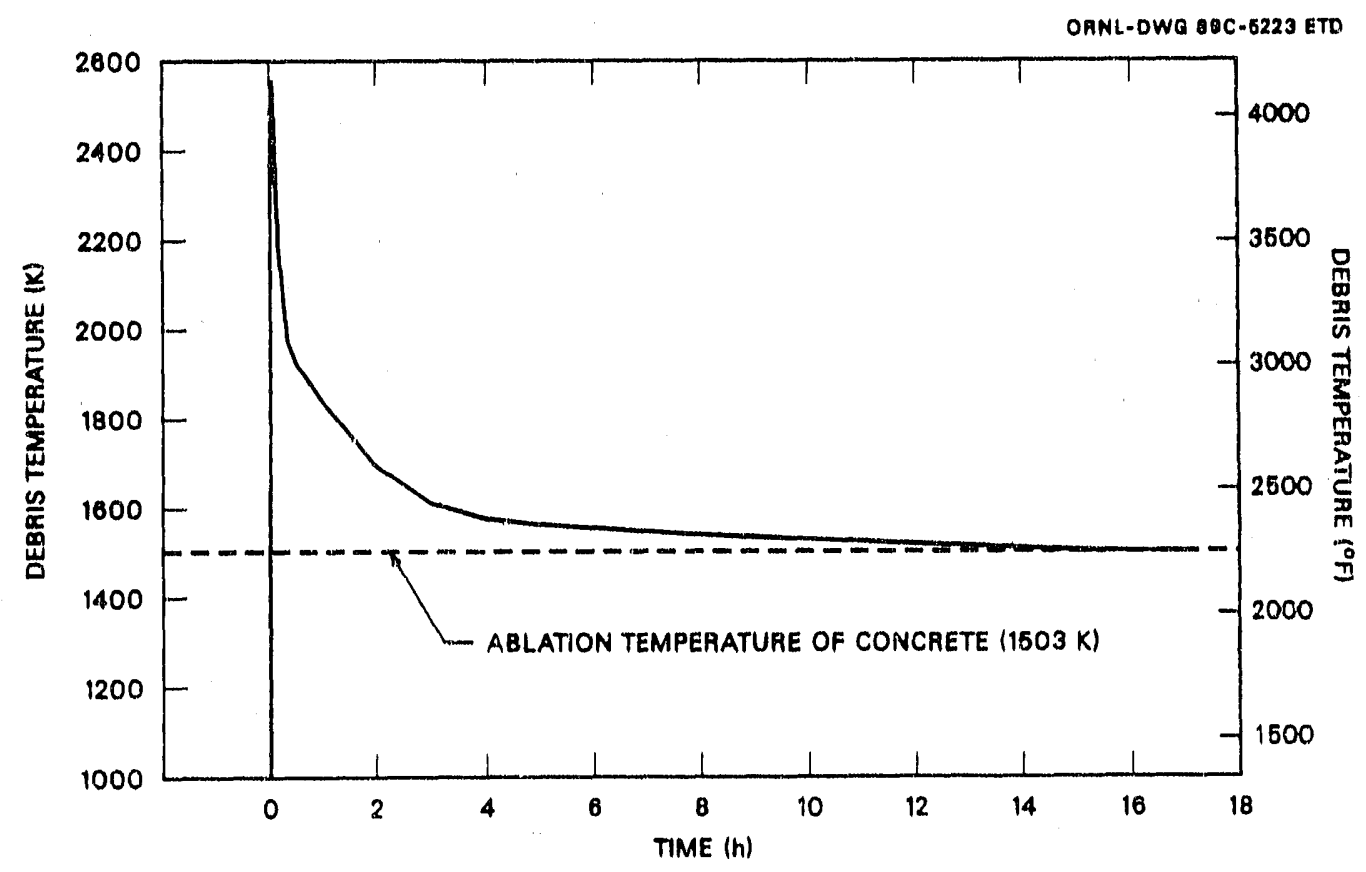

Fig. 3.3. Variation of debris temperature with time (base case). 


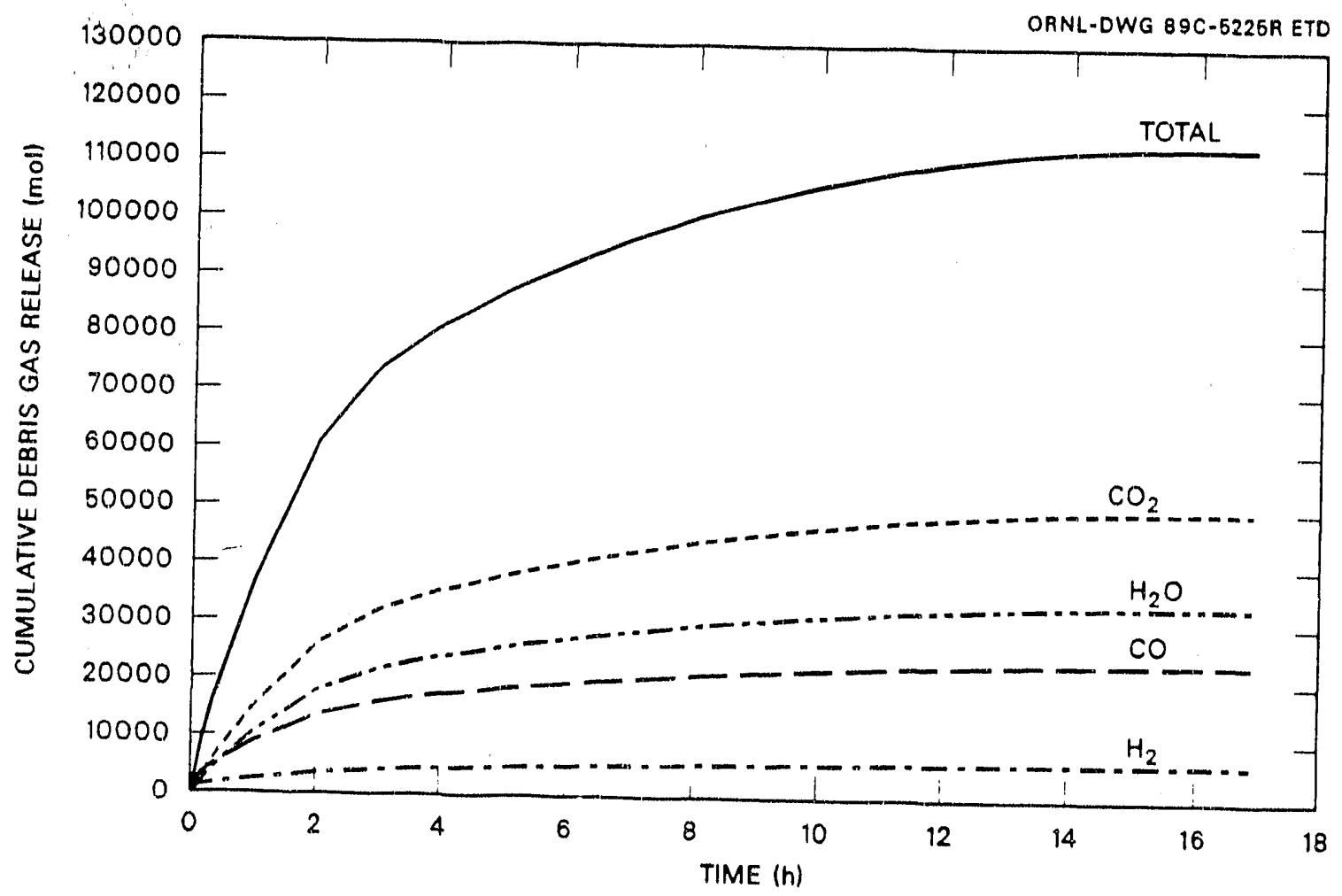

Fig. 3.4. Variation of MCCI gas releases with time (base case).

are produced by chemical reduction of the $\mathrm{CO}_{2}$ and $\mathrm{H}_{2} \mathrm{O}$ gases released from concrete ablation. It is seen that of the $114,000 \mathrm{~mol}$ of gas released, $20 \%(23,000 \mathrm{~mol})$ is $\mathrm{CO}$ and $5 \%(6,000 \mathrm{~mol})$ is $\mathrm{H}_{2}$. Thus, $\sim 26 \%(29,000 \mathrm{~mol})$ of the gas released is combustible.

It is also interesting to note that this quantity of combustible gas is higher than that released by oxidation of the $82.46 \mathrm{~kg}$ of aluminum assumed to exist at the beginning of the calculation. If it is assumed that all the aluminum were consumed by either of the two following reactions:

and

$$
2 \mathrm{Al}+3 \mathrm{H}_{2} \mathrm{O} \rightarrow \mathrm{Al}_{2} \mathrm{O}_{3}+3 \mathrm{H}_{2}
$$

$$
2 \mathrm{Al}+3 \mathrm{CO}_{2} \rightarrow \mathrm{Al}_{2} \mathrm{O}_{3}+3 \mathrm{CO},
$$

then only $4,600 \mathrm{~mol}$ of combustible gas results. We may ask where the additional combustible gas comes from.

As mentioned in Sect. 3.1, the rebar fraction assumed for the base case is 0.10 and is typical of commercial power plani construction. (The purpose of the rebar is to strengthen concrete structures, and, since concrete basemats are usually load bearing, it was assumed that the ANS basemat will have rebar.) CORCON models the concrete rebar as being pure iron, and, as the concrete is ablated, iron is adcied to the debris along with other concrete decomposition by-products $\left(\mathrm{SiO}_{2}, \mathrm{CaO}, \mathrm{CO}_{2}, \mathrm{H}_{2} \mathrm{O}\right.$, etc). Because iron can 
react with $\mathrm{CO}_{2}$ and $\mathrm{H}_{2} \mathrm{O}$ at high temperatures, CORCON calculates extensive rebar oxidation as the concrete is eroded. This results in large quantities of $\mathrm{CO}$ and $\mathrm{H}_{2}$ being produced. It has been estimated that about $15,000 \mathrm{~kg}$ of concrete is ablated in $16.9 \mathrm{~h}$ for the ANS base case. Thus, $1,500 \mathrm{~kg}$ of iron that is oxidized is added to the debris. If the iron oxidation proceeds according to the following reactions:

and

$$
\mathrm{Fe}+\mathrm{H}_{2} \mathrm{O} \rightarrow \mathrm{FeO}+\mathrm{H}_{2}
$$

$$
\mathrm{Fe}+\mathrm{CO}_{2} \rightarrow \mathrm{FeO}+\mathrm{CO}
$$

an additional 27,000 mol of combustible gas can be generated, which accounts for the high production of combustible gas reported earlier.

\subsection{EFFECT OF CONCRETE REBAR FRACTION}

Because the base case results as reported in Sect. 3.1.1 indicate a strong dependence of debris gas release composition on the rebar content of the concrete, the base case analysis was repeated with assumed rebar fractions of $0.01,0.20$, and 0.30 to establish some bounds on the effect.

Comparisons of the results are summarized in Table 3.1 and displayed graphically in Fig. 3.5. It is seen that CORCON results are indeed sensitive to the rebar fraction. For the range of rebar fractions investigated, the extent of concrete ablation decreases as the rebar fraction increases. The reason for this is the additional energy required to melt increasing quantities of iron as heat is transferred from the core debris to the concrete basemat.

\begin{tabular}{|c|c|c|c|c|}
\hline & \multicolumn{4}{|c|}{ Rebar fraction } \\
\hline & 0.01 & 0.10 & 0.20 & 0.30 \\
\hline Ablation depth, $\mathrm{m}$ & 1.28 & 1.14 & 1.10 & 0.84 \\
\hline \multicolumn{5}{|l|}{ Gas release, mol } \\
\hline $\mathrm{H}_{2}$ & $1.158 \times 10^{3}$ & $6.299 \times 10^{3}$ & $1.723 \times 10^{4}$ & $1.720 \times 10^{4}$ \\
\hline $\mathrm{H}_{2} \mathrm{O}$ & $4.165 \times 10^{4}$ & $3.343 \times 10^{4}$ & $2.155 \times 10^{4}$ & $1.865 \times 10^{4}$ \\
\hline co & $4.080 \times 10^{3}$ & $2.347 \times 10^{4}$ & $3.883 \times 10^{4}$ & $3.482 \times 10^{4}$ \\
\hline $\mathrm{CO}_{2}$ & $7.489 \times 10^{4}$ & $4.981 \times 10^{4}$ & $3.271 \times 10^{4}$ & $3.112 \times 10^{4}$ \\
\hline Total & $1.234 \times 10^{5}$ & $1.143 \times 10^{5}$ & $1.114 \times 10^{5}$ & $1.029 \times 10^{5}$ \\
\hline Percent combustible & 4 & 26 & 50 & 51 \\
\hline
\end{tabular}

Table 3.1. CORCON results as a function of concrete rebar fractiona

${ }^{a}$ These results are cumulative at $17 \mathrm{~h}$ and assume limestone common sand concrete, a debris-spreading radius of $1.1 \mathrm{~m}$, and no overlying water pool. 


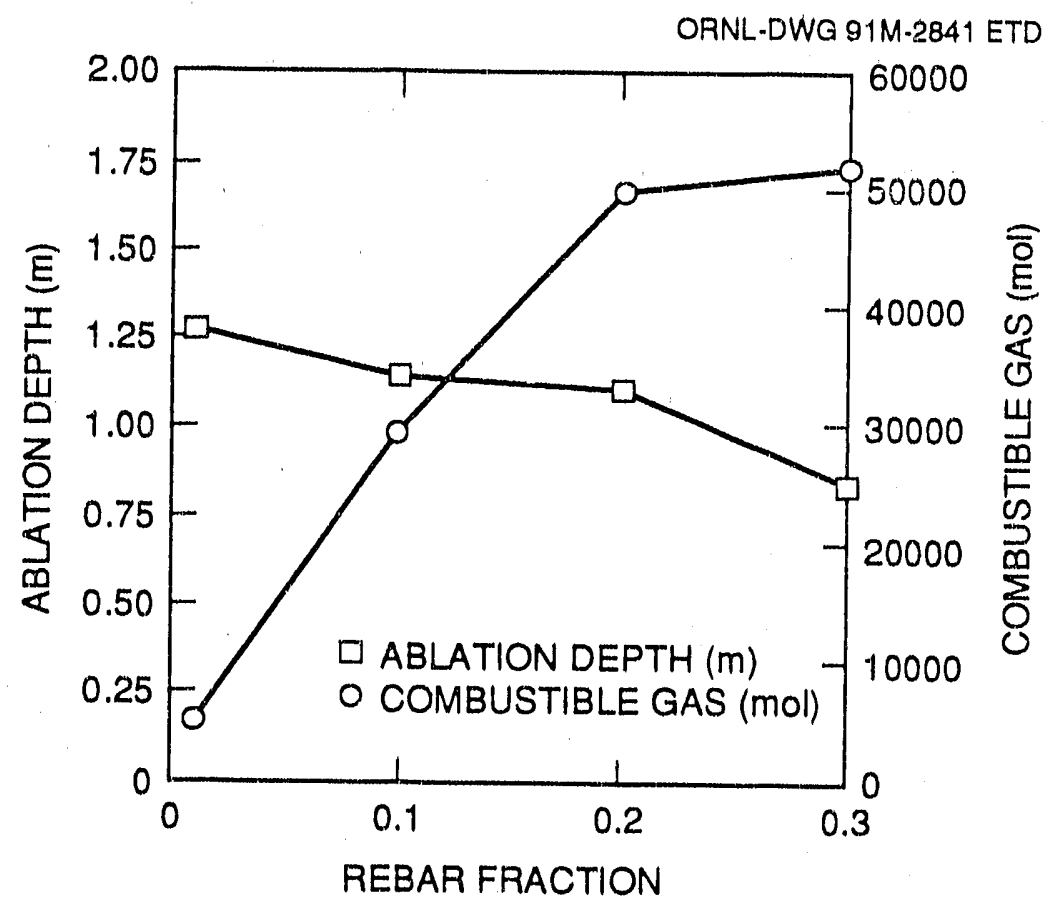
fraction.

Fig. 3.5. Variation of ablation and combustible gas release with rebar

It is also seen that increasing the rebar fraction also increases the combustible gas release but decreases the overall gas release from the debris. The decrease in overall gas release reflects the decrease in concrete ablation and therefore the gas released into the debris. The increase in combustible gas release is a result of the increased availability of unoxidized iron that can react with the concrete gases $\mathrm{CO}_{2}$ and $\mathrm{H}_{2} \mathrm{O}$.

Under ANS MCCI conditions, the production of combustible gas appears to be limited by the availability of unoxidized metal until the rebar fraction reaches the $30 \%$ level. At about this level, the equilibrium chemistry model in CORCON calculates incomplete conversion of the iron to its oxide form. At the $17-\mathrm{h}$ point (for the case of $30 \%$ rebar fraction), CORCON calculates a significant $(1358 \mathrm{~kg}$ ) lower layer of frozen iron, whereas, for smaller rebar fractions, the iron is oxidized as fast as it can be incorporated into the debris.

\subsection{EFFECT OF DEBRIS-SPREADING RADIUS}

Because the extent of debris spreading on the concrete basemat is uncertain, the base case value of $1.1-\mathrm{m}$ radius was varied by $\pm 50 \%$ (i.e., to 0.55 and $1.65 \mathrm{~m}$ ), and the base case calculations were repeated. (Hand calculations by Greene ${ }^{21}$ have indicated that heat losses from the spreading debris would be balanced or even exceeded by internal heat generation. Therefore, the spread radius of $1.1 \mathrm{~m}$ is a reliable best estimate.) The corresponding debris/concrete initial contact areas are $0.95 \mathrm{~m}^{2}, 3.8 \mathrm{~m}^{2}$ (the base case), and $9.1 \mathrm{~m}^{2}$, covering a factor of almost 10 . Once again, the reason for varying this parameter 
is that the proposed subpile room floor characteristic radius is about $3 \mathrm{~m}, 1$ more than even the whole core mass of molten aluminum can cover based upon Greene's correlation and the spread in experimental data.

Table 3.2 and Fig. 3.6 present the CORCON results for the various spreading radii. The results are cumulative and have been chosen for the $14.6-\mathrm{h}$ point. This time corresponds to the point at which CORCON calculates the debris temperature to reach the $1503 \mathrm{~K}$ level for the $1.7-\mathrm{m}$ spreading radius. This point is $\sim 2 \mathrm{~h}$ earlier than the base case, which assumed a $1.1-\mathrm{m}$ spreading radius.

As expected, the results show that increasing the debris-spreading radius results in decreased axial concrete ablation. This is due to the increase in heat transfer to the overlying atmosphere and the increase in the required heat transfer to the underlying concrete for a given increment of axial concrete ablation.

The decrease in concrete ablation is further reflected in the decrease in total debris gas release. Although the total gas release decreases, the combustible gas release, when expressed as a fraction of total gas release, is shown to increase. In addition, as seen in Fig. 3.6, a nonlinear profile is obtained for the total amount of combustible gases released as a function of spreading radius. These observations are due to the CORCON code's assumed debris configuration.

As discussed in Chap. 2, CORCON calculates a "layer flip" once the heavy oxide layer becomes sufficiently diluted that its density is less than the overlying metal layer density. When "layer flip" occurs, the metal layer is placed at the bottom of the debris pool, and the oxides of both the former heavy oxide layer and the light oxide layer are combined into a single light oxide layer.

Table 3.2. CORCON results as a function of debrisspreading radius $a$

\begin{tabular}{|c|c|c|c|}
\hline & \multicolumn{3}{|c|}{ Debris-spreading radius (m) } \\
\hline & 0.55 & 1.1 & 1.7 \\
\hline Ablation depth, m & 1.422 & 1.138 & 0.359 \\
\hline \multicolumn{4}{|l|}{ Gas release, mol } \\
\hline $\mathrm{H}_{2}$ & $8.353 \times 10^{3}$ & $6.282 \times 10^{3}$ & $4.063 \times 10^{3}$ \\
\hline $\mathrm{H}_{2} \mathrm{O}$ & $4.465 \times 10^{4}$ & $3.334 \times 10^{4}$ & $1.703 \times 10^{4}$ \\
\hline$\infty 0$ & $1.740 \times 10^{4}$ & $2.341 \times 10^{4}$ & $1.387 \times 10^{4}$ \\
\hline $\mathrm{CO}_{2}$ & $8.046 \times 10^{4}$ & $4.966 \times 10^{4}$ & $2.501 \times 10^{4}$ \\
\hline Total & $1.527 \times 10^{5}$ & $1.140 \times 10^{5}$ & $6.070 \times 10^{4}$ \\
\hline Percent combustible & 17 & 26 & 30 \\
\hline
\end{tabular}

${ }^{a}$ These results are cumulative at $14.6 \mathrm{~h}$ and assume limestone common sand concrete, a concrete rebar fraction of 0.10 , and no overlying water pool. 


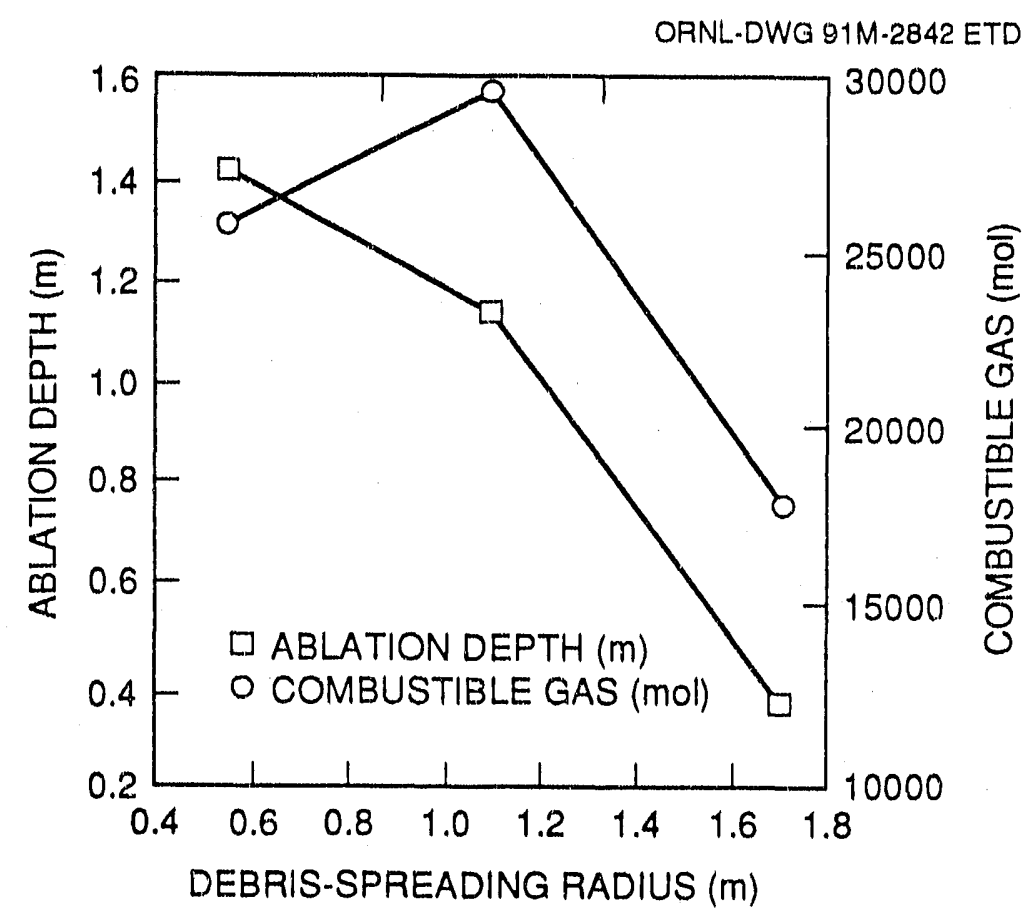

\section{Fig. 3.6. Variation of ablation depth and combustible gas release with debris spreading radius.}

In this post "layer flip" debris configuration, the metal layer can only react with those concrete gases that pass through the metal layer, while the concrete gases that are produced as a result of concrete ablation by the overlying light oxide layer bypass the metals and are not chemically converted to combustibles.

This geometrical effect is not that important for shallow cavities that have small side-wall debris/concrete interface areas. In this geometry, most of the contact area consists of the horizontal contact area at the bottom of the debris pool. All of the concrete gas passing through this interface is assumed to pass into the debris and will thus be exposed to the metal layer regardless of whecher "layer flip" has occurred.

For deep cavities, however, the side-wall debris/concrete area constitutes a larger fraction of the total contact area. It is this type of cavity geometry for which the CORCON "layer flip" has the most effect on the composition of released debris gases. Prior to "layer flip," the metal layer is exposed to most of the concrete gas. After "layer flip," the metal layer is exposed only to the gas originating because of concrete ablation by the metal layer itself. It is for this reason that the smaller spreading-radius results reported in Table 3.2 have lower fractions of combustible gas release.

\subsection{EFFECT OF CONCRETE TYPE}

Because the type of concrete to be used for construction of the ANS basemat has not, as yet, been determined, the base case assumed limestone common sand concrete. Other concretes are also in common use, and a comparison of compositions is shown in Table 3.3. 
Table 3.3 Compositions (weight percent) and ablation temperatures of commonly used concrete

\begin{tabular}{lccc}
\hline & $\begin{array}{c}\text { Basaltic } \\
\text { concrete }\end{array}$ & $\begin{array}{c}\text { Limestone } \\
\text { common sand } \\
\text { concrete }\end{array}$ & $\begin{array}{c}\text { Limestone } \\
\text { concrete }\end{array}$ \\
\hline $\mathrm{SiO}_{2}$ & 54.84 & 35.80 & 3.60 \\
$\mathrm{TiO}_{2}$ & 1.05 & 0.18 & 0.12 \\
$\mathrm{MnO}$ & 0.00 & 0.03 & 0.01 \\
$\mathrm{MgO}$ & 6.16 & 0.48 & 5.67 \\
$\mathrm{CaO}$ & 8.82 & 31.30 & 45.40 \\
$\mathrm{Na}_{2} \mathrm{O}$ & 1.80 & 0.082 & 0.0078 \\
$\mathrm{~K}_{2} \mathrm{O}$ & 5.39 & 1.22 & 0.68 \\
$\mathrm{Fe}_{2} \mathrm{O}_{3}$ & 6.26 & 1.44 & 1.20 \\
$\mathrm{Al}_{2} \mathrm{O}_{3}$ & 8.32 & 3.60 & 1.60 \\
$\mathrm{Cr}_{2} \mathrm{O}_{3}$ & 0.00 & 0.014 & 0.004 \\
$\mathrm{CO}_{2}$ & 1.50 & 21.154 & 35.698 \\
$\mathrm{H}_{2} \mathrm{O}$, free & 3.86 & 2.70 & 3.94 \\
$\mathrm{H}_{2} \mathrm{O}$, chemical & 2.00 & 2.00 & 2.00 \\
$\mathrm{Ablation}$ & & & \\
& 1450 & 1503 & 1752 \\
\hline
\end{tabular}

Basaltic concrete has the smallest gas content and the lowest ablation temperature of the three concrete types. Because of the low ablation temperature, more concrete is ablated per unit of heat transferred from the debris when compared to the other concrete types. Limestone concrete has the highest gas content and the highest ablation temperature. As a result, for a given quantity of heat transferred from the debris, less concrete is ablated. Limestone common sand concrete is an intermediate concrete.

The base case CORCON analysis was repeated assuming different concrete types, and the results are presented in Table 3.4. It is seen that the basaltic concrete is ablated much more readily than the limestone concrete $(2.2-$ vs $0.9-\mathrm{m}$ ablation) and that the limestone common sand concrete ablation is intermediate.

However, because of the much higher gas content of the limestone concrete compared to the basaltic concrete, the total gas release is rather similar for the three concretes. More than one-half of the limestone concrete debris gas release is $\mathrm{CO}_{2}$, and only $17 \%$ of the total is combustible. Basaltic concrete has a much lower gas content, and, combined with the fact that the rebar content is the same in both calculations, the conversion of concrete gases to their combustible forms is more efficient $(53 \%)$ for the basaltic concrete than for the limestone $(17 \%)$. Once again, the limestone common sand concrete is intermediate between the other two.

\subsection{EFFECT OF CONCRETE ABLATION TEMPERATURE}

As discussed in Chap. 2, the ablation temperature is not precisely known for any specific type of concrete. This is because all concretes are a solid solution of various 
Table 3.4. CORCON results as a function of concrete typea

\begin{tabular}{lccc}
\hline & \multicolumn{3}{c}{ Concrete type } \\
\cline { 2 - 4 } & Basaltic & $\begin{array}{l}\text { Limestone } \\
\text { sand }\end{array}$ & Limestone \\
\hline Ablation depth, $\mathrm{m}$ & 2.234 & 1.144 & 0.945 \\
$\begin{array}{c}\text { Gas release, mol } \\
\vdots \\
\mathrm{H}_{2}\end{array}$ & $5.061 \times 10^{4}$ & $5.299 \times 10^{3}$ & $3.022 \times 10^{3}$ \\
$\mathrm{H}_{2} \mathrm{O}$ & $4.551 \times 10^{4}$ & $3.343 \times 10^{4}$ & $3.724 \times 10^{4}$ \\
$\mathrm{CO}$ & $5.973 \times 10^{3}$ & $2.347 \times 10^{4}$ & $2.102 \times 10^{4}$ \\
$\mathrm{Moles}$ of $\mathrm{H}_{2}+\mathrm{CO}$ & $5.658 \times 10^{4}$ & $2.977 \times 10^{4}$ & $2.404 \times 10^{4}$ \\
$\mathrm{CO} 2$ & $4.101 \times 10^{3}$ & $4.981 \times 10^{4}$ & $7.829 \times 10^{4}$ \\
Total & $1.068 \times 10^{5}$ & $1.143 \times 10^{5}$ & $1.413 \times 10^{5}$ \\
Percent combustible & 53 & 26 & 17 \\
Ablation temperature, $\mathrm{K}$ & 1450 & 1503 & 1752 \\
\hline
\end{tabular}

${ }^{a}$ These results are cumulative at $16.9 \mathrm{~h}$ and assume a spreading radius of $1.1 \mathrm{~m}$, a concrete rebar fraction of 0.10 , and no overlying water pool.

materials and melt over a range of temperatures. Reference 4 suggests that an ablation temperature be specified at one-third of the way from the solidus temperature to the liquidus temperature. For limestone common sand concrete, this is $1503 \mathrm{~K}$ and is the concrete ablation temperature used for the base case.

It has been suggested 22 that CORCON better matches power reactor experimental data if the concrete ablation temperature is set closer to the liquidus temperature. For limestone common sand concrete, the liquidus temperature is $1670 \mathrm{~K}$, and the base case calculation was repeated to assess the effect of ablation temperature on the calculated results. The results of this calculation are compared against the base case results in Table 3.5 .

It is seen that an increase in the specified concrete ablation temperature results in a decrease of about $23 \%$ in the calculated concrete ablation. The reason for this is twofold. First is the increase in the amount of energy required to ablate concrete at a higher temperature compared to that required for a lower ablation temperature. Second, since the ablation temperature is increased, the magnitude of heat transfer from the debris to the concrete is decreased for the same debris temperature.

This decrease in the quantity of concrete ablation is also reflected in the calculated mass of gas released by the debris: Note that there is only $\sim 20 \%$ difference in the two results, an insignificant change in the context of our scoping study. Also, the composition of the debris gas release ( $26 \%$ combustible) is the same as in the base case because the two calculations used the same concrete composition and the same concrete rebar fraction. 


\section{Table 3.5. CORCON results as a function of concrete ablation temperature $a$}

\begin{tabular}{|c|c|c|}
\hline & \multicolumn{2}{|c|}{$\begin{array}{l}\text { Concrete ablation } \\
\text { temperature } \\
(\mathrm{K})\end{array}$} \\
\hline & 1503 & 1670 \\
\hline Ablation depth, $\mathrm{m}$ & 1.14 & 0.88 \\
\hline \multicolumn{3}{|l|}{ Gas release, mol } \\
\hline $\mathrm{H}_{2}$ & $6.299 \times 10^{3}$ & $4.770 \times 10^{3}$ \\
\hline $\mathrm{H}_{2} \mathrm{O}$ & $3.343 \times 10^{4}$ & $2.714 \times 10^{4}$ \\
\hline$\infty$ & $2.347 \times 10^{4}$ & $1.937 \times 10^{4}$ \\
\hline $\mathrm{CO}_{2}$ & $4.981 \times 10^{4}$ & $3.956 \times 10^{4}$ \\
\hline Total & $1.143 \times 10^{5}$ & $9.233 \times 10^{4}$ \\
\hline Percent combustible & 26 & 26 \\
\hline
\end{tabular}

aThese results are cumulative at $16.9 \mathrm{~h}$, assume limestone common sand concrete, a spreading radius of $1.1 \mathrm{~m}$, a concrete rebar fraction of 0.10 , and no overlying water pool.

\subsection{EFFECT OF DEBRIS INTERNAL HEATING}

As explained in Sect. 3.1 for the base case, $95 \%$ of all of the ANS whole core decay heat as represented by Fig. 3.1 was assumed to reside in the debris and was thus available to heat the debris interacting with the concrete. It is believed that this level of MCCI heating represents a conservative upper bound. It is the purpose of this section to present CORCON results if this conservative assumption is relaxed somewhat.

Reference 2 demonstrates that about $45 \%$ of the decay heat is associated with the fission product gases and the fission product volatiles. In addition, Ref. 1 indicates that about $50 \%$ of the fission product heating is involved with the radioactive decay production of gamma rays. For deep debris pools, most of this gamma ray energy is absorbed within the debris pool itself. However, as shown in Sect. 3.1 for the base case, the initial debris pool depth is only $0.8 \mathrm{~cm}$. Negligible attenuation of gamma energy in the debris is expected for this case. 2 In addition to the $95 \%$ decay heating level assumed in Sect. 3.1, heating levels of $45 \%$ and $20 \%$ have been analyzed.

Table 3.6 presents the CORCON results for the various assumed debris decay heat fractions. The results are cumulative at time $2.8 \mathrm{~h}$ into the calculation for all three cases. The 2.8-h point corresponds to the time at which the calculated debris temperature approaches the concrete ablation temperature of $1503 \mathrm{~K}$ for the case of $20 \%$ decay heat. (The corresponding times calculated for the $45 \%$ and the $95 \%$ cases are $6.9 \mathrm{~h}$ and $16.9 \mathrm{~h}$, respectively.) 

Table 3.6. CORCON results as a function of
debris powera

\begin{tabular}{lccc}
\hline & \multicolumn{3}{c}{$\begin{array}{c}\text { Percentage of whole core decay power } \\
\text { assumed in the debris }\end{array}$} \\
\cline { 2 - 4 } & 20 & 45 & $\begin{array}{c}95 \\
\text { (base case) }\end{array}$ \\
\hline Ablation depth, $\mathrm{m}$ & 0.08 & 0.34 & 0.71 \\
Gas release, mol & & & \\
$\mathrm{H}_{2}$ & $3.365 \times 10^{2}$ & $1.251 \times 10^{3}$ & $4.168 \times 10^{3}$ \\
$\mathrm{H}_{2} \mathrm{O}$ & $1.393 \times 10^{3}$ & $7.987 \times 10^{3}$ & $2.116 \times 10^{4}$ \\
$\mathrm{CO}$ & $1.118 \times 10^{3}$ & $5.362 \times 10^{3}$ & $1.568 \times 10^{4}$ \\
$\mathrm{CO}$ & $2.069 \times 10^{3}$ & $1.166 \times 10^{4}$ & $3.106 \times 10^{4}$ \\
Total & $4.917 \times 10^{3}$ & $2.626 \times 10^{4}$ & $7.334 \times 10^{4}$ \\
Percent combustible & 30 & 25 & 27 \\
Debris temperature, $\mathrm{K}$ & 1508 & 1535 & 1623 \\
\hline
\end{tabular}

"These results are cumulative at $2.8 \mathrm{~h}$, assume limestone common sand concrete, a spreading radius of $1.1 \mathrm{~m}$, a concrete rebar fraction of 0.10 , and no overlying water pool. Initial debris inventories are as follows: For the $45 \%$ and $20 \%$ power fraction cases, the initial debris inventory assumed $100 \%$ oxidation of aluminum and thus consisted of $\mathrm{U}=19.06 \mathrm{~kg}, \mathrm{Si}=1.49 \mathrm{~kg}, \mathrm{Al}_{2} \mathrm{O}_{3}=163.95 \mathrm{~kg}$, and $\mathrm{Al}=0 \mathrm{~kg}$. For the $95 \%$ power case, only $5 \%$ of the aluminum was assumed oxidized, and thus the initial masses were $U=19.06 \mathrm{~kg}, \mathrm{Si}=1.49 \mathrm{~kg}, \mathrm{Al}_{2} \mathrm{O}_{3}=8.2 \mathrm{~kg}$, and $\mathrm{Al}=82.46 \mathrm{~kg}$.

It is seen at this time $(2.8 \mathrm{~h})$ that the debris temperatures, the ablation depths, and the debris gas releases are significantly higher for the cases of $45 \%$ and $95 \%$ decay heat. It is also interesting to note that the ultimate concrete ablation was calculated to be $0.08 \mathrm{~m}$ for the $20 \%$ decay heat case at $2.8 \mathrm{~h}$ and $0.37 \mathrm{~m}$ for the $45 \%$ decay heat case at $6.9 \mathrm{~h}$, while that for the base case was $1.14 \mathrm{~m}$ at $16.9 \mathrm{~h}$.

The sensitivity of the results to this heat deposition fraction is so high that more detailed calculations are clearly essential.

\subsection{EFFECT OF ADDITIONAL INITIAL DEBRIS INVENTORY}

As described in Sect. 3.1 for the base case, the whole core inventory of fuel and cladding was assumed to compose the initial debris inventory interacting with the concrete. Because of the probable interaction of the core debris with various structures on its way to 
the subpile room floor, it is likely that the inital debris inventory relocating to the concrete floor will include additional materials. The structures with which the core debris can interact include the core pressure boundary tube (CPB' $T$ ), the inlet coolant piping connecting to the CPBT, and the structures housing the inner neutron-absorbing control plates.

Since the CPBT is made of aluminum and the coolant piping is assumed to be stainless steel, it is probable that these materials will be present in addition to the materials composing the core. It has been assumed that an extra $70 \mathrm{~kg}$ of stainless steel and $50 \mathrm{~kg}$ of aluminum may be present together with the core materials. It has been further assumed that the stainless steel is composed by mass of $74 \%$ iron, $18 \%$ chromium, and $8 \%$ nickel. This leads to the following initial debris masses (kilograms) that can interact with the concrete:

$$
\begin{array}{rlrl}
\mathrm{Fe} & =51.06 & \mathrm{U} & =19.06 \\
\mathrm{Cr} & =12.42 & \mathrm{Al}_{2} \mathrm{O}_{3} & =8.2 \\
\mathrm{Ni} & =5.52 & \mathrm{SI} & =1.49 \\
\mathrm{Al} & =132.46
\end{array}
$$

The inclusion of these extra structural materials more than doubles the base case initial inventory of debris, raising it from 111 to $230 \mathrm{~kg}$. The CORCON base case was repeated with this debris inventory, and the results are presented in Table 3.7, along with the base case results.

It is seen that there is not much difference in the axial concrete ablation or in the gases released from the debris. This reflects that the decay heating driving the interaction is the same between the two calculations as is the concrete type and the rebar fractions. The debris released gas mixture is calculated to be slightly more combustible for the calculation where the debris inventory includes rnetallic structural mass because of the increased availability of unoxidized metal.

As pointed out in Sect. 3.1.1, most of the combustible gas is produced as a result of the oxidation of the concrete rebar as it is released into the debris by the ablation of concrete. In Sect. 3.1.1, it was estimated that $\sim 1500 \mathrm{~kg}$ of iron is oxidized in the base case compared to the input inventory of only $100 \mathrm{~kg}$ of metals $(\mathrm{U}, \mathrm{Si}$, and $\mathrm{Al}$ ). For the case of considering additional structural materials, again, roughly $1500 \mathrm{~kg}$ of iron from concrete is oxidized along with $200 \mathrm{~kg}$ of input metals. This sums to around $1700 \mathrm{~kg}$, an increase of only $6 \%$ in the total mass of metal oxidized. Thus, even though the initial metallic debris inventory is doubled between the two cases, the total metallic mass oxidized increases only by a small amount. This is consistent with Table 3.7, which shows that the quantity of combustible gas increases from $3 \times 10^{4}$ to $3.4 \times 10^{4} \mathrm{~mol}$, an increase of only $13 \%$.

\subsection{EFFECT OF OVERLYING WATER POOL}

As is shown in Ref. 1, there is a significant amount of heavy water in and around the proposed ANS core. This water is located in both the reactor coolant system and in the reflector tank. In addition to the heavy water, the reflector tank is located at the bottorn of a reactor pool containing a very large quantity of light water. Because it is possible that a 
Table 3.7. CORCON results as a function of initial debris inventorya

\begin{tabular}{|c|c|c|}
\hline \multirow[t]{2}{*}{. } & \multicolumn{2}{|c|}{ Initial debris inventories } \\
\hline & $\begin{array}{l}100 \% \\
\text { core }\end{array}$ & $\begin{array}{r}100 \% \text { core } \\
+ \text { structures } \\
\end{array}$ \\
\hline Ablation depth, m & 1.14 & 1.11 \\
\hline \multicolumn{3}{|l|}{ Gas release, mol } \\
\hline $\mathrm{H}_{2}$ & $6.299 \times 10^{3}$ & $8.000 \times 10^{3}$ \\
\hline $\mathrm{H}_{2} \mathrm{O}$ & $3.343 \times 10^{4}$ & $3.209 \times 10^{3}$ \\
\hline$\infty$ & $2.347 \times 10^{4}$ & $2.576 \times 10^{4}$ \\
\hline $\mathrm{CO}_{2}$ & $4.981 \times 10^{4}$ & $4.820 \times 10^{4}$ \\
\hline $\mathrm{H}_{2} \mathrm{O}+\mathrm{CO}$ & $2.977 \times 10^{4}$ & $3.377 \times 104$ \\
\hline Total & $1.143 \times 10^{5}$ & $1.155 \times 10^{5}$ \\
\hline Percent combustible & 26 & 29 \\
\hline
\end{tabular}

${ }^{a}$ These results are cumulative at $16.9 \mathrm{~h}$, assume limestone common sand concrete, a spreading radius of $1.1 \mathrm{~m}$, a concrete rebar fraction of 0.10 , and no overlying water pool.

significant quantity of liquid water may follow/accompany the debris on its relocation to the concrete basemat, it is desirable to assess the MCCI for the ANS assuming essentially an infinite quantity $(105 \mathrm{~kg})$ of initially subcooled water $(300 \mathrm{~K})$ overlying the debris. The physical location of the MCCI could be at either the concrete floor of the reactor pool or the concrete floor of the subpile room.

A best-estimate guess was made that, along with $100 \%$ of the core material, $50 \mathrm{~kg}$ of additional aluminum and $100 \mathrm{~kg}$ of stainless steel are present at the initiation of the MCCI. The time to initiation of the MCCI has been specified as $75 \mathrm{s.}{ }^{2}$ The initial masses (kilograms) considered therefore include the following:

$$
\begin{array}{rlrl}
\mathrm{Al}_{2} \mathrm{O}_{3} & =8.2 & \mathrm{Al} & =132.46 \\
\mathrm{Fe} & =74.0 & \mathrm{U} & =19.06 \\
\mathrm{Cr} & =18.0 & \mathrm{Si} & =1.49 \\
\mathrm{Ni} & =8.0 & &
\end{array}
$$

The base case was repeated with the above initial masses and a very large overlying water pool. The results are presented in Table 3.8, along with the base case sesults, at tirne $3.6 \mathrm{~h}$ after the initiation of the transient. This time was chosen because CORCON calculates that the wet case debris temperature has fallen to the concrete ablation temperature of $1503 \mathrm{~K}$. Further CORCON analysis after this time is invalid. (It is interesting to note that this 
Table 3.8. CORCON results as a function of the presence of a large overlying pool of watera

\begin{tabular}{lcc}
\hline & $\begin{array}{c}\text { Base case } \\
\text { (Without pool) }\end{array}$ & With pool \\
\hline $\begin{array}{l}\text { Ablation depth, } \mathrm{m} \\
\text { Gas release, mol }\end{array}$ & 0.77 & 0.50 \\
$\mathrm{H}_{2}$ & $4.510 \times 10^{3}$ & $5.723 \times 10^{3}$ \\
$\mathrm{H}_{2} \mathrm{O}$ & $2.313 \times 10^{4}$ & $1.002 \times 10^{4} b$ \\
$\mathrm{CO}$ & $1.694 \times 10^{4}$ & $1.415 \times 10^{4}$ \\
$\mathrm{CO}_{2}$ & $3.407 \times 10^{4}$ & $1.493 \times 10^{4}$ \\
$\mathrm{H}_{2}+\mathrm{CO}$ & $2.145 \times 10^{4}$ & $1.987 \times 10^{4}$ \\
Total & $7.993 \times 10^{4}$ & $4.513 \times 10^{4}$ \\
Percent combustible & 27 & 44 \\
\hline
\end{tabular}

${ }^{a}$ These results are cumulative at $3.6 \mathrm{~h}$, assume limestone common sand concrete, a spreading radius of $1.1 \mathrm{~m}$, a concrete rebar fraction of 0.10 , and a decay heat fraction of 0.95 . Initial debris inventories are as follows: The base case initial debris inventory consisted of $\mathrm{U}=19.06 \mathrm{~kg}, \mathrm{Si}=1.49 \mathrm{~kg}, \mathrm{Al}_{2} \mathrm{O}_{3}=8.2 \mathrm{~kg}$, $\mathrm{Al}=82,46 \mathrm{~kg}, \mathrm{Fe}=0 \mathrm{~kg}, \mathrm{Cr}=0 \mathrm{~kg}$, and $\mathrm{Ni}=0 \mathrm{~kg}$. The water pool calculation of initial debris inventory assumed an additional $50 \mathrm{~kg}$ of $\mathrm{Al}$ and $100 \mathrm{~kg}$ of stainless steel structures and thus consisted of $\mathrm{U}=19.06 \mathrm{~kg}, \mathrm{Si}=1.49 \mathrm{~kg}, \mathrm{Al}_{2} \mathrm{O}_{3}=8.2 \mathrm{~kg}$, $\mathrm{Al}=132.46 \mathrm{~kg}, \mathrm{Fe}=74 \mathrm{~kg}, \mathrm{Cr}=18 \mathrm{~kg}$, and $\mathrm{Ni}=8 \mathrm{~kg}$.

$b$ This excludes $3.294 \times 10^{4} \mathrm{~mol}$ of $\mathrm{H}_{2} \mathrm{O}$ released from boiling of the water pool.

temperature is not calculated until $16.9 \mathrm{~h}$ in the base case analysis-a delay of $13.3 \mathrm{~h}$.) It is noted that saturation of the $105-\mathrm{kg}$ water pool was calculated to occur at $3.4 \mathrm{~h}$ after initiation of the calculation and that $593 \mathrm{~kg}$ of water were boiled off during the period from 3.4 to $3.6 \mathrm{~h}$.

It is seen that the base case ablates significantly more concrete than the case with the water pool. However, it is also noted that the presence of liquid water does not terminate/preclude the MCCI. This is consistent with the experimental observations for the SWISS tests described in Chap. 2. Because there is more concrete ablation for the dry case than the wet case, the total debris gas release is much higher.

The release of combustible gases is almost the same in the two cases, although the combustible gas release, when expressed as a fraction of total gas release, is higher for the wet case than for the dry case and is due simply to the decrease in gas leaving the concrete 
(due to the reduction in concrete ablation) and the relatively higher concentration of metals intially present in the debris.

In addition to comparing results of the wet and dry cases at $3.6 \mathrm{~h}$, it is interesting to compare the ultimate ablation and debris gas releases. "Ultimate" as used in this context is defined to be the condition existing at the 3.6-h time for the wet case, whereas for the dry (base) case "ultimate" corresponds to $16.9 \mathrm{~h}$. Ultimate ablation for the dry case is $1.14 \mathrm{~m}$ compared to $0.5 \mathrm{~m}$ for the wet case-a ratio of 2.3. Ultimate debris gas release was calculated to be $1.143 \times 105 \mathrm{~mol}$ compared to only $4.513 \times 10^{4} \mathrm{~mol}$ for the wet case-a ratio of 2.5. Ultimate combustible gas release was $2.977 \times 10^{4}$ mol compared to only $1.987 \times 10^{4} \mathrm{~mol}$ for the wet case-a ratio of 1.5 .

\subsubsection{Further ANS MCCI Analyses in the Presence of Water Pools}

Because the presence of water tends to mitigate the consequences of MCCI and because, in reality, we expect the fraction of the decay heat retained in the debris to be significantly below $95 \%$, further analyses were performed to investigate the sensitivity of wet case MCCI to assumed debris decay heat fractions. The results are shown in Table 3.9 and are cumulative at $2.4 \mathrm{~h}$, the time at which the debris temperature falls below the concrete ablation temperature of $1503 \mathrm{~K}$ for the $20 \%$ power case.

It is seen that there is a strong correlation of debris heating with the calculated extent of concrete ablation and debris gas release. There is roughly a factor of 8 reduction in axial concrete ablation and a factor of 20 reduction in total gas release as the fraction of debris decay heat is decreased from 95 to $20 \%$. Ultimate concrete erosion for the 95 and $45 \%$ cases increases only slightly to 0.50 and $0.18 \mathrm{~m}$, respectively, from those at $2.4 \mathrm{~h}$.

The combustible gas release decreases as the assu; ed debris heating fraction decreases, although not as fast as the total gas release becaust 'the increased significance of initial metal inventory oxidation compared to oxidation . A iron rebar. For the higher power cases, the available metal inventory for oxidation tends to be represented primarily by the iron produced by concrete ablation. For the lower power cases, concrete ablation is reduced, and therefore the rebar added to the debris represents a less significant fraction of metals that can be oxidized. Since the limestone common sand concrete assumed for these calculations is gas rich, the fractional conversion of concrete gas to combustible $\mathrm{CO}$ and $\mathrm{H}_{2}$ is higher for the low-power calculations compared to the high-power calculations.

It is interesting to note the relative lack of carbon-bearing gas leaving the debris for the $20 \%$ decay heat case. Inspection of CORCON results shows a significant quantity of condensed carbon in the metal layer at the $2.4-\mathrm{h}$ point. The presence of this carbon suggests the occurrence of the "coking" metal/gas reaction:

$$
4 \mathrm{Al}+3 \mathrm{CO}_{2} \rightarrow 2 \mathrm{Al}_{2} \mathrm{O}_{3}+3 \mathrm{C}
$$

The continued occurrence of this reaction leads to an accumulation of carbon until the aluminum is exhausted. This carbon inventory reacts with subsequent $\mathrm{CO}_{2}$ released from concrete ablation via the following reactions:

$$
\mathrm{C}+\mathrm{CO}_{2} \rightarrow 2 \mathrm{CO}
$$


Table 3.9. CORCON results for ANS MCCI in the presence of a large overlying pool of watera

\begin{tabular}{|c|c|c|c|c|c|}
\hline & \multicolumn{5}{|c|}{ Decay heat fractions } \\
\hline & $20 \%$ & $45 \%$ & $60 \%$ & $80 \%$ & $95 \%$ \\
\hline Ablation depth, m & 0.06 & 0.18 & 0.28 & 0.39 & 0.46 \\
\hline \multicolumn{6}{|l|}{ Gas release, mol } \\
\hline $\mathrm{H}_{2}$ & $1.611 \times 10^{3}$ & $4.119 \times 10^{3}$ & $4.865 \times 10^{3}$ & $5.306 \times 10^{3}$ & $5.575 \times 104$ \\
\hline $\mathrm{H}_{2} \mathrm{O}^{b}$ & $5.604 \times 101$ & $7.437 \times 10^{2}$ & $3.000 \times 10^{3}$ & $6.551 \times 10^{3}$ & $9.166 \times 10^{3}$ \\
\hline$\infty$ & $9.504 \times 100$ & $7.820 \times 10^{3}$ & $1.001 \times 104$ & $1.210 \times 10^{4}$ & $1.358 \times 10^{4}$ \\
\hline $\mathrm{CO}_{2}$ & $1.032 \times 10^{2}$ & $1.137 \times 10^{3}$ & $4.482 \times 10^{3}$ & $9.763 \times 10^{3}$ & $1.360 \times 10^{4}$ \\
\hline $\mathrm{H}_{2}+\mathrm{CO}$ & $1.621 \times 10^{3}$ & $1.193 \times 10^{4}$ & $1.488 \times 104$ & $1.741 \times 10^{4}$ & $1.915 \times 10^{4}$ \\
\hline Total & $1.781 \times 10^{3}$ & $1.384 \times 10^{4}$ & $2.244 \times 10^{4}$ & $3.391 \times 10^{4}$ & $4.224 \times 10^{4}$ \\
\hline Percent combustible & 91 & 86 & 66 & 51 & 45 \\
\hline
\end{tabular}

aThese results are cumulative at $2.4 \mathrm{~h}$, assume limestone common sand concrete, a spreading radius of $1.1 \mathrm{~m}$, a concrete rebar fraction of 0.10 , and various decay heat fractions. Initial debris inventory is as follows: The initial debris inventory for these calculations consisted of $100 \%$ core inventory of fuel and cladding (5\% oxidation), with an additional $50 \mathrm{~kg}$ of $\mathrm{Al}$ and $100 \mathrm{~kg}$ of stainless steel structure masses. Thus, the inventories are: $\mathrm{U}=19.06 \mathrm{~kg}, \mathrm{Si}=1.49 \mathrm{~kg}, \mathrm{Al}_{2} \mathrm{O}_{3}=8.2 \mathrm{~kg}, \mathrm{Al}=132.46 \mathrm{~kg}, \mathrm{Fe}=74.0 \mathrm{~kg}, \mathrm{Cr}=18.0 \mathrm{~kg}$, and $\mathrm{Ni}=8.0 \mathrm{~kg}$.

$b$ This represents debris gas release since no boiling of the water pool has occurred by $2.4 \mathrm{~h}$.

and

$$
\mathrm{C}+\mathrm{H}_{2} \mathrm{O} \rightarrow \mathrm{CO}+\mathrm{H}_{2}
$$

Thus the carbon produced by the "coking" reaction may be oxidized to produce combustible $\mathrm{CO}$ and $\mathrm{H}_{2}$.

The conversion of condensed carbon into combustible $\mathrm{CO}$ requires the continued availability of $\mathrm{CO}_{2}$ and $\mathrm{H}_{2} \mathrm{O}$. For the high-power cases, the debris temperature remains elevated above the concrete ablation temperature for an extended period after the exhaustion of the aluminum. As a result, concrete ablation continues to release $\mathrm{CO}_{2}$ and $\mathrm{H}_{2} \mathrm{O}$ into the debris, which then reacts with the condensed carbon to produce the $\mathrm{CO}$ from the above reactions.

If the debris temperature is low enough at the point of aluminum exhaustion that the concrete is no longer ablating, then the condensed carbon will remain in the debris, and conversion into $\mathrm{CO}$ will not occur. This is the result calculated for the low-power case of $20 \%$ decay power. 
It is also interesting to note that the presence of a water pool appears to mitigate the MCCI more for the high-power cases than for the lower-power cases. This conclusion is drawn from comparison of results from Tables 3.9 and 3.6 and is due to the increase in relative importance of the power produced from chemical reactions compared to decay power at the lower decay heating levels.

\subsection{ANS MCCI MITIGATION ANALYSIS}

A preliminary effor was made to evaluate the possible mitigative effect of an altemate basemat material in case an $\mathrm{MCCI}$ event initiates during a severe accident for the ANS. Tow'ard this end, the CORCON analysis was repeated, assuming that a highmelting-temperature refractnry concrete is used instead of commonly used concrete. The CORCON input information required for alumina concrete was suggested by Bradley. 22 The composition (weight perent) and phase change temperatures were input as follows:

$$
\begin{aligned}
\mathrm{Al}_{2} \mathrm{O}_{3} & =0.70 \\
\mathrm{C}_{3} \mathrm{O} & =0.25 \\
\mathrm{SiO}_{2} & =0.03 \\
\mathrm{Fe}_{2} \mathrm{O}_{3} & =0.01 \\
\text { Rebar } & =0.10
\end{aligned}
$$

$$
\begin{aligned}
\mathrm{H}_{2} \mathrm{O} \text { (free) } & =0.005 \\
\mathrm{H}_{2} \mathrm{O} \text { (bound) } & =0.005 \\
\mathrm{~T}_{\text {solidus }} & =2.173 \mathrm{~K} \\
\mathrm{~T}_{\text {liquidus }} & =2373 \mathrm{~K} \\
\mathrm{~T}_{\text {ablation }} & =2300 \mathrm{~K}
\end{aligned}
$$

It is seen that this concrete has a much higher ablation temperature than ordinary concretes and that its gas composition is entirely that due to a small quantity of water.

Results from CORCON analysis using this special concrete are compared to those of the base case in Table 3.10. The refractory concrete does not prevent significant ablation because the debris temperatures are calculated to remain sufficiently above the concrete ablation temperature that large quantities of heat are transferred to the concrete. The combustible gas release is reduced by about a factor of 5 from the base case because the alumina concrete is not composed of any $\mathrm{CO}_{2}$ and the $\mathrm{H}_{2} \mathrm{O}$ content is much smaller than that of the limestone common sand concrete assumed for the base case. Conversion of the $\mathrm{H}_{2} \mathrm{O}$ to $\mathrm{H}_{2}$ is enhanced compared to the base case (39\% vs $26 \%$ ) but is still incomplete, as evidenced by the relative large release of unreacted $\mathrm{H}_{2} \mathrm{O}$.

The validity of these CORCON results must be questioned in light of the very high ablation temperature employed for the alumina concrete $\mathrm{MCCI}$ analysis. Because CORCON assumes that debris/concrete interactions occur only when the debris temperature is above the user-specified concrete ablation temperature, the calculated debris temperature exceeds the boiling temperature of aluminum $(2600 \mathrm{~K})$ for $\sim 10 \mathrm{~min}$ of transient time. Since CORCON does not account for the boil-off of any species other than water, the validity of these results is suspect.

\subsubsection{Further Alumina Concrete MCCI Analyses Without Water Pools}

Because of the high probability of reduced debris heating due to volatilization of fission products prior to debris relocation to the concrete basemat and the partial loss of 
Table 3.10. CORCON results for high-meltingtemperature alumina concrete compared to limestone common sand concretea

\begin{tabular}{lcc}
\hline & $\begin{array}{c}\text { Base case } \\
\text { LCS concrete }\end{array}$ & $\begin{array}{c}\text { High- } \\
\text { temperature } \\
\text { alumina concrete }\end{array}$ \\
\hline $\begin{array}{l}\text { Ablation depth, } \mathrm{m} \\
\text { Gas release, mol }\end{array}$ & 1.14 & 0.98 \\
$\mathrm{H}_{2}$ & $6.299 \times 10^{3}$ & $6.772 \times 10^{3}$ \\
$\mathrm{H}_{2} \mathrm{O}$ & $3.343 \times 10^{4}$ & $8.189 \times 10^{3}$ \\
$\mathrm{CO}$ & $2.347 \times 10^{4}$ & 0.0 \\
$\mathrm{CO}$ & & 0.0 \\
$\mathrm{Al}_{2} \mathrm{O}$ & $4.981 \times 10^{2}$ & $2.202 \times 10^{3}$ \\
$\mathrm{H}_{2}+\mathrm{CO}$ & $1.192 \times 10^{3}$ & $6.772 \times 10^{3}$ \\
Total & $2.977 \times 10^{4}$ & $1.730 \times 10^{3}$ \\
Percent combustible & $1.143 \times 10^{5}$ & 39 \\
\hline
\end{tabular}

${ }^{\sigma}$ The results are cumulative at $16.9 \mathrm{~h}$, and the calculations assume a spreading radius of $1.1 \mathrm{~m}$, a concrete rebar fraction of 0.1 , and debris decay heat fraction of 0.95 . Initial debris inventory is as follows: $U=19.06 \mathrm{~kg}, \mathrm{Si}=1.49 \mathrm{~kg}$, $\mathrm{Al}_{2} \mathrm{O}_{3}=8.2 \mathrm{~kg}$, and $\mathrm{Al}=82.46 \mathrm{~kg}$.

gamma ray heating, the MCCI calculations reported in Sect. 3.9 were repeated with reduced debris heating values.

Cumulative results for 95,45 , and $20 \%$ decay heating fractions are shown in Table 3.11 at time $2.7 \mathrm{~h}$. This time was chosen because the debris temperature was calculated to fall to the concrete ablation temperature $(2300 \mathrm{~K})$ for the $20 \%$ case at this time.

As was the case in Sect. 3.6 for limestone common sand concrete, it was found that the extent of concrete ablation and gas release is a strong function of debris internal heating. Axial concrete ablation is reduced from 0.46 to $0.09 \mathrm{~m}$ as the debris heating rate is decreased from 95 to $20 \%$, with a similar reduction in debris gas release. The total amount of combustible gas release is lowered by about two orders of magnitude from the base case (Table 3.1), although the fractional release of combustible gas is higher for the alumina concrete than the limestone common sand and is due to the lack of $\mathrm{CO}_{2}$ in the alumina concrete. The trend of increasing fractional combustible gas release with decreasing debris power as discussed in Sect. 3.8.1 is also evident.

Reduction in the ultimate concrete ablation is also significant. As shown in Sect. 3.9 , ultimate concrete ablation was calculated to be $0.98 \mathrm{~m}$ at $16.9 \mathrm{~h}$ for alumina 
Table 3.11. CORCON results as a function of debris power for high-melting-temperature alumina concrete $a$

\begin{tabular}{lccc}
\hline & \multicolumn{3}{c}{$\begin{array}{c}\text { Percentage of whole core decay power } \\
\text { assumed in the debris }\end{array}$} \\
\cline { 2 - 4 } & 20 & 45 & 95 \\
\hline Ablation depth, $\mathrm{m}$ & 0.09 & 0.26 & 0.46 \\
Gas release, mol & & & \\
$\mathrm{H}_{2}$ & $5.623 \times 10^{2}$ & $1.602 \times 10^{3}$ & $2.896 \times 10^{3}$ \\
$\mathrm{H}_{2} \mathrm{O}$ & $3.466 \times 10^{1}$ & $4.772 \times 10^{2}$ & $1.917 \times 10^{3}$ \\
$\mathrm{CO}$ & 0.0 & 0.0 & 0.0 \\
$\mathrm{CO}$ & & 0.0 & 0.0 \\
$\mathrm{Al}_{2} \mathrm{O}$ & 0.0 & $1.494 \times 10^{3}$ & $2.202 \times 10^{3}$ \\
$\mathrm{Total}$ & $3.053 \times 10^{2}$ & $3.608 \times 10^{3}$ & $7.115 \times 10^{3}$ \\
$\mathrm{Percent}$ & $9.111 \times 10^{2}$ & 44 & 41 \\
Debris temperature, $\mathrm{K}$ & 62 & 2345 & 2371 \\
\hline
\end{tabular}

${ }^{a}$ These results are cumulative at $2.7 \mathrm{~h}$, assume a spreading radius of $1.1 \mathrm{~m}$, a concrete rebar fraction of 0.10 , and no overlying water pool. Initial debris inventory is as follows: $\mathrm{U}=19.06 \mathrm{~kg}, \mathrm{Si}=1.49 \mathrm{~kg}, \mathrm{~A}_{2} \mathrm{O}_{3}=8.2 \mathrm{~kg}$, and $\mathrm{Al}=82.46 \mathrm{~kg}$.

concrete with $95 \%$ decay heating. Thus, ultimate concrete ablation is decreased by a factor of 10 when the power is reduced from 95 to $20 \%$.

\subsubsection{Alumina Concrete MCCI Analyses in the Presence of Water Pools}

Because it is likely that not all of the debris decay heat will remain with the debris and that a significant portion of the primary system/reflector tank water inventory may accompany the debris as it relocates to the assumed alumina concrete basemat, calculations were repeated at 95,45 , and $20 \%$ debris decay heating levels for the ANS MCCI occurring in the presence of a large $\left(10^{5}-\mathrm{kg}\right)$ overlying water pool that is initially subcooled $(300 \mathrm{~K})$.

Results for the 45 and $20 \%$ decay heating levels show no MCCI and only a very small MCCI for the $95 \%$ decay heating level. This is because the film boiling heat transfer coefficient is large enough to remove the fission product power at debris temperatures low enough to preclude concrete ablation. Maximum debris temperatures were calculated to be $1670 \mathrm{~K}$ and $2198 \mathrm{~K}$ for the 20 and $45 \%$ heating levels, respectively. These maximum temperatures are far below the temperature required for the ablation of alumina concrete $(2300 \mathrm{~K})$. For the $95 \%$ power case, only $5.8 \mathrm{~cm}$ of axial concrete ablation are ultimately calculated. 
A comparison of dry and wet case results for the $95 \%$ power level is presented in Table 3.12. It is seen that there is a factor of 10 reduction in the calculated axial concrete erosion and a factor of 14 reduction in debris released gas when the alumina concrete is covered with a large water pool. Ultimate concrete ablation for the dry case is $0.98 \mathrm{~m}$ (Table 3.10); so the reduction in total erosion due to the water pool is by a factor of 17 .

It is also evident that conversion of concrete $\mathrm{H}_{2} \mathrm{O}$ vapor to $\mathrm{H}_{2}$ is more efficient for the wet case than for the dry case. This is because a significant portion of the concrete $\mathrm{H}_{2} \mathrm{O}$ vapor released by ablation for the dry case never contacts the debris metal and therefore cannot be reduced to $\mathrm{H}_{2}$. A thick layer of $\mathrm{Al}_{2} \mathrm{O}_{3}$ builds on top of the metal layer and several centimeters of radial concrete ablation are calculated. Since the metals lie below the oxides, the gas released by the radial concrete ablation is released directly into the atmosphere and does not contact the metal layer. This contrasts with the wet case, where

Table 3.12. CORCON results for alumina concrete as a function of the presence of an overlying water poola

\begin{tabular}{lcc}
\hline & Dry case & Wet case \\
\hline Ablation depth, $\mathrm{m}$ & 0.46 & 0.05 \\
Gas release, mol & & \\
$\mathrm{H}_{2}$ & $2.896 \times 10^{3}$ & $3.193 \times 10^{2}$ \\
$\mathrm{H}_{2} \mathrm{O}$ & $1.917 \times 10^{3}$ & $1.201 \times 10^{5 b}$ \\
$\mathrm{CO}$ & 0.0 & 0.0 \\
$\mathrm{CO}_{2}$ & 0.0 & 0.0 \\
$\mathrm{Al}_{2} \mathrm{O}$ & $2.202 \times 10^{3}$ & $1.503 \times 10^{2}$ \\
$\mathrm{Total}$ & $7.115 \times 10^{3}$ & $4.778 \times 10^{2}$ \\
Percent combustible & 41 & 67 \\
\hline
\end{tabular}

${ }^{a}$ These results are cumulative at $2.7 \mathrm{~h}$, assume $95 \%$ debris decay heating, a spreading radius of $1.1 \mathrm{~m}$, and a concrete rebar fraction of 0.10 . Initial debris inventories are as follows: The initial debris inventory for the dry case assumed $100 \%$ core inventory of fuel and cladding $(5 \%$ oxidation) and consisted of $U=19.06 \mathrm{~kg}, \mathrm{Si}=1.49 \mathrm{~kg}$, $\mathrm{Al}_{2} \mathrm{O}_{3}=8.2 \mathrm{~kg}$, and $\mathrm{Al}=82.46 \mathrm{~kg}$. For the wet case, an additional $50 \mathrm{~kg}$ of $\mathrm{Al}$ and $100 \mathrm{~kg}$ of stainless steel were added so that the debris inventory was $U=19.06 \mathrm{~kg}$, $\mathrm{Si}=1.49 \mathrm{~kg}, \mathrm{Al}_{2} \mathrm{O}_{3}=8.2 \mathrm{~kg}, \mathrm{Al}=132.46 \mathrm{~kg}, \mathrm{Fe}=74.0 \mathrm{~kg}$, $\mathrm{Cr}=18 \mathrm{~kg}$, and $\mathrm{Ni}=8 \mathrm{~kg}$.

$b_{\text {This }}$ quantity of water is due to boiling of the water pool and is not included in the total. 
most concrete erosion is axial and therefore the concrete gas must pass through and react with the metal layer.

\subsection{RELATIVE IMPACT OF LIMESTONE COMMON SAND AND ALUMINA CONCRETE TYPES ON ANS MCCI}

The results of Sects. 3.8 and 3.9 were analyzed for end-of-MCCI conditions, to evaluate the relative impact of key parameters on MCCI, and are summarized in Figs. 3.7 and 3.8 , respectively. Figure 3.7 shows the variation of concrete ablation with debris decay power level (expressed as a percentage of decay power without dissipation) for the two concrete types, with and without the existence of a water pool. As noted therein, the effect of debris submergence in a water pool is dramatic in terms of mitigating MCCI. This is especially true for the case of alumina concrete and is intimately tied to the radiative heat transfer process from the debris surface to the surroundings, an interrelationship that is explored more fully in the next section.

Without the existence of a water pool, the amount of ablation does not change significantly from alumina to limestone common sand concrete. However, as seen in Fig. 3.8, the amount of combustible gas release for alumina concrete is significantly less than the amount released from limestone common sand concrete. This is attributable to the low gas and water contents of alumina concrete. It attests to alumina concrete's potential suitability as an MCCI mitigative mechanism with or without a water pool since the

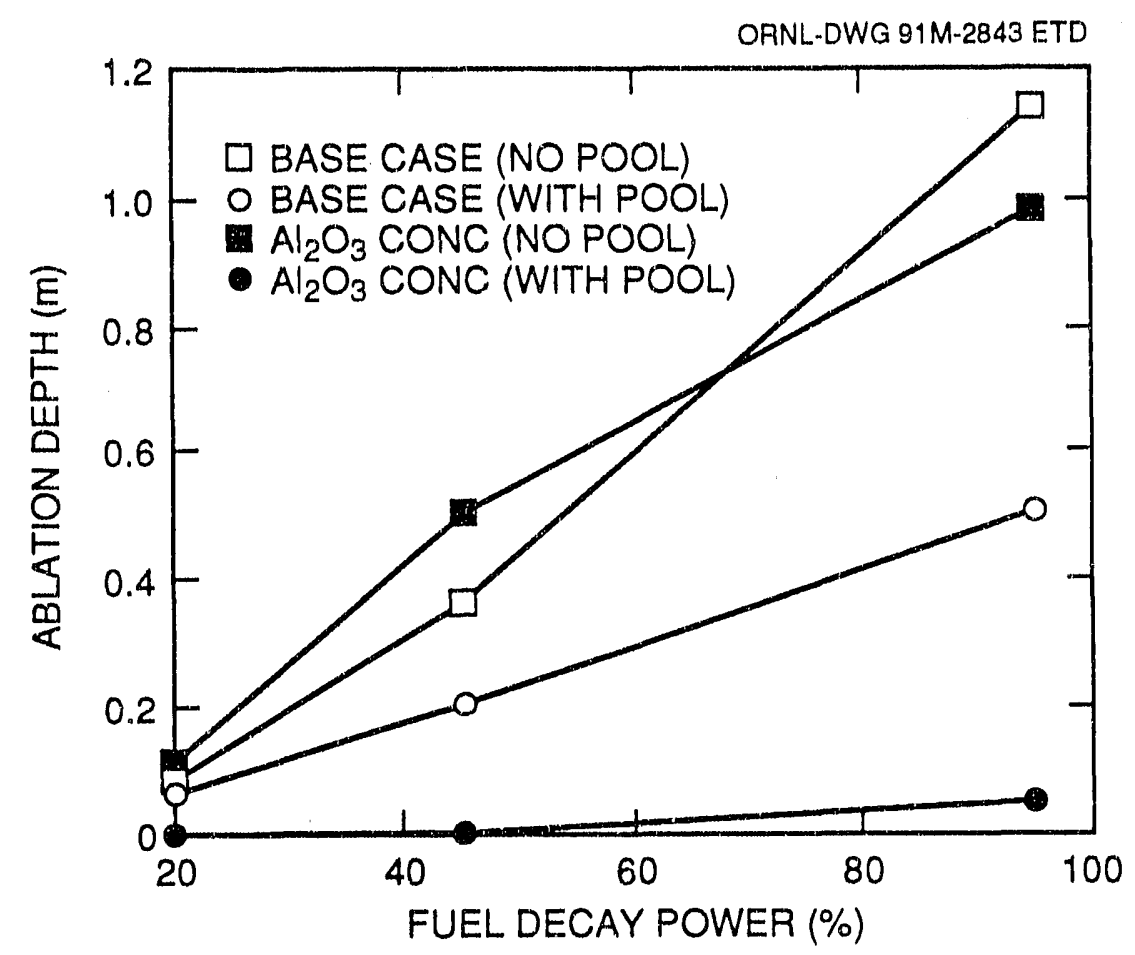

Fig. 3.7. Variation of ablation depth with concrete type, debris power, and water pool. 


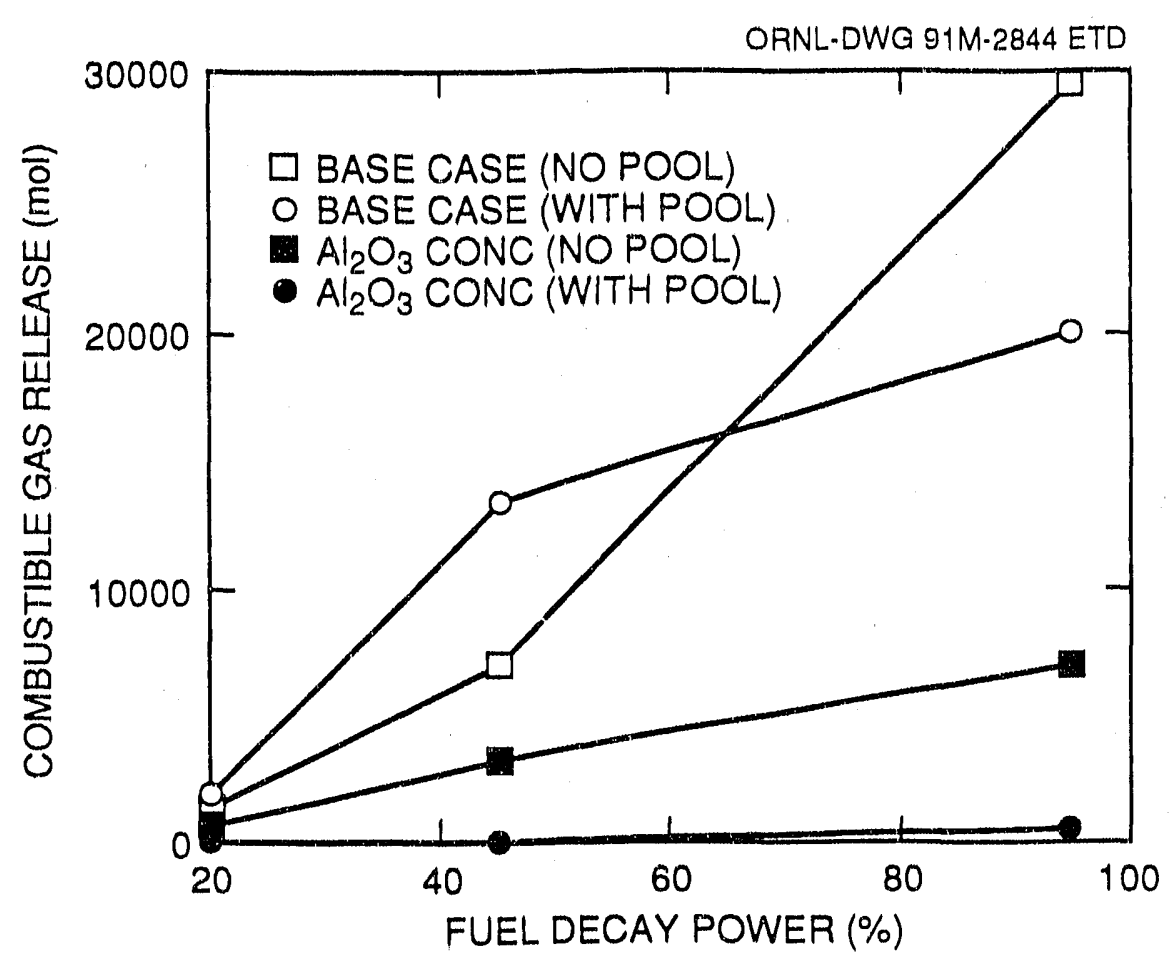

Fig. 3.8. Variation of combustible gas release with concrete type, debris power, and water pool.

generation of large amounts of combustible gases may pose a significant challenge to containment integrity.

\subsection{RELATIVE IMPACT OF DEBRIS SURFACE-TO-SURROUNDINGS RADIATION HEAT TRANSFER AND ALUMINA ABLATION TEMPERATURE ON ANS MCCI}

The amount of heat transferred from the debris surface to the surroundings will clearly play an important role in determining the debris temperature and thus the extent of MCCI. Since the radiation heat transfer component becomes increasingly important with increasing debris temperatures, a study was conducted to note the relative impact of atmosphere opacity modeling on ANS MCCI for the limestone common sand and alumina concrete types.

As mentioned previously, the debris-to-surroundings radiation heat transfer model includes the retarding effect of aerosols. This model was used for generating all of the results presented up to now. A series of CORCON runs was conducted next to remove atmosphere opacity to radiation heat transfer. The results of these calculations indicate that the impact of opacity on surface heat transfer to the surroundings is minor for the limestone common sand concrete case, both in terms of cumulative concrete ablation and combustible gas release. However, for the case of alumina concrete, the situation is quite different, primarily because of the high (i.e., $2300 \mathrm{~K}$ ) ablation temperature requirement. At these high temperatures, the impact of opacity modeling becomes significant, as seen in Figs. 3.9 


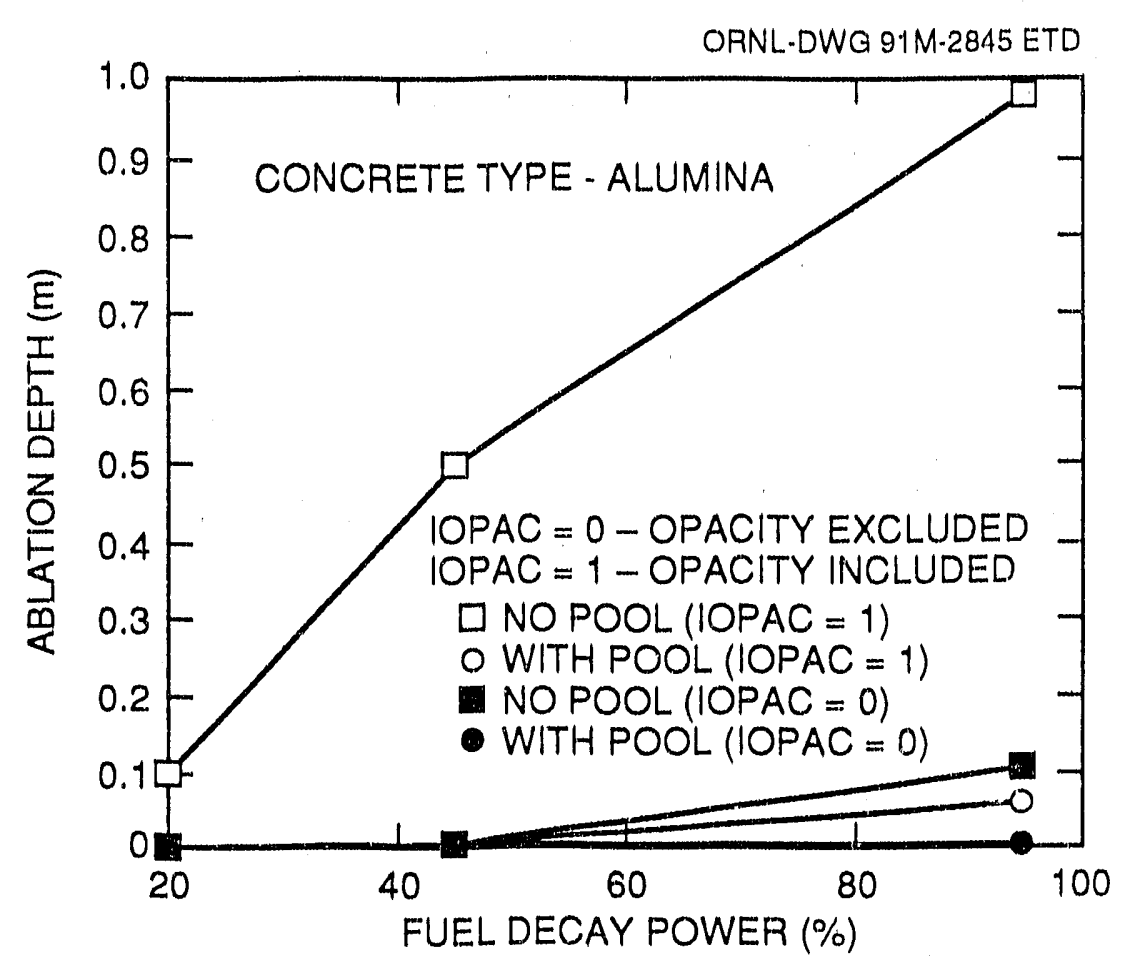
opacity.

Fig. 3.9. Variation of ablation depth with debris power and surface and 3.10. Specifically, it is noted that the total concrete ablation (at $95 \%$ decay heat power, assuming transparency) is about $10 \%$ of the value obtained with the built-in model. The release of combustible gases is also reduced by about $90 \%$. In addition, no concrete ablation is indicated for debris power levels less than or equal to $45 \%$ of total decay heat.

For ANS MCCI evaluations with no opacity, it was found that, even though concrete ablation was arrested for many cases, the debris surface temperature still remained high $(>2000 \mathrm{~K})$ even at $17 \mathrm{~h}$ into the transient. Since the assumed alumina ablation temperature of $2300 \mathrm{~K}$ was chosen on the basis of a recommendation only, 22 additional CORCON calculations were performed with the ablation temperature set at $2173 \mathrm{~K}$, which corresponds to the solidus temperature of the alumina concrete. These runs were made with and without the existence of an overhead pool of water and also discounted the effect of atmospheric opacity. The results of these exercises are shown in Figs. 3.11 and 3.12. Very little or no ablation was indicated for the cases where the debris power level was less than or equal to $45 \%$ of total decay heat. For the $95 \%$ of decay heat case, the amounts of ablation and combustible gas release are seen to increase but are still relatively small when compared to the results where the full retardant effect of opacity is modeled.

These are significant findings in relation to the use of alumina-type concrete as an MCCI mitigative inaterial for the ANS, a feature that would depend greatly upon the accident scenario, the true ablation temperature of alumina-type concretes, as well as the debris free surface radiant heat transfer conditions that are generated during $\mathrm{MCCI}$. The 


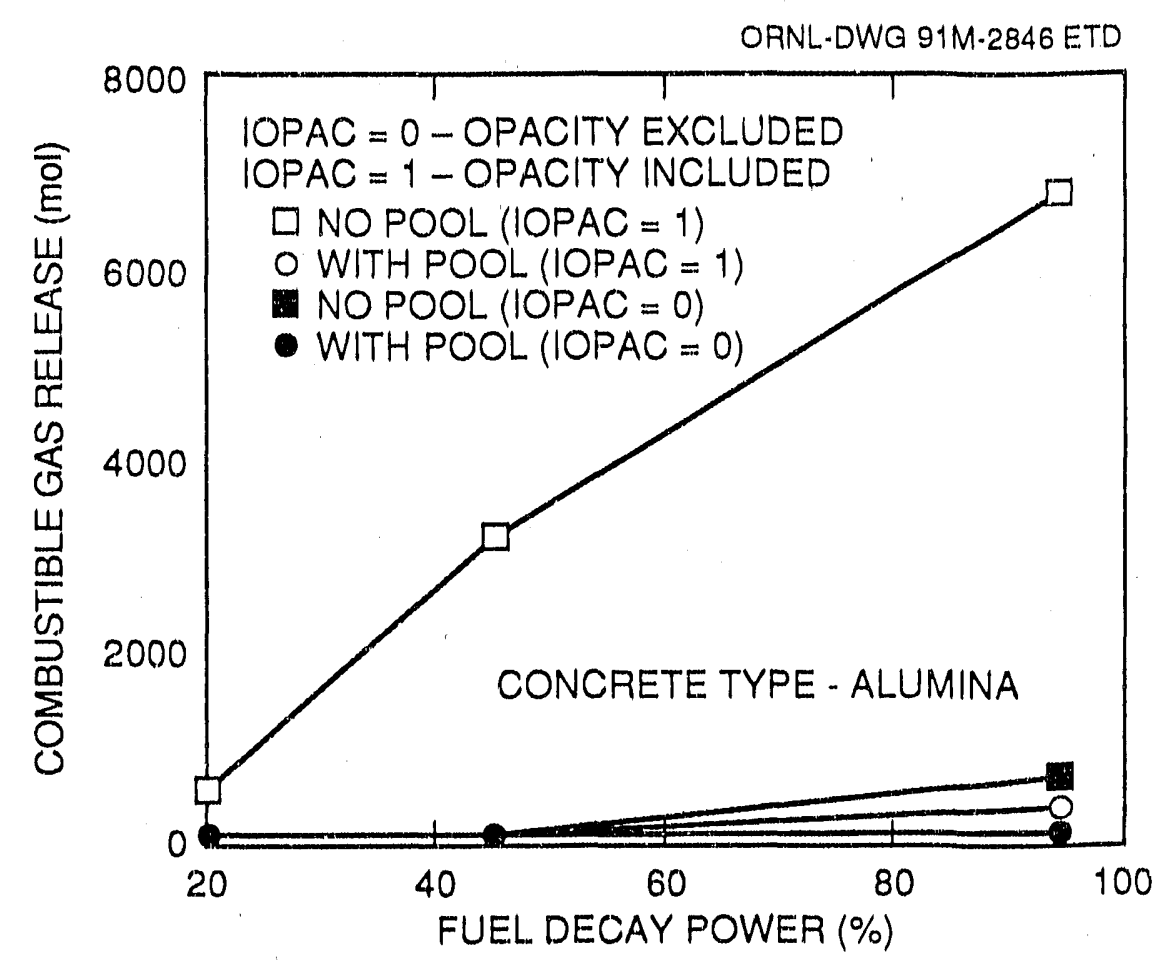

Fig. 3.10. Variation of combustible gas release with debris power and surface opacity.

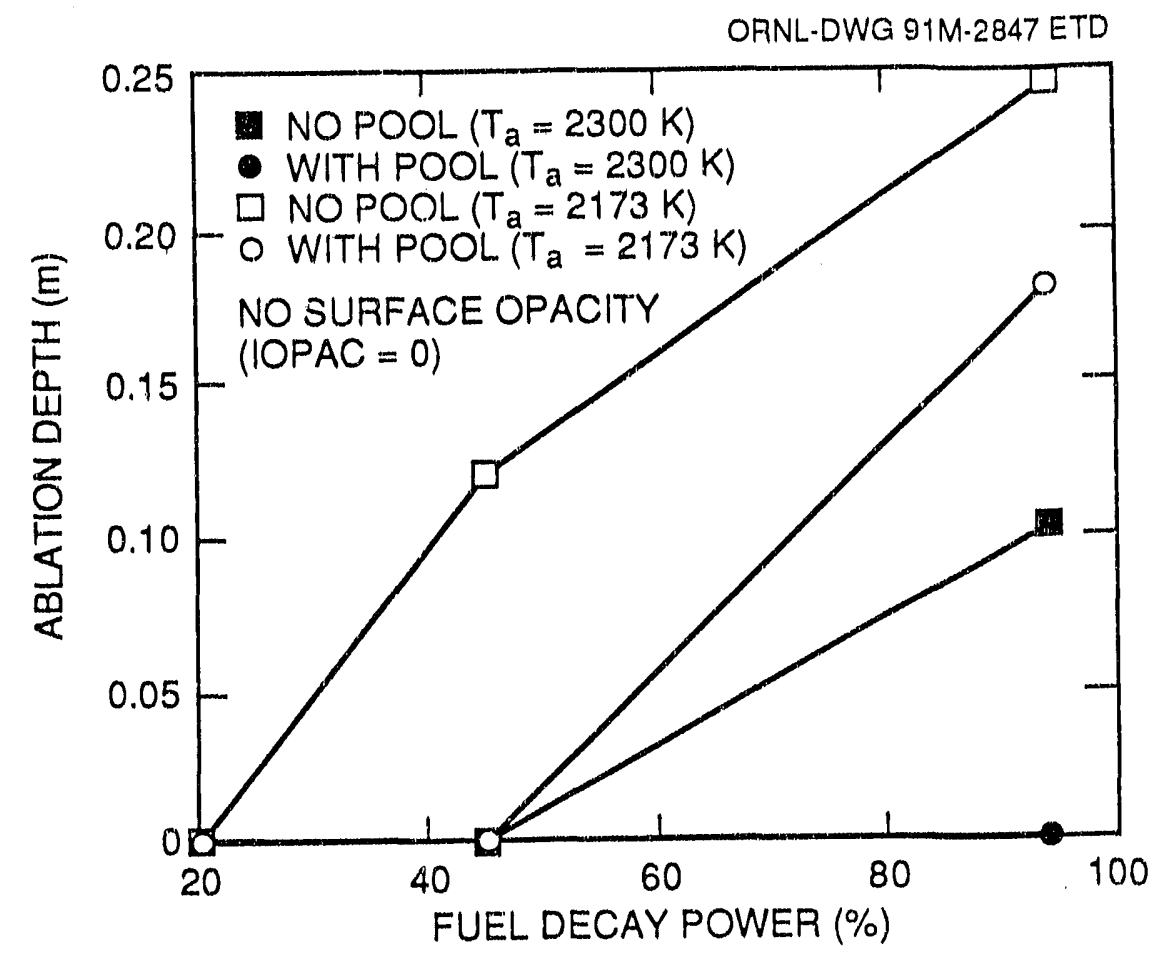

Fig. 3.11. Variation of ablation depth with debris power and $\mathrm{Al}_{2} \mathrm{O}_{3}$ sblation temperature. 


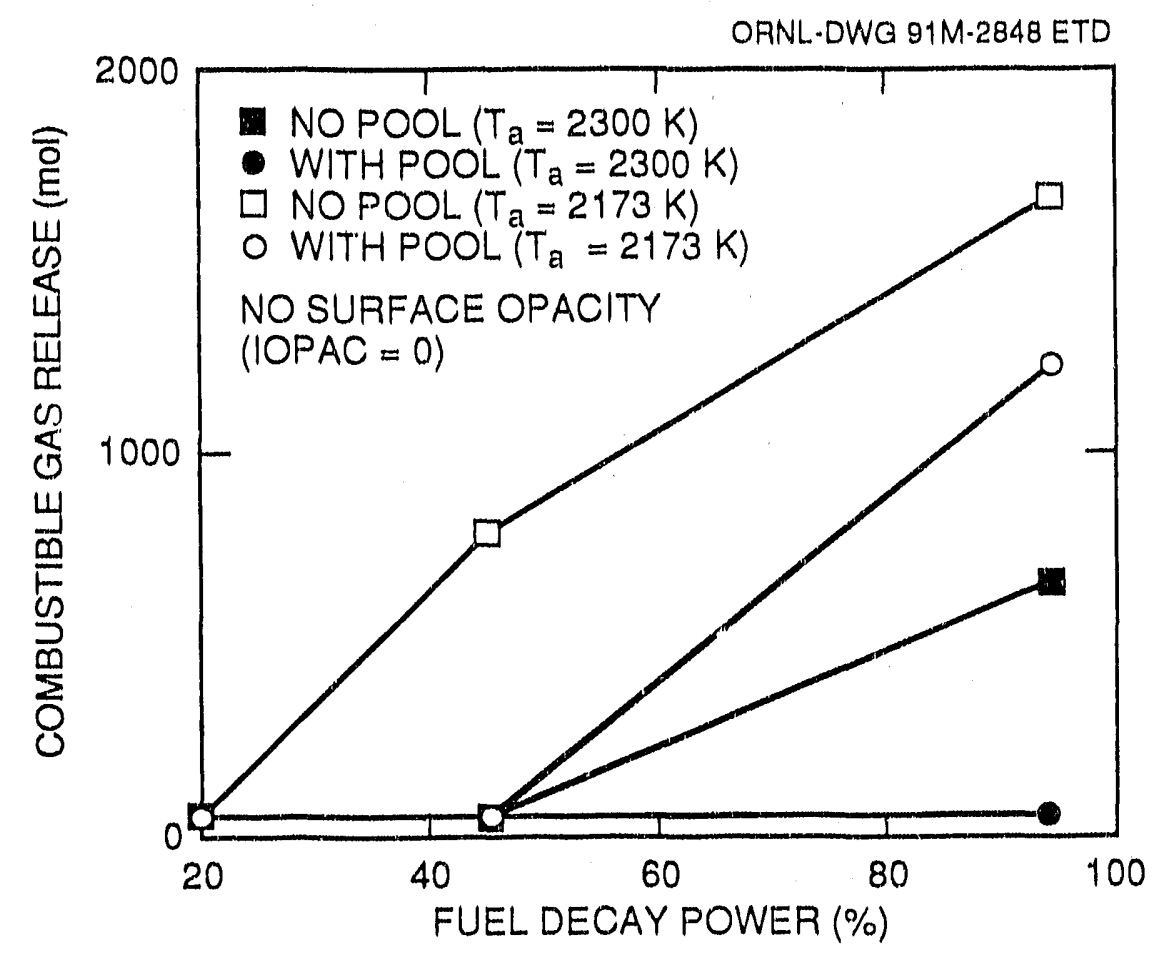

Fig. 3.12. Variation of Combustible gas release with debris power and $\mathrm{Al}_{2} \mathrm{O}_{3}$ ablation temperature.

proper modeling of ANS specific phenomena will need experimental guidance, an aspect that is elaborated further in Chap. 5.

\subsection{IMPACT OF MCCI ON CONTAINMENT RESPONSE}

As seen in Sect. 3.1 for the base case, the debris gas release is significant (especially the combustible gases). It becomes necessary, therefore, to consider the pressure and temperature response of the containment to such loadings. The purpose of the present section is to discuss bounding estimates of the ANS containment response to the MCCI.

CORCON results for the base case indicate a gas release of about $1.14 \times 10^{5} \mathrm{~mol}$ compared to the initial gas content of about $2.2 \times 10^{6} \mathrm{~mol}$ initially present in the ANS containment (high-bay volume) prior to the MCCI. Assuming adiabatic conditions, no gas condensation, no gas combustion, and constant atmospheric temperature, this quantity of gas release would increase the containment pressure from an assumed initial pressure of $1.0135 \times 10^{5} \mathrm{~Pa}(0 \mathrm{psig})$ to $\sim 1.066 \times 10^{5} \mathrm{~Pa}(0.8 \mathrm{psig})$. This is much lower than the 24.7 psia pressure the proposed ANS containment is being designed to withstand. Furthermore, it is estimated that the quantity of MCCI gas required to directly pressurize the containment high-bay volume of about $53,000 \mathrm{~m}^{3}$ to the leakage pressure of $1.70 \times 10^{5}$ 
$\mathrm{Pa}(10 \mathrm{psig})$ is $1.47 \times 10^{6} \mathrm{~mol}$, roughly 13 times the amount actually calculated to be released.

However, because of the significant generation and release of $\mathrm{CO}$ and $\mathrm{H}_{2}$, combustion effects must also be considered. CORCON calculates that $6.3 \times 10^{3} \mathrm{~mol} \mathrm{of}_{2}$ and $2.35 \times 10^{4} \mathrm{~mol}$ of $\mathrm{CO}$ are released into the ANS containment atmosphere. If these gases were uniformly mixed throughout the containment, the resulting $\mathrm{H}_{2}$ and $\mathrm{CO}$ mole fractions are 0.0026 and 0.0099 , respectively, which, as explained in the next paragraph, would not be combustible.

If the gas concentrations are substituted into the following expression 23 and the condition is satisfied, then a judgment can be made concerning the possibility of gas combustion:

$$
\mathrm{XH}_{2}+\left(\mathrm{LH}_{2} \mathrm{IGN} / \mathrm{LCOIGN}\right) * \mathrm{XCO}>\mathrm{LH}_{2} \mathrm{IGN}
$$

where

$\mathrm{XH}_{2}=$ hydrogen mole fraction,

$\mathrm{XCO}=$ carbon monoxide mole fraction,

$\mathrm{LH}_{2} \mathrm{IGN}=0.10$,

LCOIGN $=0.167$.

Evaluation of the above inequality indicates that combustion conditions would not exist for the uniformly mixed assumption.

It is likely, however, that local regions of the containment (e.g., the subpile room) could contain combustible mixtures of gas. It has been estimated that only $3 \%$ of the combustible gases (from the base case) are required to enrich the atmosphere of the subpile room to the deflagration limit, as suggested by the above inequality.

Assuming that all of the $\mathrm{CO}$ and $\mathrm{H}_{2}$ released into the ANS containment (high-bay volume) can be burned, $\sim 8.17 \times 10^{9} \mathrm{~J}\left(\sim 1.95 \times 10^{9} \mathrm{cal}\right)$ of heat will be produced. Assuming adiabatic conditions and a constant heat capacity, this quantity of chemical heat is sufficient to raise the average atmospheric temperature there from 294 to $399 \mathrm{~K}$. The corresponding containment pressure would come close to the targeted design pressure and is undesirable from safety considerations. This implies that best-estimate evaluations and/or mitigative features that reduce either the expected $\mathrm{CO} / \mathrm{H}_{2}$ release or the thermal energy available in the atmosphere would significantly reduce this problem. However, it should be recognized that containment pressurization to design pressure levels does not necessarily imply containment failure. Conventionally, the American Society for Mechanical Engineers (ASME) Pressure Vessel Code allows transient overpressurization by $\sim 10 \%$ above design pressure.

The adiabatic assumption in the above combustion considerations is also crucially important. This is because of the large heat capacity of ANS containment structures that can potentially absorb significant quantities of heat from the atmosphere, the large structural surface areas through which the heat may be transferred, and the long time $(\sim 17 \mathrm{~h})$ over which the transient occurs. As an example, the inner steel shell of the ANS containment dome has an estimated mass of $350,000 \mathrm{~kg}$ and a surface area of $\sim 4,400 \mathrm{~m}^{2}$ (Ref. 24). If it 
is assumed that all of the chemical heat produced from the combustion of MCCI $\mathrm{CO}$ and $\mathrm{H}_{2}$ were used to uniformly heat this inner steel shell, it has been estimated that the temperature rise of the shell would be only $47 \mathrm{~K}$.

Another loading mechanism that should be considered in containment response evaluations is the so-called direct containment heating phenomenon. This mechanism of containment heating can potentially lead to overpressurization of the containment atmosphere if the ANS core debris is dispersed into the containment atmosphere. Such a dispersal may occur during MCCI or even if the debris is ejected into the subplle room under high pressure from the primary system during certain melt-progtession sequences, In order to evaluate the potential loads from such a mechanism, scoping calculations were conducted similar to those for containnient pressurization from deflagration of combustible gases presented earlier. It was assumed that the fission products sourced into the containment would have an average decay power level equal to $4 \mathrm{MW}$ (i.e., about $100 \%$ of total debris decay power at $5000 \mathrm{~s}$ ). An adiabatic evaluation of containment dome atmosphere heatup reveals that in the absence of mitigative mechanisms the containment design pressure would be reached in about $40 \mathrm{~min}$. Once again, it should be borne in mind that these are highly conservative evaluations that assume the volatilization of large fractions of the total debris inventory of fission products and do not take into account several mechanisms such as containment structural heatup (including direct energy transfer to structures from gamma ray attenuation) and the possible existence of fan coolers or other heat transfer equipment. However, these calculations do indicate that this aspect of containment overpressurization is not a second-order effect. Conservative evaluations of this kind can lead to undesirable, possibly erroneous conclusions, but they are indeed valuable in establishing the need for a careful and more sophisticated evaluation process.

It is evident from the above discussion that the impact of appreciable heat transfer to the containment structures may be quite significant. Only detailed dynamic calculations of the containment response coupled to MCCI analysis can provide further insights into the consequences of ANS MCCI. Such calculations should be performed with current tools such as CONTAIN25 or MELCOR.23 


\section{SUMMARY AND CONCLUSIONS}

The MCCI issue represents an important phase of any hypothetical ANS severe accident that has progressed to the point of core debris relocation outside the primary system into the containment. This is becuuse of the potential for (1) the direct attack of the concrete basemat of the containment, (2) the generation and debris release of large quantities of gas that can pressurize the containment, (3) the potential threat posed by combustion of gases generated by $\mathrm{MCCl}$, and (4) the generation, release, and transport of aerosols. The purpose of this report was to characterize the rough order of magnitude of structural concrete ablation and the subsequent release of debris gases for a hypothetical ANS severe accident scenario.

The report was orgunized in the following fashion. First, a brief discussion of recent MCCI research sponsored by the NRC for commercial nuclear plant materials and by the SRL for the materials of the production reactors was provided. This was followed by a description of some of the more important characteristics of the CORCON code. Finnally, results of a CORCON code parametric study were presented for the proposed ANS reactor, along with some sooping estimates (adlabatic hand calculations) of containment response to $\mathrm{MCCI}$.

Because the issue of MCCI is strongly coupled to in-vessel core-melt progression and fission product release, selected results from a different study 2 in this area were used to define the inittal conditions for the present ANS MCCI study. Because large uncertaintios exist in the input parameters defining the CORCON initial and boundary conditions, parametric variations of these input quantities were used to address CORCON-calculated MCCI sensitivities. Where possible, the parametric variations were bounded about bestestimate values. Parametric variations included the following subjects: concrete rebar fraction, initial debris-spreading radius, concrete type, concrete ablation temperature, magnitude of debris internal heating, initial debris inventory, debris-to-surroundings radiative heat transfer, and the effect of an overlying water pool. In addition to the CORCON parameter study, a limited analysis was performed to evaluate the MCCI mitigative effect that might be gained if the basemat were to consist of an alumina concrete of very high melting temperature.

Results of base case CORCON analysis indicate about $1.2 \mathrm{~m}$ of axial concrete ablation for limestone common sund concrete before the debris cools to the ablation temperature of concrete. The cumulative gas release was calculated to be $\sim 1.1 \times 10^{5} \mathrm{~mol}$, which included $\sim 6.3 \times 10^{3} \mathrm{~mol}$ of $\mathrm{H}_{2}, \sim 3.3 \times 10^{4} \mathrm{~mol}$ of $\mathrm{H}_{2} \mathrm{O}, \sim 2.3 \times 10^{4} \mathrm{~mol}$ of $\mathrm{CO}$, and $\sim 5.0 \times 10^{4} \mathrm{~mol}$ of $\mathrm{CO}_{2}$. The $\sim 82 \mathrm{~kg}$ of unoxidized aluminum at the beginning of the CORCON calculations were oxidized within $2 \mathrm{~min}$ of the start of $\mathrm{MCCl}$, and the maximum debris temperature neared the aluminum boil-off temperature of $2600 \mathrm{~K}$. The average axial concrete erosion rate for the entire $16.9 \mathrm{~h}$ was $68 \mathrm{~mm} / \mathrm{h}$, while the maximum rate was calculated to be $1.4 \mathrm{~m} / \mathrm{h}$ during the first $2 \mathrm{~min}$.

It was observed that the primary variable affecting the composition of the released debris gas was the rebar fraction assumed for the concrete basemat. $\mathrm{As} \mathrm{CO}_{2}$ and $\mathrm{H}_{2} \mathrm{O}$ are released by concrete ablation and react with unoxidized metals in the debris, combustible $\mathrm{CO}$ and $\mathrm{H}_{2}$ are produced. As mentioned above, the small initial inventory of unoxidized 
metals is rapidly oxidized $(<2 \mathrm{~min})$; so limited quantities $(\sim 4,600 \mathrm{~mol})$ of $\mathrm{H}_{2}$ and/or $\mathrm{CO}$ are expected from this source. CORCON results show, however, that $\sim 30,000$ mol of combustible gas are produced, arising from the oxidation of concrete rebar (10 wt \%) continuously added to the debris as concrete was ablated. This rebar was assumed to exist because of normal strength requirements of concrete structures.

CORCON results indicate a proportional reduction (from $50 \%$ to $4 \%$ ) in the combustible gas release as the rebar fraction can be reduced from 30 to 1 wt $\%$ for limestone/sand concrete. Similar decreases are expected for other gas-bearing concrete types.

Important parameters affecting axial concrete ablation are the concrete type and the initial debris"spreading radius. For limestone common sand concrete, the axial concrete penetration was calculated to be $0.36 \mathrm{~m}$ for an initial radius of $1.7 \mathrm{~m}$, as opposed to the penetration depth of $1.4 \mathrm{~m}$ for a radius of $0.55 \mathrm{~m}$. The best estimate for the initial spreading radius of the molten debris was $1.1 \mathrm{~m}$, which resulted in an ablation depth of $\sim 1.2 \mathrm{~m}$. This best-cstimate value was obtained using a correlation developed by G. A. Greene at BNL from melt-pour experiments.

The influence of concrete type on calculated axial ablation is also significant. Results for a debris-spreading radius of $1.1 \mathrm{~m}$ indicate that basaltic concrete is eroded to a depth of $2.2 \mathrm{~m}$, more than twice that of the $0.95 \mathrm{~m}$ calculated for limestone concrete. Limestone common sand concrete gives an intermediate value of $1.14 \mathrm{~m}$ of erosion. The reason for these variations is that the differences in ancrete compositions give rise to different ablation temperatures. Basaltic concrete has the lowest ablation temperature at $1450 \mathrm{~K}$, while for limestone common sand and limestone the ablation temperatures are $1500 \mathrm{~K}$ and $1752 \mathrm{~K}$, respectively.

The influence of a water pool on top of debris interacting with limestone common sand concrete significantly reduced calculated axial concrete ablation from $1.14 \mathrm{~m}$ to $0.5 \mathrm{~m}$. The debris gas release was likewise reduced from $1.14 \times 10^{5} \mathrm{~mol}$ to $0.45 \times 10^{5} \mathrm{~mol}$. Although MCCI mitigation is significant, the existence of a water pool could not be assumed to preclude ANS MCCI if debris retained $95 \%$ of the whole core decay heat.

The most important parameter influencing calculated MCCI behavior is the debris internal heating due to the radioactive decay of fission products. This parameter is uncertain for two distinct reasons. First is the loss of gaseous and volatile fission products from the debris prior to its relocation onto the containment basemat. Debris temperatures may exceed the boiling points of some of the fission products while the debris is still inside the reactor vessel. It has been estimated 2 that upwards of $50 \%$ of the total core decay power is associated with such volatile fission products.

The second reason for uncertainty in the debris internal heating is the reduction due to losses of gamma rays from the debris: Gammas carry up to $\sim 50 \%$ of the decay heat. For an initially thin $(10-\mathrm{mm})$ layer of aluminum, a preliminary analysis 2 has shown that a significant portion of the gamma ray energy would escape the debris.

Three fractions of decay heating have been investigated by this study. The base case assumes $95 \%$ retention of whole core decay heat in the debris and is believed to constitute a reasonable upper bound of decay heating. The second and third cases assume $45 \%$ and $20 \%$ retention of whole core decay power in the debris and represent moderate 
and maximum estimates of decay heat losses from the debris through loss of volatile fission products and gamma ray heat transport.

CORCON results for these three cases are not surprising. Ultimate axial concrete ablation was calculated to be $0.08,0.88$, and $1.14 \mathrm{~m}$ for the 20,45 , and $95 \%$ cases, respectively. Thus, more than a factor of 10 , reduction can be achieved in concrete ablation if the debris internal heating is, or can be, reduced to $20 \%$ of whole core decay power. Cumulative debris gas releases are calculated to behave likewise.

The effect of debris-to-surroundings radiative heat transfer modeling uncertainties was found to be small for the case of $\mathrm{MCCI}$ with limestone common sand concrete.

If water is assumed to cover the debris interacting with limestone common sand concrete, the ultimate concrete erosion depths are $0.06,0.18$, and $0.50 \mathrm{~m}$ for the 20,45 , and $95 \%$ decay power cases. By comparing with dry case results, it can be concluded that a significant decrease in the debris internal heating is more effective in mitigating ANS MCCI than is the presence of an overlying pool of water.

The ANS base case $\mathrm{MCCI}$ analysis was also performed with a high-melting-temperature $(2300 \mathrm{~K})$ alumina concrete to investigate the mitigative effect that this type of concrete might have on the calculated $\mathrm{MCCI}$. CORCON results showed minimal effect on the calculated axial erosion but a dramatic (fourfold) reduction in the calculated combustible gas release. Total combustible $\left(\mathrm{CO}\right.$ and $\mathrm{H}_{2}$ ) release summed to $30,000 \mathrm{~mol}$ for the limestone common sand base case, while they summed to only $7,000 \mathrm{~mol}$ for the alumina concrete. Even if all of the $7,000 \mathrm{~mol}$ of combustible gas underwent deflagration and the containment air heated adiabatically, scoping calculations show that the ANS containment design pressure would not be exceeded. This is an important conclusion and clearly underscores the potential benefits of using alumina concrete.

The effects of a reduction in debris power and the presence of an overlying water pool were also investigated for the alumina concrete basemat. Ultimate dry case concrete erosion amounted to $0.09,0.50$, and $0.98 \mathrm{~m}$, respectively, for the 20,45 , and $95 \%$ decay power levels. These results were found to be very sensitive, however, to the phenomenological modeling of debris-to-surroundings radiative heat transfer. If no opacity is assumed, it was found that no significant concrete erosion occurs for the $20 \%$ and $45 \%$ decay power levels and that only $0.11 \mathrm{~m}$ of concrete erosion occurs even for the $95 \%$ decay power level. If there was an overlying water pool, the $95 \%$ power case erosion was reduced to $50 \mathrm{~mm}$.

Estimates of the effect of the base case $\mathrm{MCCI}$ on direct containment pressurization from released gases indicate a pressure rise of only $5.3 \mathrm{kPa}(0.8 \mathrm{psid})$ from the initial assumed pressure of $1.0135 \times 10^{5} \mathrm{~Pa}(14.7 \mathrm{psia})$. This is much lower than the $70 \mathrm{kPa}$ (10 psid) pressure difference necessary across the containment which is proposed as an ANS design criterion. To directly pressurize to the design criterion pressure would require $1.5 \times 10^{6} \mathrm{~mol}$, roughly 13 times the calculated debris gas release.

Assuming uniform gas dispersion throughout the containment, it appears that the gas released from $\mathrm{MCCI}$ is not within flammability limits. However, the proposed ANS containment design' does not appear to promote MCCI gas mixing, and we note that only a small retention ( $-3 \mathrm{~mol} \%$ ) of combustible $\mathrm{MCCI}$ gas (dry case, $95 \%$ decay heat, limestone common sand concrete) is required to enrich the local subpile room atmosphere to a 
combustible mixture. Scoping calculations (assuming adiabatic conditions) revealed that the combustion of all of the $\mathrm{CO}$ and $\mathrm{H}_{2}$ released (i.e., for the base case $\mathrm{MCCI}$ with limestone common sand concrete) would generate sufficient energy to cause the containment high-bay pressure to nearly reach the targeted design pressure of $0.17 \mathrm{MPa}$ (24.7 psia).

A related conservative scoping estimate of containment pressurization from uniform deposition of the ANS core debris into the containment (so-called direct containment heating) was also conducted. This highly conservative calculation indicated the possibility of rapid overpressurization and demonstrated the need for best-estimate evaluations using codes such as MELCOR, in conjunction with designed mitigative features.

The results of this study make it evident that, without mitigative features, the ANS containment may be vulnerable to severe accidents in which a significant portion of the core debris and its decay heat ( $95 \%$ retention in the debris) leave the reactor coolant system and are relocated in a coherent manner (with or without a pool of water) onto a limestone common sand concrete basemat typical of those employed in commercial nuclear power plants. These vulnerabilities include the direct and significant penetration of the concrete basemat, the possible overpressurization of portions of the containment due to burning of $\mathrm{CO}$ and $\mathrm{H}_{2}$ produced as a result of $\mathrm{MCCI}$, and containment heating and pressurization due to the volatilization of significant amounts of radioactive core debris.

The mitigative measures that look promising have been suggested on the basis of CORCON calculations. They consist of using alumina concrete for the ANS basemat and simultaneous provision of debris submergence in subcooled water. However, until more realistic calculations or other data become available to assess the validity of the models used in this study, we cannot know with confidence whether such mitigative features will be needed. Key uncertainties that require further research include the volatilization and release of fission products from the core debris prior to $\mathrm{MCCI}$ and the loss of fission product decay heat due to gamma ray escape from thin layers $(-1 \mathrm{~cm})$ of debris. In any case, the implementation of such suggested mitigative measures will require experimental verification, an aspect that is discussed further in the next section. 


\section{RECOMMENDATIONS}

The results of this study indicate that if a significant portion of the core debris leaves the reactor coolant system and is relocated to the concrete basemat typical of those used in power reactors and if the molten debris retains nearly all of its decay heat, the present ANS containment may be vulnerable to direct penetration of the concrete basemat and possible overpressurization in various regions of the containment (e.g., subpile room) due to the burning of released combustible gases, as well as from direct containment heating.

The following recommendations are presented in order to develop a robust ANS design that reduces the potential for significant ablation, overpressurization within the containment boundary, and subsequent escape of radioactivity during severe accidents.

\section{Incorporate and qualify a concrete basemat design in conjunction with operator or system actions to preclude or mitigate MCCI occurrence.}

Because many of the challenges to containment integrity can be avoided if MCCI does not occur, it is highly recommended that further research be devoted to designing an appropriate basemat concrete material that significantly mitigates or even precludes the MCCI process. The current study indicates that alumina concrete may be a good candidate for such a basemat material if actions are introduced to ensure the availability of subcooled water over the debris (even if the disruption that provided a path for the molten debris did not also provide a path for reactor coolant system (RCS) or pool water, possibly due to blockages). Another good candidate for the material of such a basemat may be thorium oxide. 26

It should be noted that CORCON has not been validated for the results presented in Chap. 3 for MCCI with alumina concrete at temperatures close to the vaporization temperature of aluminum. This aspect is especially true for thin $(<10-\mathrm{mm})$ debris layers with intense power densities and will definitely require experimental guidance. Such guidance would conceivably be possible to obtain from cost-effective, small-scale experiments of the type conducted at SRL with electron beam heating. Contacts with SRL researchers have been made, and they have offered to perform some experimental investigations into the $\mathrm{MCCI}$ of $\mathrm{U}_{3} \mathrm{Si}_{2}-\mathrm{Al}$ materials. It is thus recommended that (if the ANS Project deems it necessary to incorporate MCCI mitigative measures in the ANS design) a few hundred grams of depleted $\mathrm{U}_{3} \mathrm{Si}_{2}$ be made available for this purpose and that efforts be initiated toward obtaining the necessary fundamental information. Insights gained from analysis of these experiments would then be used to incorporate ANS-specific phenomenological modeling features in the CORCON code. The resulting code could then be used with greater confidence as a design tool and for best-estimate severe accident sequence analysis (after introduction into system codes such as MELCOR). If, indeed, the MCCI process can be prevented from occurring in the ANS, it would represent a major reduction in containment loading and would assist greatly in reducing the overall uncertainties for source-term predictions. 


\section{Address ANS MCCI issues using common power reactor concrete
basemats.}

In the event that ANS debris/basemat interaction cannot be sufficiently mitigated through appropriate basemat design (or by other means), it becomes more important to understand the physics of debris/concrete interactions for materials actually used in the ANS. Much research involving the MCCI expected for power reactor materials has been sponsored by the NRC. None has been performed specifically appropriate for the ANS. SRL is currently sponsoring research to investigate MCCI for the U-Al alloy fuel of production reactors. It is recommended that the ANS Project should continue to follow the SRL research and, where appropriate, should participate in the ongoing effort: Contacts with SRL researchers have already been made, and experimentation with $\mathrm{U}_{3} \mathrm{Si}_{2}-\mathrm{Al}$ materials has been discussed.

There also exists a need for the determination of basic thermophysical properties of $\mathrm{U}_{3} \mathrm{Si}_{2}-\mathrm{Al}$ under molten conditions. This includes properties of both solid and liquid states. A particular need exists for data concerning eutectic interactions of $\mathrm{U}_{3} \mathrm{Si}_{2}$ with other structural materials such as aluminum, stainless steel, carbon steel, control plates, irradiation capsules, and transplutonium targets. Such information would be valuable not only for ex-vessel analysis but also for in-vessel core-melt progression analysis. Further assessment would be necessary for the interactions of these materials with concrete compo-
nents such as $\mathrm{SiO}_{2}$ and $\mathrm{CaO}$.

Based on insights gained from experiments, it is recommended that MCCI codes, such as CORCON and VANESA, be amended to include the important aspects of ANS $\mathrm{MCCI}$, which differ from traditional commercial power plant MCCI considerations. It is specifically recommended that the phase diagram for U-Si mixtures be incorporated into CORCON and that other material eutectic formations be allowed. An important aspect of ANS MCCI involves the generation of radioactive aerosols, which depend greatly on salient chemistry effects. It is thus recommended that the current SRL MCCI experiments being conducted with tracer elements be closely monitored and used for benchmarking purposes. The resulting CORCON code could then be introduced into the main body of system codes such as MELCOR for best-estimate severe accident sequence analysis.

\section{Set up an integrated containment response evaluation capability.}

As reported in Chap. 3, scoping containment loading evaluations from burning of released combustible gases and direct containment heating (from aerosols and volatile fission products) have indicated the need for an appropriate integrated containment response evaluation capability that is commensurate with various stages of the ANS Project. Such as assessment can be made with codes such as MELCOR and CONTAIN once the modified CORCON code is incorporated therein as a module. Otherwise, results of the stand-alone CORCON code calculations should be used as time-dependent input to the MELCOR or CONTAIN code analyses. This capability should be upgraded as new information or modeling upgrades become available. In the short run, this integrated tool 
would be useful for locating and sizing mitigative features in the ANS containment such as containment venting, containment sprays, fan coolers, or containment shell cooling.

\section{Introduce efforts to reduce CORCON modeling uncertainties.}

As reported in Appendix A, there are several areas of known CORCON deficiencies with respect to power reactor $\mathrm{MCCI}$ applications. These deficiencies are recognized by the code developers at SNL, and efforts are slowly under way to address them. Similar deficiencies also apply to ANS applications. It is recommended that new CORCON models be implemented and assessed for ANS applications as soon as they are made available.

Perhaps the most important of these deficiencies for the ANS is the debris layer assumption predicated by CORCON. For the ANS applications reported herein, it was observed that CORCON frequently calculated a small $(<1-\mathrm{kg})$ continuous layer of iron at the bottom of the debris pool once the debris mixture of aluminum and/or iron had oxidized and layer flip had occurred. The source of this iron was the concrete rebar incorporated into the debris as the concrete was ablated. Because the debris was at elevated temperatures, iron oxidation was so rapid that the iron mass in the metal layer did not accumulate. Because pure iron has a melting temperature of about $1800 \mathrm{~K}$, CORCON calculated that the small metal layer was frozen for much of the transient. As a result, heat transfer to the underlying concrete was conduction limited. This CORCON result should be experimentally verified since the debris interacting with the concrete was predominantly oxidic and homogeneously mixed.

It was shown in Chap. 3 that the extent of ablation and combustible gas release was quite sensitive to the extent of debris spreading over the concrete basemat. Hence, it would be instructive to conduct confirmatory tests with ANS debris constituents and note deviations, if any, from experimentally derived correlation (Ref. 20, Appendix B) predictions. Such tests may be most effectively conducted at BNL by George Greene ${ }^{21}$ and would gain from the extensive research already sponsored there. Contacts have already been made with Greene, who has agreed to assist ORNL in this regard.

Another large source of uncertainty deals with the magnitude of internal volumetric heating for a very thin $(<10-\mathrm{mm})$ initial layer of debris. ${ }^{2}$ This uncertainty arises from the lack of pertinent information relating to loss of energy from volatilizing fission products, chemistry effects, and the distribution of gamma ray energy. As it stands, CORCON modeling does not allow for a reduction of decay heat in the debris due to escape of gamma rays, nor does it include concrete heatup from deposition of gamma ray energy. For ANS conditions where about $50 \%$ of decay power is carried by gamma rays, these are crucial effects to be properly modeled.

Finally, it should be mentioned that the ANS MCCI results for alumina concrete were found to be highly sensitive to the model used for debris-to-surroundings radiation heat transfer. This is not surprising because alumina concrete ablation occurs at such high temperatures that radiation heat transfer is predominant. The opacity formulation in CORCON based on data for power reactor MCCI conditions tied to the generation of aerosols should be reassessed for applicability to ANS conditions. 


\section{REFERENCES}

1. F. J. Peretz, Preliminary Description of the Advanced Neutron Source, ORNL/ANS/INT-1, Martin Marietta Energy Systems, Inc., Oak Ridge Natl. Lab., March 1989.

2. R. P. Taleyarkhan, Core Melt Progression and Fission Product Release Considerations for the Advanced Neutron Source Reactor at ORNL, ORNL/TM11815, Martin Marietta Energy Systems, Oak Ridge Natl. Lab. (to be published).

3. S. A. Hodge, C. R. Hyman, and L. J. Ott, "Boiling Water Reactor Severe Accident Technology at Oak Ridge - Purpose and Goals," letter report to Dr. Thornas J. Walker, Accident Evaluation Branch, Division of Systems Research, RES, USNRC, dated December 6, 1988.

4. R. K. Cole, D. P. Kelly, and M. A. Ellis, CORCON-MOD2: A Computer Program for Analysis of Molten Core-Concrete Interactions, NUREG/CR-3920, (SAND841246) Sandia National Laboratories, August 1984.

5. C. R. Hyman, C. F. Weber, and S. A. Hodge, "Effects of Lateral Separation of Oxidic and Metallic Core Debris on the BWR Mk I Containment Drywell Floor," pp. 6-83-6-94 in Proceedings of the Committee on the Safety of Nuclear Installations (CSNI) Specialists Meeting on Core Debris-Concrete Interactions, EPRI NP-5054-SR, Electric Power Research Institute, February 1987.

6. C. R. Hyman, "CONTAIN Calculations of Debris Conditions Adjacent to the BWR MARK I Drywell Shell During the Later Phases of a Severe Accident," to be published in the Journal of Nuclear Engineering and Design.

7. S. R. Greene, "The Role of BWR Secondary Containments in Severe Accident Mitigation: Issues and Insights from Recent Analyses," Nuclear Engineering and Design 120, p. 75-86, 1990, North-Holland, Amsterdam.

8. M. Reimann and W. B. Murfin, The WECHSL Code: A Computer Program for the Interaction of Core Melt and Concrete, KfK2890, Kernforschungszentrum, Karlsruhe, Germany, 1981.

9. MAPP - Modular Accident Analysis Program Users' Manual, IDCOR Technical Report 16.2-3, Fauske and Associates, Inc., developed for the IDCOR Program, January 1985 .

10. J. E. Gronager, A. J. Suo-Anttila, D. R. Bradley, and J. E. Brockmann, TURC1: Large Scale Metallic Melt-Concrete Interaction Experiments and Analysis, NUREG/CR -4420 (SAND85-0707), Sandia National Laboratories, January 1986. 
11. J. E. Gronager, A. J. Suo-Anttila, and J. E. Brockmann, TURC2 and 3: Large Scale $\mathrm{UO}_{2} / \mathrm{ZrO}_{2} / \mathrm{Zr}$ Melt-Concrete Interaction Experiments and Analysis, NUREG/CR4521 (SAND86-0318), Sandia National Laboratories, June 1986.

12. R. E. Blose, J. E. Gronager, A. J. Suo-Anttila, and J. E. Brockmann, SWISS: Sustained Heated Metallic Melt/Concrete Interactions with Overlying Water Pools, NUREG/CR-4727 (SAND85-1546), Sandia National Laboratories, July 1987.

13. E. R. Copus, R. E. Blose, J. E. Brockmann, R. D. Gomez, and D. A. Lucero, Core-Concrete Interactions Using Molten Steel with Zirconium on a Basaltic Basemat: The SURC-4 Experiment, NUREG/CR-4994, (SAND87-2008), Sandia National Laboratories, April 1989.

14. Reactor Safety Research Semiannual Report, July-December 1985, Vol. 34, NUREG/CR-4340 (2 of 2) [SAND85-1606 (2 of 2)], pp. 34-36, Sandia National Laboratories, July 1986.

15. D. R. Bradley, "Status of CORCON Model Development and Validation," presented at the Severe Accident Research Program Partners' Meeting, April 13, 1989.

16. D. R. Bradley and A. J. Suo-Anttila, "Improvements in CORCON Heat Transfer Modeling," pp. 4-3-4-14 in Proceedings of the Committee on the Safety of Nuclear Installations (CSNI) Specialists' Meeting on Core Debris-Concrete Interactions, EPRI NP-5054-SR, Electric Power Research Institute, February 1987.

17. H. W. Randolph, J. E. Payne, and J. L. Margrave, "Molten Core-Granitic Concrete Reaction Studies at Savannah River," presented at the ANS Workshop on Safety of Uranium-Aluminum Fuel Reactors, March 1989.

18. Reactor Safety Research Semiannual Report January-June 1985, Vol. 33, NUREG/CR-4340 (1 of 2) [SAND85-1606 (1 of 2)], p. 61, Sandia National Laboratories, October 1985.

19. C. R. Hyman, Oak Ridge Natl. Lab., personal communication with Dave Bradley, Sandia National Laboratories, November 15, 1989.

20. G. A. Greene, "Recent Progress in Research on Melt Spreading Phenomena," presented at the Severe Accident Research Program Partners' Meeting, April 10-14, 1989.

21. R. P. Taleyarkhan, Oak Ridge Natl. Lab., personal communication with G. Greene, Brookhaven Natl. Lab., March 1990. 
22. Personal communication with D. Bradley, September 1989.

23. R. M. Summers et al, MELCOR 1.8.0: A Computer Code for Nuclear Reactor Severe Accident Source Term and Risk Assessment Analyses, NUREG/CR-5531, Sandia National Laboratories, 1991.

24. F. J. Peretz, Preliminary Description of the Advanced Neutron Source, ORNL/ANS/INT-1, Vols. 1 and 2, Martin Marietta Energy Systems, Inc., Oak Ridge Natl, Lab., March 1989.

25. K. K. Murata et al., Users' Manual for CONTAIN 1.1: A Computer Code for Severe Nuclear Reactor Accident Containment Analysis, NUREG/CR-5026 (SAND 87-2309) Sandia National Laboratories, November 1989.

26. D. G. Swanson, J. N. Castle, P. D. Anderson, and I. Catton, Core Melt Materials Interactions Evaluations, NUREG/CR-3299, U.S. Nuclear Regulatory Commission, September 1983. 


\section{Appendix A:}

\section{DEFICIENCIES IN CORCON MODELING}

The purpose of this appendix is to identify areas of CORCON modeling where improvements are needed to more appropriately address MCCI phenomena for the ANS.

\section{REPRESENTATION OF CONCRETE OUTGASSING}

With the latest released version of CORCON (Version 2, mod 5), none of the water vapor stored in the concrete is released unless and until the temperature of the overlying debris is sufficient to cause ablation. For the base case concrete assumed for this report, this ablation temperature is $1503 \mathrm{~K}$ and is much higher than the entire temperature range (360-798 K.) over which water is released. Thus, once the debris temperature falls below the concrete ablation temperature, no debris-concrete interaction is calculated even though the debris is still very hot and is physically still transferring heat to the underlying concrete. It is expected that water vapor would continue to be released into the debris and would continue to provide the oxidizer for metallic debris oxidation. The magnitude of the gas release from this mechanism is unknown, but because the ANS decay heat diminishes very slowly with time, the debris can remain at elevated temperatures for tens of hours. It is because of this deficiency that the analyses reported in Chap. 3 were terminated when the calculated debris temperatures fell to the concrete ablation temperature.

Perhaps the most vivid example of where this may be important is the case considered in Chap. 3 where a large water pool is assumed to overlay the debris interacting with the concrete. As reported there, the debris temperature is calculated to fall to the concrete ablation temperature at $3.6 \mathrm{~h}$ into the transient. As seen in Fig. 3.1, the decay power is about $0.7 \%$ of full operating power [ $350 \mathrm{MW}(\mathrm{t})$ ] and decays very slowly with time. Even though the calculated debris temperature has fallen to the concrete ablation temperature at this time, it is expected that the debris would remain near this elevated temperature for several hours and would continuously release $\mathrm{H}_{2} \mathrm{O}$ into the debris.

\section{REPRESENTATION OF MATERIAL PHASE DIAGRAMS AND EXOTHERMIC REACTIONS}

The version of CORCON used in this study has a very simple model to represent the melting behavior of debris interacting with the underlying concrete. Since CORCON assumes that the debris is segregated into layers of metals and oxides, it models the melting behavior of each of these layers separately. For the metal layer, melting is assumed to be that of aluminum-uranium mixture as long as the combined mass fraction of $\mathrm{U}-\mathrm{Al}$ in the metal layer is $>30 \%$. For lower concentrations of $\mathrm{U}-\mathrm{Al}$, the melting behavior is based on a tertiary phase diagram of $\mathrm{Fe}-\mathrm{Cr}-\mathrm{Ni}$. No modeling of the possible [U(Al,Si) 3 ] eutectic mixture melting behavior is included.

For the oxidic debris layers, CORCON bases the melting behavior of the layer on the melting behavior of $\mathrm{ZrO}_{2} / \mathrm{UO}_{2}$ mixtures combined with the melting behavior of the 
concrete oxides $\left(\mathrm{SiO}_{2}, \mathrm{CaO}\right.$, etc.). Since the ANS debris has no zirconium dioxide, the $\mathrm{ZrO}_{2} / \mathrm{UO}_{2}$ melting behavior is that of pure $\mathrm{UO}_{2}$, which has a melting temperature of around $3000 \mathrm{~K}$. This is then nonlinearly weighted with the solidus and liquidus temperatures of the concrete to determine the solidus and liquidus temperatures of the mixture of $\mathrm{UO}_{2}$ and concrete oxides. There is no accounting of the melting behavior of the large fraction of $\mathrm{Al}_{2} \mathrm{O}_{3}$ which may exist in the oxidic debris layers.

Based on comments received from Henry Randolph of SRL, it was revealed that the present modeling in CORCON for exothermic reactions does not account for an exotherm of $16.9 \mathrm{kcal}$. This exothermic energy is released when aluminum oxide reacts with calcium oxide and silicon dioxide according to the reaction

$$
\mathrm{CaO}+\mathrm{Al}_{2} \mathrm{O}_{3}+2 \mathrm{SiO}_{2} \rightarrow \mathrm{CaAl}_{2} \mathrm{Si}_{2} \mathrm{O}_{8}+16.9 \mathrm{kcal}
$$

to produce the compound $\mathrm{CaAl}_{2} \mathrm{Si}_{2} \mathrm{O}_{8}$, which is referred to as the mineral anorthite.

It is not clear whether the $16.9-\mathrm{kcal}$ exotherm will significantly affect concrete ablation or gas generation. This energy is significantly lower than the exothermic energy released upon aluminum oxidation. However, it may impact ablation evaluations later in the calculation after all of the aluminum has been oxidized. It is thus recornmended that the code developers introduce this reaction into the chemistry modeling package of CORCON and also MELCOR or CONTAIN.

\section{CORCON DEBRIS LAYER MODELING}

The debris layer structure as currently modeled in CORCON is based on an assumption that individual layers of oxides and metals always exist. During periods of rapid concrete ablation, gas sparging through molten debris makes this debris layering assumption questionable. It is anticipated that there is considerable debris mixing and that the well-defined segregation of metals and oxides assumed by CORCON will not always occur. Instead, mixtures of oxide and metal will form such that the composition is based on the degree of mixing, which, in turn, will depend on such factors as the gas velocity through the melt.

The debris configuration assumed by CORCON should be modified to account for such debris mixing as well as to allow for well-defined layers of oxide and metals. It is also noted that this, in turn, will lead to questions concerning the large uncertainties in the chemical and thermophysical environment existing in such mixtures of metals and oxides.

\section{IMPROVED DEBRIS/WATER POOL HEAT TRANSFER MODELING}

Recent experimental evidence 20 indicates that heat transfer from debris to an overlying water pool is greater than that predicted within CORCON by the currently used flat-plate film-boiling correlation. The enhancement is caused by the increase in the interface heat transfer area as bubbles of gas pass through the surface of the debris into the water pool. The magnitude of the enhancement is the subject of present debate. It is important that accurate modeling of this heat transfer phenomenon be incorporated into 
CORCON; but until such time, modifications should be made to permit the sensitivity of calculated results to this parameter to be addressed by user input.

\section{CORCON EXECUTION DIFFICULTIES}

CORCON code execution difficulties were observed in several of the CORCON analyses performed for this report. These difficulties appeared near the end of each calculation and involved the INTEMP subroutine. Characteristics of the MCCI calculation at the time of the difficulty were that (1) the debris temperature had fallen to the ablation temperature of the concrete, (2) the INTEMP subroutine could not converge to a meaningful temperature at one of the debris layer interfaces, (3) the calculation of layer temperature was unrealistic, (4) there was nonphysical calculation of concrete axial ablation, and (5) there was nonphysical release of a large quantity of monatomic oxygen from the debris.

Table A.1 exhibits the abnormal code behavior for the case of an overlying water pool reported in Chap. 3. Calculated results from three times are displayed. As shown at time $3.5 \mathrm{~h}$, the debris temperature has fallen close to the concrete ablation temperature $(1503 \mathrm{~K})$, and very little monatomic oxygen has been released from the debris. The same bohavior is noted at time $3.6 \mathrm{~h}$ except that the debris temperature has fallen even closer to the concrete ablation temperature. At time $3.7 \mathrm{~h}$, however, $>10,000$ mol of monatomic oxygen have been calculated to have been released from the debris, the water pool is calculated to have become subcooled, and the debris temperature is calculated to have reached the freezing point of water. Clearly, something nonphysical has occurred in the calculation.

It is to be noted that this anomalous behavior is not calculated for earlier times and that the CORCON deficiency producing them does not appear to affect the quality of the analysis during these earlier periods. As explained in Chap. 2, CORCON analysis is invalid beyond the time when the debris temperature has fallen to the ablation temperature of the concrete. This is because of the assumption in CORCON that the debris no longer interacts with the concrete once the debris temperature has fallen below the concrete ablation temperature. This is discussed in the degassing deficiency described above.

Although not affecting the current ANS MCCI analysis, the observed difficulty may be important for situations whereby the debris temporarily cools below the concrete ablation temperature and then for some reason begins to reheat. An example of such behavior might occur if the debris accumulated on the containment basemat in a timedependent manner. Conditions could be envisioned whereby the debris cooled below the ablation temperature and then reheated (due to additional debris relocation from the reactor primary system) to a temperature above the ablation temperature. It would be desirable in such instances to continue the CORCON calculation through this quiescent period and into the period of active $\mathrm{MCCl}$.

Another such instance could be where the pool of water submerging the core debris has finally boiled off. At this stage, the debris surface convective heat transfer coefficient would drop dramatically, leading to rapid heatup and an onset of vigorous $\mathrm{MCCI}$. 
Table A.1. Anomalous CORCON results near the $3.6 \mathrm{~h}$ time for the case of overlying water pool reported in Chap. 3

\begin{tabular}{|c|c|c|c|c|c|c|}
\hline \multirow{2}{*}{$\begin{array}{c}\text { Time } \\
\text { (h) }\end{array}$} & \multirow{2}{*}{$\begin{array}{c}\text { Ablation } \\
\text { depth } \\
\text { (m) }\end{array}$} & \multirow{2}{*}{$\begin{array}{c}\text { Debris } \\
\text { temperature } \\
\text { (K) }\end{array}$} & \multirow{2}{*}{$\begin{array}{l}\text { Water } \\
\text { temperature } \\
(\mathrm{K})\end{array}$} & \multicolumn{3}{|c|}{$\begin{array}{l}\text { Debris gas release } \\
\text { (mol) }\end{array}$} \\
\hline & & & & $\infty$ & $\mathrm{O}$ & $\mathrm{H}_{2}$ \\
\hline 3.5 & 0.503481 & 1505.9 & 373.14 & & & \\
\hline 3.6 & 0.503761 & 1503.9 & 373.14 & & & \\
\hline 3.7 & 0.585324 & 273.0 & 351.9 & $1.7494 \times 10^{4}$ & $1.3589 \times 10^{4}$ & $5.7435 \times 10.3$ \\
\hline
\end{tabular}




\section{Appendix B:}

\section{EVALUATION OF ANS DEBRIS-SPREADING CHARACTERISTICS}

It was shown in Chap. 3 that the extent of dobris spreading on the concrete basemat can have a substantial effect on the resulting ablation and combustible gas release. Thus, it is useful to minimize uncertaintios in this modeling parameter for MCCl studies. This appendix deals with the aspect of molten debris spreading over flat surfaces. The technology presented herein has been excerpted from presentation slldes 20 prepared by G. A, Greene of BNL,

Greene studled the spreading behavior of molten lead and aluminum pours over a range of experimental parameters. Table B.1 summarizes the test matrix for lead, whlle Table B.2 summarizes the tests for aluminum. Greene categorized his analysis of spreading phenomona as occurring in five regimes, as shown in Table B.3, which also indicates the suggested mathematical modeling approaches for each regime. Exporimental results for water-flooded surfaces were found to correlate nicely in the so-called $t^{*}$ versus $\mathrm{N}_{\text {sp }}$ plane and can be elegantly expressed as

$$
t^{*}=1.51 \mathrm{~N}_{\mathrm{sp}}^{-0.5}
$$

based on recent small-scale $(2-3-\mathrm{kg})$ and larger scale $(15-\mathrm{kg})$ melt-spreading tests with molten aluminum, where

$$
\begin{aligned}
& t^{*}=\text { dimensionless thickness }=t_{\mathrm{av}} / \mathrm{t}_{\mathrm{dry}} \text {, } \\
& t_{a v}=\text { area-averaged melt thickness, } \\
& t_{\text {chy }}=\text { theoretical surface tension limit }=\left(2 \sigma / \rho_{\text {molt } g}\right)^{1 / 2} \text {, } \\
& N_{\mathrm{sp}}=\text { dimensionless spreading parameter } \\
& =\left(\frac{\mathrm{V}^{1 / 3}}{\mathrm{H}_{\mathrm{w}}}\right)\left(\frac{\mathrm{h}_{\mathrm{fl}}}{\mathrm{h}_{\mathrm{f}}}\right) \vartheta\left(\frac{1+\mathrm{S}_{\mathrm{f}}}{1+J_{\mathrm{a}}}\right) \text {, } \\
& \mathrm{V}=\text { melt volume, } \\
& \mathrm{H}_{\mathrm{W}}=\text { water depth, } \\
& \vartheta=\text { melt/water density ratio, } \\
& h_{\mathrm{fs}}=\text { melt latent heat of freezing, } \\
& \mathrm{h}_{\mathrm{fg}}=\text { water latent heat of vaporization, } \\
& S_{f}=\text { Stefan number }=\left(C_{p, \text { moll }} \Delta T_{\text {supertieat }}\right) / h_{f s} \text {. } \\
& \mathrm{Ja}=\mathrm{Jakob} \text { number }=\left(\mathrm{C}_{\mathrm{p}, \text { water }} \Delta \mathrm{T}_{\text {auboouling }}\right) / \mathrm{h}_{\mathrm{f}_{\mathrm{g}}} \text {, } \\
& \Delta \mathrm{T}_{\text {superheat }}=\mathrm{T}_{\text {melt }}-\mathrm{T}_{\text {freczo, }} \\
& \Delta \mathrm{T}_{\text {subcooling }}=\mathrm{T}_{\text {sat }}-\mathrm{T}_{\text {water, }} \\
& \sigma=\text { melt surface tension, } \\
& \rho=\text { melt density, } \\
& g=\text { gravitational acceleration. }
\end{aligned}
$$


Table B.1. Molten lead melt-spreading experimental test matrix

\begin{tabular}{lll}
\hline \multicolumn{1}{c}{ Variable } & \multicolumn{1}{c}{$\begin{array}{c}\text { Small-scale } \\
\text { tests }\end{array}$} & \multicolumn{1}{c}{$\begin{array}{c}\text { Large-scale } \\
\text { tests }\end{array}$} \\
\hline Melt mass, $\mathrm{kg}$ & $4-10$ & $60-70$ \\
Melt superheat, $\mathrm{K}$ & $10-200$ & $10-200$ \\
Melt flow rate, $\mathrm{kg} / \mathrm{s}$ & 2.5 & $3,6,12$ \\
Nozzle diarneter, $\mathrm{cm}$ & 1.27 & $1,27,2.54,5.08$ \\
Water pool depth, $\mathrm{cm}$ & $0-6$ & $0-6$ \\
Surface geometry & Unconfined \& quadrant & Unconfined \\
Surface materials & Wood, steel, marble & Wood \\
Total number of tests & 156 & 50 \\
\hline
\end{tabular}

Table B.2. Molten aluminum melt-spreading experimental test matrix

\begin{tabular}{lll}
\hline \multicolumn{1}{c}{ Variable } & \multicolumn{1}{c}{$\begin{array}{c}\text { Small-scale } \\
\text { tests }\end{array}$} & \multicolumn{1}{c}{$\begin{array}{c}\text { Large-scale } \\
\text { tests }\end{array}$} \\
\hline Melt mass, $\mathrm{kg}$ & $2-3$ & 15 \\
Melt superheat, $\mathrm{K}$ & $0-200$ & $3-40$ \\
Melt flow rate, $\mathrm{kg} / \mathrm{s}$ & $0.07-1.7$ & $0.45-0.60$ \\
Nozzle diameter, $\mathrm{cm}$ & $0.635,1.27,2.54$ & 1.27 \\
Water pool depth, cm & $0-15$ & $0-20$ \\
Surface geometry & Unconfined & Unconfined \\
Surface materials & Wood, steel, marble & Wood \\
Total number of tests & 46 & 10 \\
\hline
\end{tabular}

Table B.3. Mathematical modeling and representation of melt-spreading experimental observations 21 based on aluminum data

\begin{tabular}{clll}
\hline Regime & \multicolumn{1}{c}{$N_{\mathrm{sp}}$} & \multicolumn{1}{c}{ Debris geometry } & \multicolumn{1}{c}{ Modeling approach } \\
\hline 1 & $(-)$ & Dry surface & Surface tension limited \\
2 & $0.7-4.0$ & Shallow water pool & Semiempirical perturbation to regime 1 \\
3 & $0.4-0.7$ & Transition regime & Same approach as regime 2 \\
4 & $0.2-0.5$ & Deep pool-cone & Mathematical model expected \\
5 & 0.2 & Deep pool & $\begin{array}{l}\text { Heat transfer limited, dictated by water } \\
\text { depth }\end{array}$ \\
\hline
\end{tabular}


The approximate range of $\mathrm{N}_{\mathrm{sp}}$ values for individual regimes is also given in Table B.3. Further, Greene also found that for the case of melt spreading over dry surfaces (i.e., regime 1), the melt thickness could be nicely correlated with the Bond number (i.e., product of the Weber number and Froude number). The best-estimate debris-spreading thickness over dry surfaces can be obtained as

$$
t=\operatorname{Sqrt}\left[(B o \times \sigma) /\left(\rho_{\text {mo } 1 \mathrm{t}} \times g\right)\right]
$$

where Bo is the Bond number. For ANS MCCI analysis conducted in Chap. 3, it was assumed that the ANS debris would enter the subpile room and spread over an essentially dry surface (1.e., regime 1) before a pool of water was formed (if any). For regime 1, the debris thickness (for molten ANS core debris) was evaluated using Eq. (B.2) with $\mathrm{Bo}=2$. This resulted in a value of about $0.8 \mathrm{~cm}$ for the base case analysis. 
ORNL/TM-11761

Internal Distribution

1. E. W. Carver

2. D. H. Cook

3. W. G. Craddick

4. G. F. Flanagan

5. M. H. Fontana

6. E. C. Fox

7. S. R. Greene

8. R. M. Harrington

9. S. A. Hodge

10. F. J. Homan

11. C. R. Hyman

12. J. E. Jones Jr.

13. B. S. Maxon

14. G. L. McNutt

15. D. L. Moses

16. D. G. Morris

17. L. J. Ott
18. B. W. Patton

19. F. J. Peretz

20. C. C. Queen, Jr.

21. D. L. Selby

22. D. B. Simpson

23. R. P. Taleyarkhan

24. P. B. Thompson

25. D. B. Trauger

26. B. D. Warnick

27. C. D. West

28. A. Zucker

29. ORNL Patent Section

30. Central Research Library

31. Document Reference Section

32-33. Laboratory Records Department

34. Laboratory Records, RC

\section{External Distribution}

35. D. R. Bradley, Sandia National Laboratory, P.O. Box 5800, Albuquerque, NM 87185

36. L. Y. Cheng, Brookhaven National Laboraiory, Bldg. 703, Department of Nuclear Energy, Upton, NY 11973

37. G. Greene, Brookhaven National Laboratory, Bldg. 820, Upton NY 11973

38. M. L. Hyder, Reactor Safety Research Division, Westinghouse Savannah River Company, Savarnah River Laboratory, Aiken, SC 29808

39. R. T. Lahey, Jr., Department of Nuclear Engineering and Engineering Physics, Jonsson Engineering Center, Rensselaer Polytechnic Institute, Troy, NY 121803590

40. I. Madni, Brookhaven National Laboratory, Bldg. 703, Department of Nuclear Energy, Upton, NY 11973

41. M. Z. Podowski, Department of Nuclear Engineering and Engineering Physics, Jonsson Engineering Center, Rensselaer Polytechnic Institute, Troy, NY 121803590

42. H. Randolph, Westinghouse Savannah River Company, Savannah River Laboratory, Aiken, SC, 29808

43. D. A. Sharp, Reactor Safety Research Division, Westinghouse Savannah River Company, Savannah River Laboratory, Aiken, SC 29808

44. R. M. Summers, Sandia National Laboratory, Division 6418, P.O. Box 5800, Albuquerque, NM 87185

45. P. R. Tichler, Brookhaven National Laboratory, Bldg. 703, Department of Nuclear Energy, Upton, NY 11973

46. A. L. Wooten, Reactor Safety Research Division, Westinghouse Savannah River Company, Savannah River Laboratory, Aiken, SC 29808 
47. Office of Assistant Manager for Energy Research and Development, Department of Energy, ORO, P.O. Box 2001, Oak Ridge, TN 37831

48-57. Office of Scientific and Technical Information, P.O. Box 62, Oak Ridge, TN 37831 

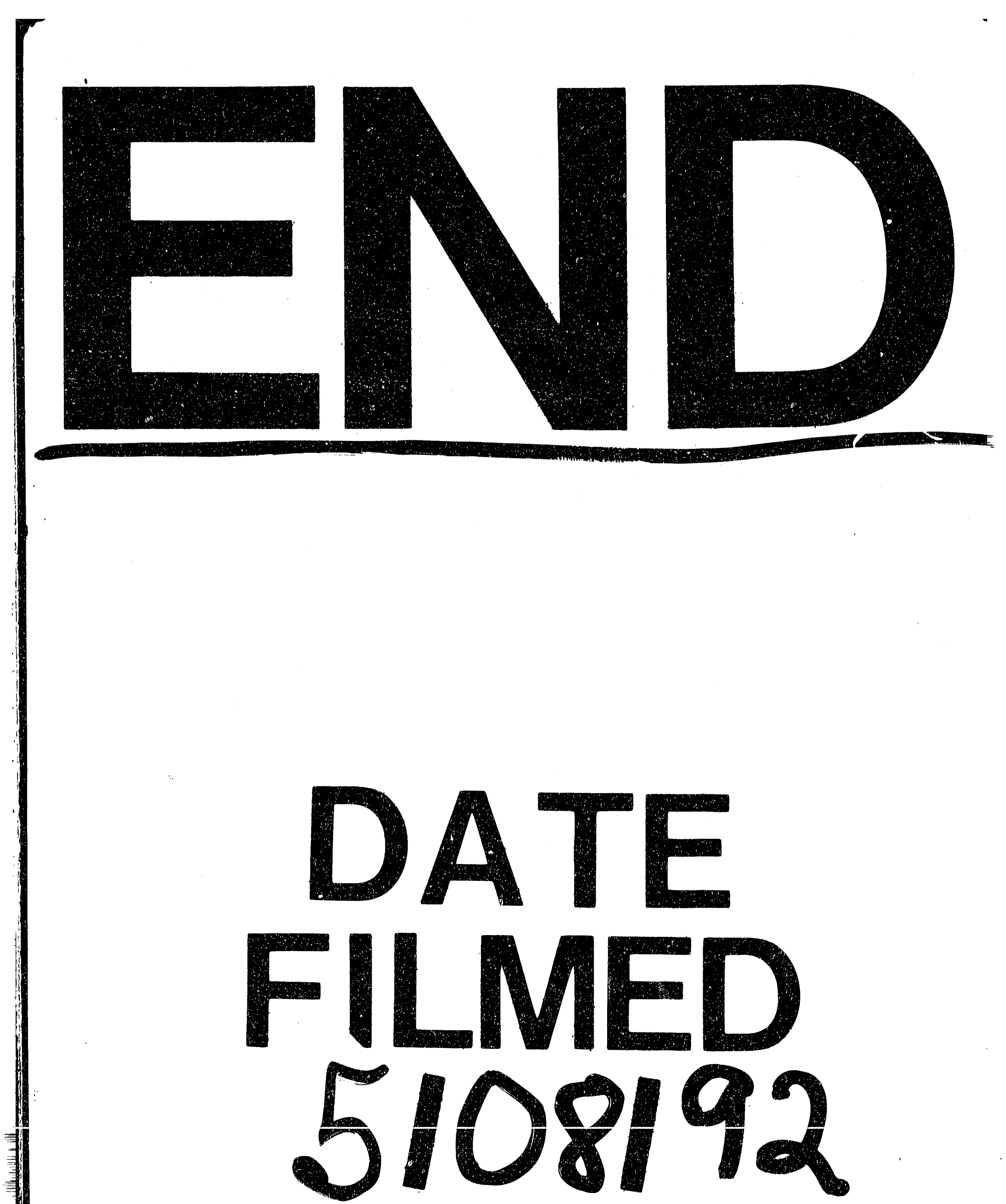


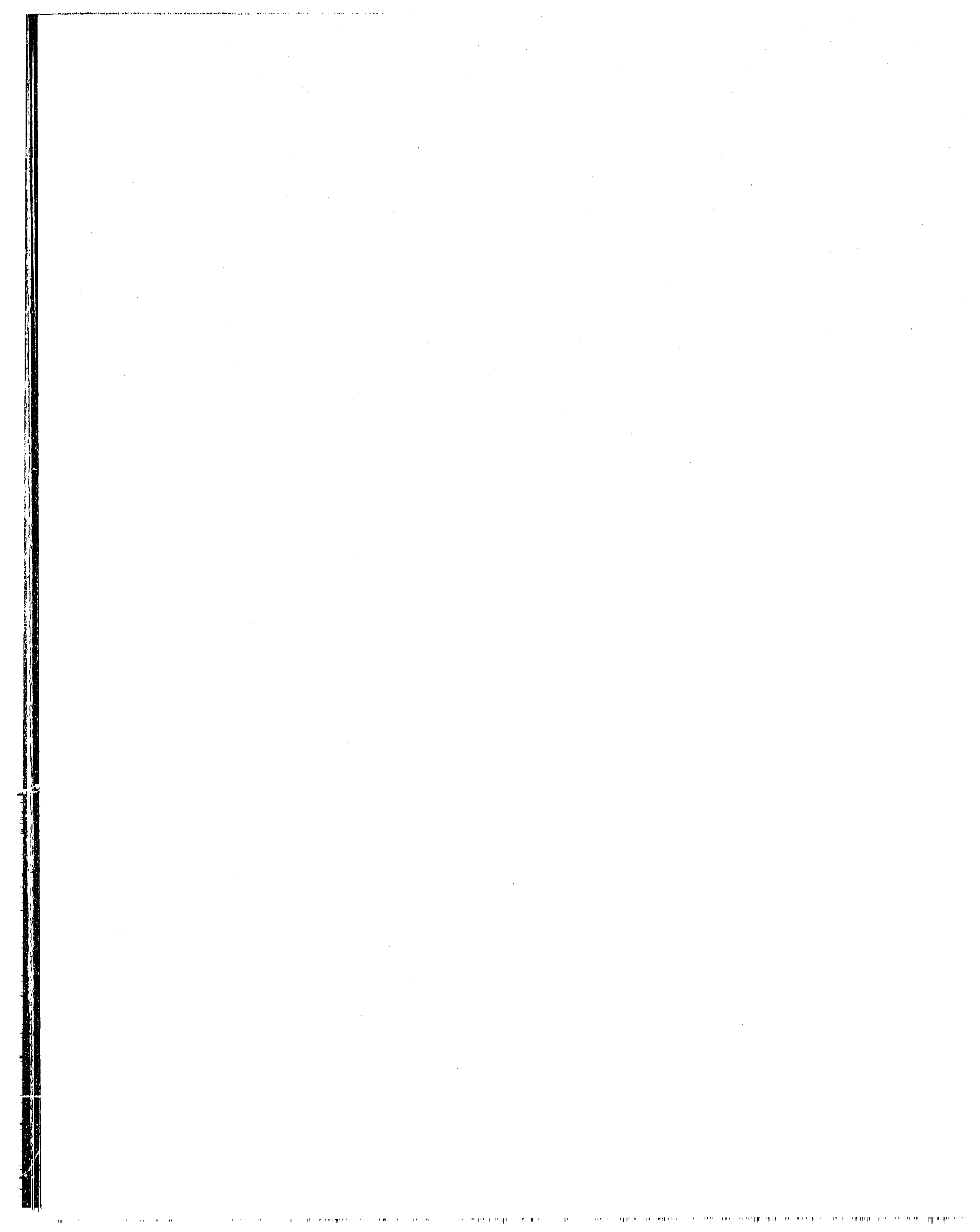

